Let's Get Prototypical: The Role of Complainant/Defendant Gender and Form of Sexual Act on Mock Jurors' Decisions in Sexual Assault Trials

$$
\text { by }
$$

\title{
Cassandra Starosta
}

A thesis submitted to the Faculty of Graduate and Postdoctoral Affairs in partial fulfillment of the requirements for the degree of

\author{
Master of Arts \\ in \\ Psychology \\ Carleton University \\ Ottawa, Ontario \\ (C)2021
}

Cassandra Starosta 


\section{Abstract}

This mock juror study $(N=437)$ serves as a first examination of mock jurors' perceived prototypicality of a sexual assault case, complainant, and defendant in various conditions, to ascertain if mock jurors' sexual assault prototypes are one of the mechanisms behind their caserelated decisions. To this end, the present study offers an initial examination of the impact of the form of alleged sexual assault (forced oral sex onto the complainant vs. forced vaginal intercourse) and complainant and defendant gender (i.e., male complainant-female defendant vs. female complainant-male defendant) on mock jurors' sexual assault prototypes and, in turn, their assessments and decisions. The results of a path analysis demonstrate a cautious optimism that the form of sexual assault does not play a significant role in mock jurors' decisions. However, the complainant's gender (tied to defendant's gender) does. Mock jurors perceived the male complainant-female defendant condition as less prototypical of a sexual assault case, complainant, and defendant than the female complainant-male defendant condition, resulting in negative evaluations of the male complainant and favourable evaluations of the female defendant, which lowered mock jurors' probability of rendering a guilty verdict. Simultaneously, the present study suggests that for fixed levels of prototypicality, the female complainant received heightened negative evaluations from mock jurors, and the male defendant received more favourable evaluations from mock jurors, which lowered mock jurors' probability of rendering a guilty verdict. Collectively, these results provide evidence to suggests that prototypicality is one of the mechanisms behind mock juror decisions in sexual assault cases. My results reveal a potential bias in our legal system that should be furthered researched and mitigated to ensure fairer decisions for the 37,855 sexual assault trials held in Canada each year (Statistics Canada, 2019). 


\section{Acknowledgements}

"I'll be quiet when we can say sexual assault, and they stop screaming liar" (Rupi Kaur, 2020)

I want to acknowledge all of those who have been sexually assaulted and not believed and all who were told it was their fault. Sexual assault is a much bigger issue than what was examined through my thesis. My thesis cannot be the end of the discussion; it is the beginning. I hope that my thesis can contribute to the ongoing understanding of jury bias involved in sexual assault cases and can help bring male victims of female perpetrated sexual assault and forced oral sex perpetrated against both genders into the conversation, so all victims of sexual assault get the justice and resources they deserve.

I want to express my sincere gratitude to my exceptional supervisor Dr. Evelyn Maeder for her endless mentorship, encouragement, patience and support. I want to express my appreciation to my committee Dr. Craig Leth-Steenson, Dr. Suzanne Cooper and Dr. Dale Spencer, for their feedback and expertise. Dr. Leth-Steensen, thank you for your patience and guidance with the statistical portion of my thesis; I truly could not have done this without you. Dr. Cooper, thank you for always encouraging and supporting me. Dr. Dale Spencer, thank you for your time and insight. I also extend my deep appreciation to Etelle Bourassa for her assistance throughout my Graduate studies at Carleton University.

I want to thank my friends and family for their unconditional love and support. I am so fortunate to have a loving mother, Iris Beer, and sister, Lindsay Starosta, who are steadfast in their unconditional love, encouragement, and belief in me. Words cannot do justice for the gratitude I feel to you both. Thank you from the bottom of my heart! I also thank my loving boyfriend, Vince, for his endless support.

Finally, a huge thank you to my exceptional lab mates Logan, Susan, Roxana, Benjamin, Araby, and Andleeb for helping to make this journey as remarkable as it was. I will never forget the kindness of my cohort, and I am eternally grateful for the friendships I have made in this program. 


\section{Table of Contents}

Abstract___ ii

Acknowledgements___ iii

Table of Contents __ iv

List of Tables _ $\mathrm{v}$

List of Figures ___ vi

List of Appendices __ vii

Introduction __ 1

Canadian Legislation __ 4

The History of the Legal Definition of Consent in Canada ___ 4

Medieval Sexual Assault Laws. 4

Second-Wave Feminism and Sexual Assault Laws.

Current Sexual Assault Laws. 6

Juror Bias in Sexual Assault Cases __ 7

Prototype Theory _ 8

Prototype Theory and the Justice System 10

What is the Prototype of a Sexual Assault Case

Gender Stereotypes and Rape Myths ___ 14

Gender Stereotypes __ 14

Rape Myths _ 16

Circumstances Informed by Rape Myths and their Effect on Jurors' Decisions.___ 18

Rape myths: Victim and Perpetrator Gender and Their Effect on Jurors' Decisions

Rape Myths: Form of the Sexual Assault and their Effect on Jurors' Decisions. ___ 26

Current study__ 27

Hypotheses __ 31

Methods 39

Participants __ 39

Materials _ 43

Juror Instructions — 43

Trial Transcript

Juror Questionnaire _ـ 44

$\underline{\text { Path Analysis }} \longrightarrow 50$

Results _ 53 
Discussion _ 75

Implications _ 86

Limitations and future directions __ 92

Conclusion _ـ 95

References __ 97 


\section{List of Tables}

Table 1. Breakdown of Participants by Gender by Condition ___ 43

Table 2. Demographics of Study Sample ___ 44

Table 3. Descriptive Statistics for Study Variables __ 57

Table 4. Model Results for Study Variables___ 61

Table 5. Means for Illinois Rape Myth Acceptance Scale, Male Rape Myth Acceptance Scale and Oral Sex Scale___ 72

Table 6. Rape Myth Acceptance Scales and Severity___ 75

Table 7. Gender Differences for Predicted Relationships __ 77

Table 8. Gender Differences for Rape Myth Acceptance Scales and the

Predicted Relationships__ 78 


\section{List of Figures}

Figure 1. Hypothesized Conceptual Model 28

Figure 2. Hypothesized path analysis for the effect of form of the sexual assault on jurors' verdict decisions in sexual assault cases 35

Figure 3. Hypothesized path analysis for the effect of complainant gender (and defendant gender) on jurors' verdict decisions in sexual assault cases

Figure 4. Hypothesized path anaylsis for the interaction between form of the sexual assault and complainant (and defendant) gender on juror verdict decisions 40

Figure 5. Hypothesized Conceptual Model 53

Figure 6. Hypothesized Conceptual Model Results 60

Figure 7. Exploratory Model 70 


\section{List of Appendices}

Appendix A: Screener

113

Appendix B: Consent Form

Appendix C: Juror Instructions 117

Appendix D: Trial Summary 118

Appendix E: Questionnaire 122

Appendix F: The Illinois Rape Myth Acceptance Scale 126

Appendix G: Male Rape Myth Acceptance Scale 128

Appendix H: Oral Sex Scale 131

Appendix I: Demographic Questions 141

Appendix J: Debriefing Form 143

Appendix K: Consent-to-keep-data 145 
Let's Get Prototypical: The Role of Complainant/Defendant Gender and Form of Sexual Act on Jurors' Decisions in Sexual Assault Trials

Sexual assault is a pervasive problem in Canada, with one in three women and one in eight men victimized each year (Statistics Canada, 2017). Numerous legal reforms have been established over the last 40 years to expand the definition of sexual assault (R. v. Find, 2001) to better encompass the breadth of forms in which it can manifest, as well as the diversity of individuals that can be involved. These reforms aimed to increase both sexual assault reporting and sexual assault conviction rates (Rotenberg, 2017). However, prevalence rates of sexual assault crimes have increased and, when compared to other crimes, sexual assault cases have had higher attrition rates, or "losses" of cases within the criminal justice chain (Bureau of Justice Statistics, 2017). In fact, out of every 1000 sexual assaults, only 230 are reported, 46 reports lead to arrest, nine cases get referred to prosecutors, six cases are accepted to be prosecuted, and once a sexual assault case makes it to court, only $20 \%$ actually result in a conviction (Department of Justice, 2019). Therefore, out of every 1000 sexual assaults, only approximately five individuals accused of sexual assault will be convicted (Department of Justice, 2019). One of the factors identified as underlying these troubling attrition statistics found between trial and conviction involves decision-makers' conceptions, or perhaps more aptly, their misconceptions, about sexual assault and sexual assault complainants (Schuller et al., 2010). The prevailing assumption of our legal system is that jurors are blank slates who objectively decide on the facts of the case and apply the law to those facts to reach legally accurate decisions (Skeem \& Golding, 2001). However, research has challenged this notion by instead demonstrating that jurors' expectations and beliefs about a crime can play an influential role in their decisions (Schuller et al., 2010). 
Researchers have turned to Prototype Theory (Rosch, 1978) to explain the role of jurors' attitudes about sexual assault cases/sexual assault complainants in their case-related decisions (e.g., guilt, complainant/defendant credibility and blameworthiness; Kessler et al., 2020; McKimmie et al., 2014; Smith, 1991). Prototypes are defined as the best exemplars or cognitive representations of a member within a certain category (Rosch, 1978). Prototypes are instinctively employed because they enhance an individual's memory and recall while saving cognitive resources (Rosch, 1978). Applying Prototype Theory to the Criminal Justice System, Smith (1991) conceptualized selecting a verdict as a prototype-relevant categorization task. Additionally, the Director's Cut Model (Devine, 2012) proposes that jurors' previously held ideas about a crime may influence their perceptions of the trial evidence. Therefore, it seems plausible that jurors in sexual assault cases would rely on their sexual assault prototypes in their determinations of plausibility (e.g., verdict, blame, and credibility).

Research has found that juror prototypes are informed by rape myths (McKimmie et al., 2014). Rape myths are defined as "prejudicial, stereotyped or false beliefs about rape, rape victims, and rapists" (Burt, 1980, p. 217). These attitudes are influenced by society's dependence on gender norms that dictate what it means to be masculine and feminine (Cislaghi, \& Heise, 2019). Rape myths dictate what constitutes a prototypical sexual assault case, complainant, and defendant (McKimmie et al., 2014), as they are centered around what circumstances represent a "genuine" sexual assault, who is involved, and under what form (Burt, 1980; Lonsway \& Fitzgerald, 1994). Psycho-legal research has predominantly focused on the role rape myths surrounding the circumstances of a "genuine" sexual assault case have on jurors' decisions (e.g., Ellison \& Munro, 2009; Duke \& Desforges, 2007; Masser et al., 2010; Pack, 2019; Schuller et al., 2010; Stuart et al., 2019). The consensus among these 
studies is that sexual assault complainants whose behaviours and assaults do not align with those prescribed by rape myths are more likely to be blamed and/or considered as less credible. The majority of these studies also found that not-guilty verdicts were more frequent than guilty verdicts when the complainant's behaviours and the circumstances of their sexual assaults did not align with those dictated by rape myths, which may suggest that rape myths play an important role in jurors' decision-making.

Preceding research primarily has stayed within the dimensions of a female complainant, male defendant, and vaginal intercourse sexual assault. However, there has been limited empirical focus on what specifically constitutes a "genuine" sexual assault act or complainant. Furthermore, prototypicality of the complainant, defendant, and the case itself has not been explicitly empirically examined as the mechanism behind jurors' decisions. Consequently, the aim of my Master's thesis was to ascertain whether prototypicality mediates the effects of (1) complainant gender, (2) defendant gender, and (3) form of the sexual assault (i.e., vaginal intercourse vs. oral sex) on jurors' defendant/complainant blameworthiness and credibility assessments, and the relationship between these assessments and jurors' verdict decisions in sexual assault cases. On a broader level, I hoped to expand our understanding of jurors' sexual assault prototypes to examine if variations in gender of the trial parties and the alleged sexual act play a role in jurors' decisions. This line of inquiry is essential to potentially discover extra-legal factors that need to be understood and mitigated against by future researchers to ensure fair trials without discrimination for all. Canadian sexual assault legislation, Prototype Theory (Rosch, 1978), Crime Prototype Theory (Smith, 1999), The Director's Cut Model (Devine, 2012), Gender Stereotype Theory (Kachel et al., 2016), and rape myths (Burt, 1980; Lonsway \& Fitzgerald, 1994), were reviewed to demonstrate why it is crucial to examine the 
influence of these unstudied variables on juror decision-making in Canadian sexual assault trials as well as the importance of prototypicality as a mediator.

\section{Canadian Legislation ${ }^{1}$}

Laws form the basis for how we ought to act (R.S., c. C-34, s. 1). Therefore, I believe it is essential that our criminal code defines sexual assault in a way that encompasses all nonconsenting sexual acts against all genders. With this in mind, I examined research on Canada's sexual assault laws and reforms to assess how sexual assault has been defined in Canada over time, including the various amendments that have taken place. This was done to establish Canada's current definitions, and the manners in which the law provides protection for sexual assault victims.

\section{The History of the Legal Definition of Consent in Canada}

Medieval Sexual Assault Laws. Canadian law is derived from English law, which can be traced back to medieval laws (Department of Justice, 2017). Common-Law considered rape as a branch of abduction. It referred to a "male having non-consensual vaginal intercourse with a female who was not his wife" (Criminal Code, 1892, S.C. 1893, c.32, s.1). Within these laws, a woman's credibility depended on her past sexual history. As such, her sexual reputation was legally open for questioning in court (R.S.C. 1970, c. C-34 1953-54, c.51, s.135; Johnson, 2012). For a claim to be considered valid, a woman was required to immediately report the rape after its occurrence (R.S.C. 1970, c. C-34 1953-54, c.51, s.135). A woman also had to demonstrate, with physical evidence (e.g., bruises), that she actively resisted her assailant (McColgan, 1996; R.S.C. 1970, c. C-34 1953-54, c.51, s.135). Moreover,

\footnotetext{
${ }^{1}$ It is important to note that the author acknowledges that gender and sex are two separate entities, with sex being one's biological makeup, and gender being a social construct (Little, 2016). However, within Canadian sexual assault legislation, gender and sex are confounded, and thus this section reports and summarizes the laws as they were written.
} 
women's testimonies alone could not convict a defendant; a male relative was required to testify (Bill C-46 (278.1-279.91). Not only did these laws narrowly define who is involved in sexual assault, but they also limited what acts were considered to be sexual assault and under what specific circumstances. Under these laws, the definition of rape made it impossible for a man to be considered a victim of sexual assault or a woman to be the perpetrator (Johnson, 2012). It also limited sexual assault to vaginal intercourse, thereby excluding other forms of sex from the legal conversation (Gotell, 2012). These laws also de-emphasized the perpetrator's act of rape and instead prioritized circumstantial behaviour related to a victim and narrowly defined non-consent.

Second-Wave Feminism and Sexual Assault Laws. The advancement of second-wave feminism in the 1980s began to address these legal limitations (Gotell, 2012). During this time, the following new definition of sexual assault was implemented: "Sexual assault is an assault... which is committed in circumstances of a sexual nature such that the sexual integrity of the victim is violated" (Bill C-127). This definition had practical implications. First, by replacing the term "rape" with sexual assault (Bill C-127), a whole range of sexual activities were able to be criminalized and considered sexual assault (McGlynn, 2018). Specifically, these legal reforms allowed punishment for sexual assaults that did not involve vaginal penetration $(\mathrm{s} .79(3))$.

Second, these reforms also redefined the offence in gender-neutral terms (Johnson, 2012) by using the term victim rather than specifying "woman" or "female", which allowed for greater diversity of who can be considered a victim. These reforms led to positive developments whereby sexual assault reporting increased (Roberts \& Grossman, 1994). However, high attrition rates persisted, resulting in few sexual assault convictions (Conroy \& 
Cotter, 2014). For example, in 1992, 57\% of reported sexual assault cases were filtered out of the criminal justice system (Statistics Canada’s Uniform Crime Reporting Survey (UCR), 1994). In one case, a judge proposed that one of the reasons for this was that these reforms did not address the broad and unclear definition of consent (R. v. Ewanchuk, 1999). As such, Canadian sexual assault laws were once again reformed in 2017, resulting in our current laws (R.S., c. C-34, s. 265).

Current Sexual Assault Laws. The Government of Canada initiated Bill- C-51 on June 6,2017 , to make the definition of consent more transparent, revise previous sexual assault legislation, help ensure fairer trials, and reduce victim-blaming (Casavant et al., 2018). Major changes brought forth by this bill include (1) one cannot consent while heavily intoxicated, (2) one's sexual history cannot be used to challenge their credibility, (3) sexual assault allegations do not require evidence of forceful victim resistance, and (4) one's sexual orientation cannot be mentioned in court (S.276). To this end, sexual assault is currently defined under Section 265 of the Criminal Code, which states that:

(1) A person commits an assault when (a) without the consent of another person, (s)he applies force intentionally to that other person, directly or indirectly, (2) this section applies to all forms of assault, including sexual assault, sexual assault with a weapon, threats to a third party or causing bodily harm, and aggravated sexual assault (R.S., c. C-34, s. 265).

This section goes on to elaborate that consent is not obtained when: “...the complainant submits or does not resist by reason of (a) the application of force to the complainant or to a person other than the complainant, (b) threats or fear of the application of force to the complainant or to a person other than the complainant, (c) fraud, or (d) the exercise of authority" (R.S., c. C-34, s. 265). 
It is clear from reviewing the legal reforms on sexual assault that the laws have evolved drastically over the years. From medieval times to now, the laws have expanded to reflect a broad concept of who is involved in a sexual assault, as well as what constitutes a sexual assault, and under what circumstances. Sexual assault scholar and lawyer Elaine Craig (2018) argues that legislation is considered to be a potent weapon to combat myths against victims and to provide justice in sexual assault cases. However, researchers suggest that it may take many years before a newly implemented law is consistently applied to jurors' decisions (Koehler, 2006; Levin \& Alkoby, 2017), because of jurors' heavy reliance on their own biases and pervasive myths about sexual assault (Leverick, 2020).

\section{Juror Bias in Sexual Assault Cases}

Jurors' personal attitudes and perceptions have been shown to play a strong role in their verdict decisions in sexual assault cases (Gravelin et al., 2018). Even when jurors are provided with judicial instructions that explicitly tell them not to use their own attitudes about a crime during their deliberations, jurors still seem to rely on their own opinions (Carlson \& Russo, 2001). Research has suggested that due to the complexity and ambiguity of sexual assault trials (i.e., the majority being "he said/she said"; Daly, 2006), jurors have a difficult time keeping track of both the specific case details and procedural legal instructions (Devine et al., 2012). They instead may rely on cognitive representations of the typical/ideal features of the crime (referred to as prototypes; Rosch, 1978) and their preconceived notions of what constitutes sexual assault (referred to as rape myths; Burt, 1980) to determine how guilt, credibility, and blame should be assigned (Du Mont et al., 2003; Ellison \& Munro, 2010). The relations between prototypes, rape myths, and sexual assault cases will be reviewed in the following sections. 


\section{Prototype Theory}

In Prototype Theory, Rosch (1978) describes how individuals tend to categorize items into memberships, where some members of a category are more central than others, and these then form our prototype for that category. Members of a category are more likely to become more central, and thus prototypes, when they are frequently viewed and constantly associated with that category (Hayes-Roth \& Hayes-Roth, 1977; Posner \& Keele, 1968; Reed, 1972). Building on their own work, Rosch and Brooks (1978) discovered that once a prototype is learned, it is represented in one's long-term memory as a member of that category; this leads to quick and effortless cognitive recall when that category is cued. In contrast, it is harder to add less central members of a category into our memories, which means they are less likely to be recalled when that category is cued, and they are harder to recognize as qualifying as a member (Brooks \& Rosch, 1978). For example, when the fruit category is cued, many people quickly recall apples since they are a central member of this category, whereas few recall tomatoes, even though both are members of the category. Even when provided with the definition of what constitutes a fruit, individuals will debate whether a tomato is truly a fruit because it does not fit with their prototype.

Therefore, it appears that people's recollection and knowledge of object categories are represented by a prototype of the category. If a target object has many features that are characteristic of the prototype, then it will likely be judged to be a category member; if the target has few characteristic features, then it will likely be rejected as a category member (Rosch, 1978). One implication of this prototype model is that categories have a graded structure; the more typical features an object possesses, the more representative of the category it is perceived 
to be (Rosch, 1978). More recent research has demonstrated that this prototype model of categorization generalizes to social categories as well. Categories such as social situations (e.g., parties, interviews, and work; Brooks et al., 2018), and social groups (e.g., fraternity members; DeSantis, 2020) all appear to be organized around prototypes. Research suggests that these prototypes inform participants' behaviours towards group members (Brooks et al., 2018; DeSantis, 2020) and their inferences about the group (Brooks et al., 2018; DeSantis, 2020). This research indicates that prototypes are present in a variety of decision contexts.

Given people's facility with constructing and using prototypes, it is possible that individuals rely on prototypes when evaluating criminal cases. They may, for example, believe that the typical burglary is committed by a person dressed in black clothing who breaks into an unoccupied house late at night and steals jewelry, or that complainants of sexual assault are females, defendants are males, and the act in question was vaginal intercourse. Suppose jurors have constructed prototypes of crime categories. In that case, it is plausible that they may determine the guilt or innocence of a defendant by comparing the characteristics of the defendant's alleged crime with the features of their prototype.

Research on Prototype Theory and the Justice System sheds light on such inquiry.

Prototype Theory and the Justice System. Smith (1991) was one of the first to utilize the Prototype Theory within legal psychology; she wanted to build on Pennington and Hastie's (1986) Story Model, which proposes a three stage "story model" for understanding the decision-making process of individual jurors. First, the juror forms the presented evidence into a story. Second, following instructions from a judge, the juror categorizes the verdict choices. Finally, the juror attempts to match the acceptable story to an appropriate verdict. 
Smith (1991) recognized that the Story Model did not account for how jurors represent verdict decisions or how jurors integrate the judge's instructions, the facts of the case, and the law to select a verdict. Smith (1991) conceptualized selecting a verdict as a prototype-relevant categorization task; when a juror is asked to decide whether a defendant is guilty of a certain crime, the juror must decide whether the defendant's actions qualify as a member of the crime category charged. To investigate this, Smith (1991) presented mock jurors with case descriptions that, in accordance with legal definitions and judicial instructions given to them about the crime, should have produced guilty verdicts. However, as the number of aspects from the case diverted from the jurors' crime prototype, mock jurors were significantly less likely to judge defendants as guilty of a crime. Smith (1991) therefore concluded that mock jurors had prototypical perceptions of crime categories that differed from legal definitions. Smith's (1991) work demonstrated that people within our justice system (e.g., police, judges, jurors) also represent crime categories with prototypes. Smith's (1991) innovative findings have led researchers to consider the effects of juror prototyping in our criminal justice system.

Specifically, Devine (2012) expanded on the Story Model to create the Director's Cut Model. The model is concerned with the decisions of individual jurors before deliberation. The primary metaphor underlying the model is that of a film director. Much as a director assembles the footage from many scenes into a cohesive narrative, the model postulates that jurors work with the evidence presented at trial to formulate a narrative account of the events preceding it. According to the model, jurors acquire and understand information concerning the trial from external (presented evidence, witness testimony, etc.) and internal (stereotypes, pre-existing knowledge and beliefs, etc.) sources (Devine, 2012). As the trial proceeds, jurors will form mental pictures of the events leading up to the trial (Devine, 2012). 
According to the model (Devine, 2012), two types of cognitive structures play a fundamental role in constructing trial representations: scripts and stereotypes. Scripts are event-centred cognitive structures that involve a series of actions occurring in a causal sequence (Schank \& Abelson, 1989). Stereotypes are person-centred cognitive structures consisting of a category label and a set of associated characteristics (Bower et al.,1979). The Director's Cut Model (Devine, 2012) proposes that for jurors, case types may function like movie genres. In the world of movies, there are several common film genres. Movie genres have fairly standard plotlines, character types, and event sequences. Metaphorically, jurors will be familiar with various types of legal cases. According to the model, these types of cases may activate an associated script that brings to mind assumptions, beliefs, images, and expectations about what the evidence will show. Critically, evidence is more likely to be added to a juror's story if congruent with their pre-existing scripts and stereotypes (Devine, 2012). Therefore, according to this theory, jurors appear to rely on pre-existing attitudes in coming to their verdict decisions.

This theory appears to contend that jurors' scripts and stereotypes inform jurors' mental representation of a case. I argue that these mental representations may be informed by jurors' crime prototypes as well. This supposition seems plausible due to prototype researchers arguing that when individuals utilize scripts, the process that occurs is that they simplify their perception members by classifying them into pre-existing categories based on the similarity of the stimulus to a prototype (St. Amant, 2017). Therefore, it appears plausible that these scripts are being formulated based on prototypes. However, limited research has separated prototypes from scripts and appears to have confounded the two terms (St. Amant, 2017), despite them being different by definition (Foti, 1987). As the Director's Cut Model suggests, jurors' scripts 
are activated based on their familiarity with crime types, and these scripts bring about assumptions, beliefs, and expectations about the crime. Perhaps, these scripts could be influenced by jurors having a prototypical image of what qualifies as that specific crime. For instance, suppose an individual is a juror on a sexual assault case involving a male complainant, female defendant and forced oral sex, which does not fit within their sexual assault prototypes. In that case, perhaps, the deviation from the prototype is the mechanism for jurors' scripts and stereotypes informing their mental representation of the case. Perhaps this is why Green (2000) proposes that mock jurors have more prototypical images of sexual assault cases than they do of cases depicting crimes of murder and burglary. However, limited research has explicitly empirically evaluated what jurors constitute as a prototypical sexual assault. This line of inquiry is the main focus of the present study.

What is the Prototype of a Sexual Assault Case? Crime prototype theorists suggest that the complainant and the defendant's gender are highly salient in formulating a prototype about crime in general (Green, 2004). Applying this to sexual assault, it appears that society has developed a conceptualization for sexually aggressive behaviour that necessitates men oppressing women (Horvath \& Brown, 2013). This has made male-on-female violence seem to be more accessible in people's memory as a "typical" instance of sexual assault in contrast to female-on-male sexual offences (Bates et al., 2019). As such, there appears to be a prototype in jurors' minds about who is involved in a sexual assault case. Yet, many specific details regarding jurors' conceptualizations of sexual assault cases still remain unclear because only the following two studies have directly examined this.

Anderson (2007) asked mock jurors to write down characteristics of a stereotypical sexual assault case (i.e., describing the complainant, the act, and the defendant). Results 
revealed that all 240 participants maintained that the complainant was a female, and that the defendant was male and a stranger to the complainant. These findings align with crime prototype theorists' contentions of the importance of the complainant's and defendant's genders in formulating a crime prototype (Green, 2004). In a subsequent study focusing on female complainants, Ferrone (2018) confirmed that participants' mental representation of a sexual assault involves a male perpetrator who is a stranger to the complainant. Further, this study added to the conceptualization of sexual assault cases by demonstrating that participants' mental representation also included physical resistance (with injuries to prove it) and complainant sobriety.

As stereotypes describe aspects repeatedly attributed to one group (Geeraerts et al., 2008) rather than a model of the category (which is defined as a prototype; Rosch, 1978), it appears both studies were testing the effect of individuals' sexual assault prototypes using the term "stereotype." Although these studies did not directly measure sexual assault prototypes, they provide valuable information on what may comprise individuals' representation of a sexual assault case. These findings appear to align with the Director's Cut Model's (Devine, 2012) contention that individuals' scripts and stereotypes about crimes have informed their mental representations of a case. Additionally, these results appear to support my argument that deviating from individuals' perceptions of a prototypical sexual assault scenario may be the mechanism for which these scripts and stereotypes inform ones' mental representation. Therefore, it stands to reason that individuals may have a prototype of a sexual assault case, which appears to involve a male perpetrator, stranger assault, complainant sobriety, and complainant resistance. Notably, these prototypes were not directly examined, and the 
previously reviewed studies did not ask participants to describe the form of the sexual assault.

Therefore, many aspects of the prototypical sexual assault scenario remain unknown.

Interestingly, the mental representation of sexual assault cases revealed in these studies reflect the old legal understanding of sexual assault (Bill C-127), without incorporating the legal reforms around gender neutrality and consent (Bill C-51), demonstrating that legislation is not the sole determinant of individuals' sexual assault perceptions. Instead, there appear to be other mechanisms driving individuals' understanding of, and attitudes about, sexual assault cases. To this end, research has suggested that there are widespread false beliefs about sexual assault, referred to as rape myths (Burt, 1980; Lonsway \& Fitzgerald), which prescribe the prototype of a "genuine" sexual assault case, "genuine" sexual assault complainant, and a "genuine" defendant (McKimmie et al., 2014). Research also suggests that these rape myths are by-products of gender stereotypes (Gravelin et al., 2018).

\section{${ }^{2}$ Gender Stereotypes and Rape Myths}

\section{Gender Stereotypes}

Gender studies research has demonstrated that individuals are socialized based on their gender starting from an early age (Harrison et al., 2008). Girls and boys quickly learn what it means to be masculine and feminine, what roles society holds for each of these categories (Danube et al., 2014), and according to Kachel's Gender Stereotypes Theory (2016), how one

\footnotetext{
${ }^{2}$ It is important to note that the author acknowledges that gender and sex are two separate entities, with sex being one's biological makeup, and gender being a social construct (Little, 2016). For the scope of this master's thesis, gender was examined within a binary concept of cisgender masculinity and femininity. While the issue of sexual assault against people who are transgender (Jaffray, 2020) deserves future research attention, the rape myths associated within the transgender and cisgender community are different (Davies \& Hudson, 2011) and beyond the scope of this thesis. My research focused on heterosexuality, despite the awareness and advocation of homosexuality and bisexuality. There are unique rape myths associated with those who are homosexual (Davies \& Mccartney, 2003; Wakelin \& Long, 2007) and bisexual (Mann, 2018), and this was beyond the scope of this thesis. Future research should focus on sexual assault victims and accused who are transgender/non-binary/fluid, and those who are gay/lesbian/bisexual/pansexual, to allow for a gender-neutral and non-heteronormative understanding of juror decision-making in Canadian sexual assault cases.
} 
needs to act according to these concepts of masculinity and femininity in order to be perceived as a "true woman" and a "true man." The theory explains that gender stereotypes consist of both a descriptive and prescriptive component. The descriptive elements include beliefs of what men and women typically do, whereas the prescriptive part dictates what men and women should do. Previous research has suggested that the prescriptive component of gender stereotypes is important in understanding prejudice and gender bias because it indicates approval or disapproval of the behaviour for a specific gender (i.e., aggression is approved of in men but disapproved of in women; Kachel et al., 2016). The prescriptive component is broken down into positive and negative aspects (Kachel et al., 2016). Positive prescriptive stereotypes are desirable behaviours a particular gender is expected to display, while negative prescriptive stereotypes are behaviours considered undesirable when exhibited by one gender, but encouraged in another (Kachel et al., 2016). For example, women are expected to be warm, sensitive, and cooperative, and to avoid aggressive and dominant types of behaviours (Koenig, 2018). Conversely, men are expected to be assertive, competitive, and independent while avoiding signs of weakness (Koenig, 2018). Violations of prescriptive stereotypes create reactions of anger and moral outrage because the person is not acting as they are "supposed to act" (Kachel et al., 2016).

Gender Stereotypes Theory (Kachel et al., 2016) also informs sexual scripts (Wiederman, 2005). A script dictates appropriate social behaviours (Sakaluk et al., 2014), and sexual scripts are specific scripts that assign gender-based expectations for sexual behaviour ranging from dating to intercourse (Simon \& Gagnon, 2003). For example, society expects men to be promiscuous, and to be the initiators of sex, while it expects women to be pure and chaste (Harrison et al. 2008; White \& Yamawaki, 2009). Individuals are expected to adhere to 
these norms and, similar to the prescriptive component of gender stereotypes, violations of these sexual scripts create a reaction of anger (Leftowitz, 2014). These gender stereotypes and sexual scripts form the basis of rape myths (Gravelin et al., 2018) and have negative consequences for victims of sexual assault who do not conform to these stereotypes. This would therefore suggest that male victims of female perpetrated sexual assault are in violation of these sexual scripts and gender stereotypes and would be treated differently than female victims of male perpetrated sexual assault.

\section{Rape Myths}

Rape myths are defined as "prejudicial, stereotyped and false beliefs about sexual assaults, rapists, and rape victims" (Burt, 1980, p. 217). The Rape Myth Acceptance Scale was developed to measure individuals' endorsement of rape myths in relation to female victims of sexual assault (Burt, 1990; Payne et al., 1999; McMahon \& Farmer, 2011). Rape myth endorsement is suggested to be one of the most consistent predictors for complainant and defendant blame in terms of heightened complainant blame and lowered defendant blame (Abrams et al., 2003). Jurors' attribution of complainant/defendant credibility and blame are important, as they may play a role in verdict decisions (Ellison \& Munro, 2009; Finch \& Munro, 2005; Morabito et al., 2019). Psycho-legal research has demonstrated that jurors in sexual assault cases blame complainants and find them less credible if they do not adhere to specific rape myths that dictate who is a "genuine" sexual assault complainant and what is a "genuine" sexual assault case (e.g., McKimmie et al., 2014). Further, researchers have suggested that there is a negative relationship between jurors' blame/credibility assessment of the complainant and their verdict decisions (Ellison \& Munro, 2009; Finch \& Munro, 2005), whereby the more blameworthy and less credible jurors find the complainant to be, the fewer 
guilty verdicts they render. As such, it stands to reason that any blameworthy behaviour of the complainant, as informed by rape myths, may negatively predict jurors' judgments of the defendant's guilt. As noted in R. v. Seaboyer (1991), the sexual assault victim "who comes to the attention of the authorities has her victimization measured against the current rape mythologies." Parallel to Gender Stereotype Theory, rape myths also contain both descriptive and prescriptive elements (Gerger et al., 2007). The descriptive element in rape myths specifies the behaviours and actions that typically occur in a sexual assault. In contrast, the prescriptive elements dictate the actions and behaviours that are expected to occur (Gerger et al., 2007). As such, the aggregated concept of rape myths provides a stereotype of a "genuine" sexual assault victim, a "genuine" perpetrator, and a "genuine" sexual assault (McKimmie et al., 2014).

Presently the rape myths that prevail are: (1)Women "ask for" rape, by flirting, dressing provocatively, consuming alcohol or behaving promiscuously (Burt, 1980; Lonsway \& Fitzgerald, 1994); (2) Most rapes are committed by strangers (Burt, 1980; Lonsway \& Fitzgerald, 1994); (3) A woman should be able to avoid rape by "fighting off" the rapist, and she has the responsibility to do so (Burt, 1980; Lonsway \& Fitzgerald, 1994); (4) Real men can defend themselves against sexual assault (Anderson, 2007); (5) Men cannot be sexually assaulted (Anderson, 2007); (6) Only gay men are victims of sexual assault (Anderson, 2007); (7) A woman cannot sexually assault a man (Anderson, 2007); (8) Male sexual assault only occurs in prisons (Anderson, 2007); (9) Physiological arousal only occurs in consensual sex (Anderson, 2007); and (10) vaginal intercourse is the only form of a sexual assault (Lefkovitz et al., 2016; Lefkovitz et al., 2014). Collectively, these rape myths have damaging implications 
for sexual assault complainants whose behaviours and assaults do not align with them (Ellison \& Munro, 2009; Finch \& Munro, 2005; Klement et al., 2019).

The reviewed rape myths appear centered around three areas: what circumstances constitute a sexual assault, who is involved, and under what form. When considering the effects of these rape myths on jurors' decision-making, the majority of research has focused on the circumstances. Some literature has also been focused on who can be involved, but there still remain numerous gaps, and no study has focused on form.

\section{Circumstances Informed by Rape Myths and their Effect on Jurors' Decisions.}

Numerous psycho-legal studies have employed mock juror simulations to ascertain the impact of rape myths on juror verdict, as well as credibility and blameworthiness allocated towards the complainant and defendant (McKimmie et al., 2014; Stuart et al., 2019; Schuller et al., 2011; Starosta \& Schuller, 2020; Wenger \& Bornstein, 2006). For example, Schuller and Wall (1998) conducted a mock juror simulation study to determine the effects victim intoxication has on jurors' decisions. One hundred and fifty-two participants were given a hypothetical sexual assault vignette that either depicted the complainant drinking alcohol or cola. The results demonstrated that jurors in the alcohol condition rendered significantly fewer guilty verdicts, attributed greater blame to the complainant and less to the defendant, found the complainant less credible, and found the defendant more credible than did jurors in the cola condition. This study demonstrates that the rape myth that a woman "asked for it" if she drank alcohol is strongly predictive of mock jurors' decision-making.

Subsequent mock juror studies have used similar methods to examine the impact of the following rape myths on juror decision-making: stranger versus acquaintance assault (e.g., Abrams et al., 2003; Ellison \& Munro, 2010; McKimmie et al., 2014; Viki et al., 2004), 
resistance vs. no-resistance vs. verbal resistance (e.g., Abrams et al., 2003; Ellison \& Munro, 2009; Randall, 2010), immediately reporting the assault vs. delays in reporting the assault (e.g., Raitt \& Zeedyk, 1997), the victim being visibly upset at the time of reporting vs. not visibility upset (e.g., Schuller et al., 2010), and the amount of alcohol a victim had consumed (e.g., Abbey et al., 2002; Gravelin et al., 2018; Masser et al., 2010). The results of these studies consistently demonstrate that complainants who deviate from what rape myths prescribe as a "genuine" sexual assault (e.g., intoxicated complainant, lack of complainant's physical resistance, the defendant was known to the complainant) receive more blame from mock jurors, receive fewer guilty verdicts, and are seen as less credible compared to complainants who are seen as "genuine", as defined by rape myths. Accordingly, defendants in "ingenuine" complainant conditions are seen as less blameworthy and more credible than defendants in the "genuine" complainant condition (Abbey et al., 2002; Abrams et al., 2003; Ellison \& Munro, 2010; Gravelin et al., 2018; Klippenstine \& Schuller, 2012; McKimmie et al., 2014; Persson et al., 2018; Sims et al., 2007; Schuller et al., 2010; Viki et al., 2004; Wall \& Schuller, 2002). These studies demonstrate the potentially strong impact that rape myths can have on mock jurors' decisions.

Importantly, Du Mont and associates (2003) found that the same applies in real-life cases. They examined archival cases of female complainants of male perpetrated sexual assault cases to ascertain if rape myths could predict which of the sexual assault cases would result in guilty verdicts. The findings demonstrated that rape myths of stranger assault, required resistance, "modesty," and sobriety could in fact predict verdicts. Based on the results, the researchers concluded that rape myths are strongly held in our society and are so pervasive that they have created a 'real rape' prototype (Du Mont et al., 2003). Within the 
'real rape' prototype, a "genuine" sexual assault victim has the following attributes: the victim was assaulted by a stranger, she actively resisted the assault, she was sober at the time of the assault, immediately reported the assault, and was visibly upset when she reported the crime (Du Mont et al., 2003). Notably, for these researchers what is considered prototypical is what led to a conviction, and therefore jurors' perceived prototypicality of the sexual assault case, complainant, and defendant were not explicitly empirically measured. Similarly, because the archival data comprised sexual assault cases involving female complainants of vaginal intercourse sexual assault, how the form of the sexual assault and complainant/defendant's gender relates to this 'real rape' prototype is unknown.

In an effort to examine deviations from Du Mont and colleagues (2003) 'real rape' prototype on jurors' decisions, McKimmie and colleagues (2014) presented participants with one of two different case summaries. The scenarios were the same except the researchers depicted the female complainant as either "prototypical" or "counter-prototypical". The researchers assumed these prototypes based on the rape myth literature and Du Mont and colleagues' (2003) 'real rape' prototype. Therefore, the "prototypical complainant" aligned with rape myths and was assaulted by a stranger, resisted, immediately reported the assault, was emotional when reported the crime, and was sober at the time of the assault. The "counterprototypical complainant" was depicted in opposition to these rape myths. Participants were randomly assigned to either the "prototypical" or "counter-prototypical" condition. The results revealed that mock jurors in the "prototypical" condition rendered significantly more guilty verdicts and attributed less blame along with higher credibility to the complainant than mock jurors in the "counter-prototypical" condition (McKimmie et al., 2014). These results appear to parallel the Director's Cut Model's (Devine, 2012) conception that jurors rely on pre- 
existing attitudes in coming to their verdict decisions, and so it stands to reason that jurors will use prototypes when evaluating their determination of guilt, blame, and credibility in a sexual assault trial. Importantly, although it appears as though deviating from the prototype is the mechanism through which factors of rape myths influence juror decision-making, prototypicality in itself was not actually measured within McKimmie and colleagues'study (2014). In fact, the role of prototypicality in jurors' decisions in sexual assault cases has never actually been measured. Rather, previous research has manipulated how "prototypical" a sexual assault scenario is based on if the condition adheres to the specific rape myths that dictate who is a "genuine" sexual assault complainant and what is a "genuine" sexual assault case. Therefore, previous research has not directly measured mock jurors' perceived prototypicality of a sexual assault case, complainant, and defendant in various conditions. Consequently, it is unknown what comprises mock jurors' sexual assault prototypes and if/how they use their prototypical assessments to inform their case-related decisions; this was a specific gap that the present study aimed to fill.

Collectively, these results demonstrate that jurors hold an image of a sexual assault complainant that is based on rape myths and is in sharp contrast to current legislation (e.g., Bill C-51) as well as to the realities of our current society. Canadian data demonstrates that most sexual assaults are perpetrated by someone known to the complainant (Canadian Centre for Justice Statistics, 2020), and approximately one-half of sexual assault cases in Canada involved alcohol consumption by the complainant (Statistics Canada, 2018). Studies also exemplify that the majority of complainants do not resist their assaults (Haskell \& Randall, 2019), but rather experience "frozen helplessness" where freezing is an automatic, involuntary response to a threat (Marx et al., 2008). Furthermore, deviations from what rape myths 
prescribe as an "appropriate" sexual assault, potentially because they deviate from one's prototypical image, seem to result in fewer guilty verdicts and harsher complainant judgements (Ellison \& Munro, 2009; Finch \& Munro, 2005; Klement, 2017; Sommer et al., 2016).

In all of the preceding mock juror psycho-legal research, the researchers solely examined mock jurors' perceptions of a female complainant of male perpetrated sexual assault (Abbey et al., 2002; Abrams et al., 2003; Ellison \& Munro, 2010; Gravelin et al., 2018; Klippenstine \& Schuller, 2012; McKimmie et al., 2014; Persson et al., 2018; Schuller et al., 2010; Viki et al., 2004). These are important studies given the multitude of women who experience forced vaginal intercourse by men each year (World Health Organization, 2019). However, the singular focus on only one type of complainant (i.e., female) perpetuates the false narrative that only females are victims of sexual assaults and only men are the perpetrators (Anderson, 2007).

\section{${ }^{3}$ Rape myths: Victim and Perpetrator Gender and Their Effect on Jurors'}

Decisions. The rape myths that define who can be involved in a sexual assault (e.g., men cannot be sexually assaulted, women cannot sexually assault a man; Anderson, 2007) appear to be by- products of the socially constructed ideals of sexual victimization, where victims of sexual assault are perceived to be weak and defenseless. This aligns with the social construct of femininity (Javaid, 2017). Thus, male victimization contradicts the notions of socially constructed ideas of masculinity, because society notes that men are strong (Lindsey, 2016). Additionally, female perpetrators of sexual assault challenge the ideas of femininity because

\footnotetext{
${ }^{3}$ For the purpose of this thesis, we are interested in prototypicality within heterosexual pairings because same-sex sexual assault can bring perceptions of homosexuality and the potential of homophobia. Furthermore, same-sex sexual assault has its own rape myths (Davies et al., 2012; White \& Kurpius, 2002), and was outside of the scope of this thesis. I fully recognize that same-sex sexual assault and juror decision-making warrants empirical investigation, and it is my future research goal to do so.
} 
all female relations are socialized to be nurturing and passive (Lindsey, 2016). As such, it would follow that sexual assault scenarios involving male complainants and female perpetrators would not align with jurors' prototypical image of a sexual assault case, complainant, and defendant. It is feasible, then, that jurors' complainant/defendant blame and credibility assessments may reflect this misalignment with sexual assault prototypes, which may in turn predict their verdict decisions. However, few empirical studies have examined a male complainant with a female defendant, with the bulk of the research using a male defendant (Anderson, 2004; Burt \& DeMello, 2002; Davies \& Boden, 2012; Davies et al., 2001; Davies et al., 2011; Davies \& McCartney, 2003; Davies et al., 2012; Wakelin \& Long, 2003). Additionally, no previous study has examined prototypicality as the mechanism behind juror decisions in sexual assault cases. The present study sought to fill this gap.

Female-on-Male Sexual Assault. Sexual victimization conducted by a woman towards a man may produce suspicion of the male victim because the gender stereotype associated with men is that they are more sexually assertive, and always willing to engage in sex with a woman (Wakelin \& Long, 2003). Thus, this gender stereotype portrays men as unlikely to become unwilling victims of forced sexual assaults by women (Caleo, 2016). This gender stereotype seems to have helped in creating the rape myth that women cannot sexually assault men (Anderson, 2007). This rape myth, however, is not reflective of our society. Stemple and Meyer (2017) pooled four years of National Crime Victimization Survey data and demonstrated that over $35 \%$ of male victims who experienced a sexual assault were victims of a female perpetrator. This serves to dispel the myths that men cannot be sexually assaulted, and that women cannot sexually assault men (Anderson, 2007). 
Of the scant research that has examined female perpetrated male victimization, the studies focused on other rape myths such as the requirements of resistance, victim sobriety, and assault by a stranger (Anderson, 2007; Pica et al., 2018). The results elucidate clear parallels for male complainants of sexual assault with the female sexual assault literature concerning stranger vs. acquaintance sexual assault (Anderson, 2007), resistance vs. no resistance (Anderson, 2007; Pica et al., 2018), and intoxicated vs. sober (Pica et al., 2018). Specifically, male complainants who knew their assailant, who did not resist the assault, and who were intoxicated at the time of their assault were blamed more than those who were assaulted by a stranger, actively resisted, and were sober. Of importance, the male complainant in every condition was blamed significantly more than his female complainant counterpart (Anderson, 2007; Pica et al., 2018; Starosta \& Schuller, 2020). Similarly, the female defendant was viewed as significantly more credible and less blameworthy than the male defendant regardless of the other conditions (Anderson, 2007; Pica et al., 2018; Starosta $\&$ Schuller, 2020). Interestingly, no significant differences were found between jurors' verdict decisions for a male or a female complainant within these studies.

These results have very important implications. First, they demonstrate that jurors blame male complainants more and view them as less credible than their female complainant counterparts. Subsequently, the female perpetrator of male sexual assault is viewed as less blameworthy and more credible than a male perpetrator of female sexual assault. This is concerning if a male victim of female-perpetrated sexual assault decides to bring his case to trial because, based on the research, his claims are less likely to be believed, and his perpetrator will be seen as more credible than he is. Second, these findings imply that knowing one's assailant, inebriation, and lack of resistance can influence the levels of blame attributed 
toward the complainant regardless of their gender. Together, these findings should be of concern for our criminal justice system because they reflect the strong role rape myths play in jurors' decision-making.

It appears from the reviewed literature that sexual assault cases involving a male complainant and a female defendant are treated less favourably by jurors (i.e., greater complainant blame, and lower complainant credibility) than sexual assault cases involving a female complainant and a male defendant (Anderson, 2007; Pica et al., 2018; Starosta \& Schuller, 2020). It is feasible that this occurs because male complainants of female perpetrated sexual assault contradict current gender stereotypes (Kachel et al., 2016) and would thereby not fit within jurors' prototypes of a sexual assault case, complainant, or defendant. In accordance with Smith's (1991) findings, deviating from a prototype should play a role in jurors' decisions, and following the Director's Cut model, aspects that do not fit within jurors' pre-existing attitudes should play a role in jurors' use of the evidence. However, it is unknown how jurors may rate the prototypicality of a sexual assault case involving a male complainant and a female defendant because no study has examined this. Furthermore, limited studies have examined sexual assault cases involving male complainants and female defendants in general. Therefore, more research is warranted on this prevalent, yet understudied population.

\section{Rape Myths: Form of the Sexual Assault and their Effect on Jurors' Decisions.}

The Canadian legal definition of sexual assault includes forced oral sex (Criminal Code of Canada, s. 276). Furthermore, as of 2015 approximately 287,450 victims in North America had reported a forced oral sexual assault (Truman \& Langton, 2015). These numbers are likely an underrepresentation due to low reporting rates of sexual assault crimes (Statistics Canada, 2017). However, in line with the prevailing rape myth that only vaginal intercourse 
equates a sexual assault (Lefkovitz et al., 2014; Lefkovitz et al., 2016), there appears to be a common belief that oral sex is a less serious form of assault. For example, Chambers (2007) interviewed college students' opinions of different sexual activities to examine the sexual script surrounding various sexual acts. The results found that men and women regarded oral sex as less serious and less intimate than intercourse. This study is important in the context of juror decision-making because The Director's Cut Model contends that scripts inform mock jurors' representation of a case (Devine, 2012), and I argue these scripts are formulated based on prototypes. Therefore, it stands to reason that mock jurors may not view oral sex as a prototypical sexual assault form.

The impact of this rape myth on societal perceptions is further highlighted in a study conducted by George and Spohn (2019), who examined 517 prosecutors' decisions to charge suspects in an alleged sexual assault involving either vaginal intercourse or oral sex. The authors decided to use oral sex to depict a less serious assault to ascertain if offence seriousness influences prosecutors' decisions. However, by labelling forced oral sex as less serious, the authors themselves endorsed the notion that oral sex is a lesser form of sexual assault and not equivalent to an assault involving vaginal intercourse, which ignores the lived experiences of victims who demonstrate that a forced sexual encounter is damaging both physically and emotionally regardless of its form (Brown et al., 2009; Petersson \& Plantin, 2019; Reddit, Raising Awareness for Male survivors of Rape, 2013; Reddit, Was this rape? Forced oral sex, 2008; Weare, 2018). Nonetheless, the study found that prosecutors did not prosecute as many oral sex sexual assault claims as they did of those involving vaginal intercourse. Although this study had limitations, the results do demonstrate that oral sex sexual assault is not taken as seriously, despite the harm it causes. Prosecutors have an 
important role in sexual assault cases, as they decide whether to prosecute a sexual assault (Kannanayakal, 2020). Notably, however, prosecutors are not the only decision makers within a sexual assault case. As such, it is necessary to examine the role this rape myth has on various members involved in the decision-making process of a sexual assault case.

Unfortunately, a large gap exists in the jury decision-making research with regards to jurors' decisions in oral sex sexual assault cases. A review of the literature was unable to identify a single peer-reviewed jury study involving an oral sex sexual assault case.

Conceivably, the previous legal assumption that sexual assault can only be a vaginally penetrative act (Bill C-127) still prevails among the empirical discourse. Thus, the role this rape myth has on jurors' prototypes and decisions is a specific gap that the current study aimed to address.

\section{Current study}

Jurors bring their own attitudes with them into the jury room (Horvath \& Brown, 2009). Due to the complexity of sexual assault trials, it is feasible that jurors in sexual assault cases would rely on prototypes in an effort to save cognitive resources. Similarly, the Director's Cut Model maintains that jurors' evaluations of the trial evidence are influenced not only by the facts of the case but also by their pre-existing attitudes (Devine, 2012), which I argue may be informed by their sexual assault prototypes. Importantly, prototypes are predictive of jurors' verdicts (Smith, 1991). Research has recognized that prototypes are advantageous for their ability to quickly assess if a situation fits a category of a member (Rosch, 1978), and there is empirical support that jurors have more prototypes regarding a sexual assault case than they do for other crimes (Green, 2000). Furthermore, these prototypes are informed by rape myths (McKimmie et al., 2014) that are centered around what circumstances represent a "genuine" 
sexual assault, who is involved, and under what form. Presently, the rape myths that have received the most empirical support are the rape myths surrounding the circumstances that constitute a "genuine" sexual assault case (i.e., stranger, victim resistance, and sobriety). There is limited empirical investigation devoted to the rape myths that (1) men cannot be sexually assaulted, (2) women cannot sexually assault men and (3) vaginal intercourse is the only form of a sexual assault, and how these rape myths may be informing mock jurors' prototypes in sexual assault cases. Because psycho-legal research has not explicitly measured mock jurors' perceived prototypicality of a sexual assault case, complainant, or defendant, it is unknown if mock jurors' sexual assault prototypes are one of the mechanisms behind their case-related decisions. It is also unknown what genders and forms are perceived as a prototypical sexual assault case, complainant, or defendant.

In an effort to begin to fill these gaps in the psycho-legal literature, my thesis sought to advance our understanding of 1) what jurors perceive as a prototypical sexual assault case, complainant, and defendant, 2) the role of deviations from this prototypical image on jurors' complainant/defendant blame and credibility assessments, and 3) the relationship between jurors' complainant/defendant blame and credibility assessments and their verdict decisions in sexual assault cases. Specifically, the objectives of my Master's thesis were three-fold. The first objective was to ascertain if the form of the sexual assault and the complainant and defendant's genders (male defendant/female complainant vs. female defendant/male complainant) influence mock jurors' perceptions of a sexual assault case's, complainant's, and defendant's prototypicality. The second objective was to examine if prototypicality of the case, complainant, and defendant are related to mock jurors' complainant/defendant blame and credibility assessments. Thirdly, I aimed to investigate the relationship between mock jurors' 
complainant/defendant blame and credibility assessments and their verdict decisions in sexual assault cases. I conducted a path analysis to examine the possible linkages between these constructs. This allowed for a better understanding of the processes and mechanisms behind the phenomenon of mock jurors' verdict decisions in sexual assault cases (see figure 1).

\section{Figure 1}

Hypothesized conceptual model (see design section).

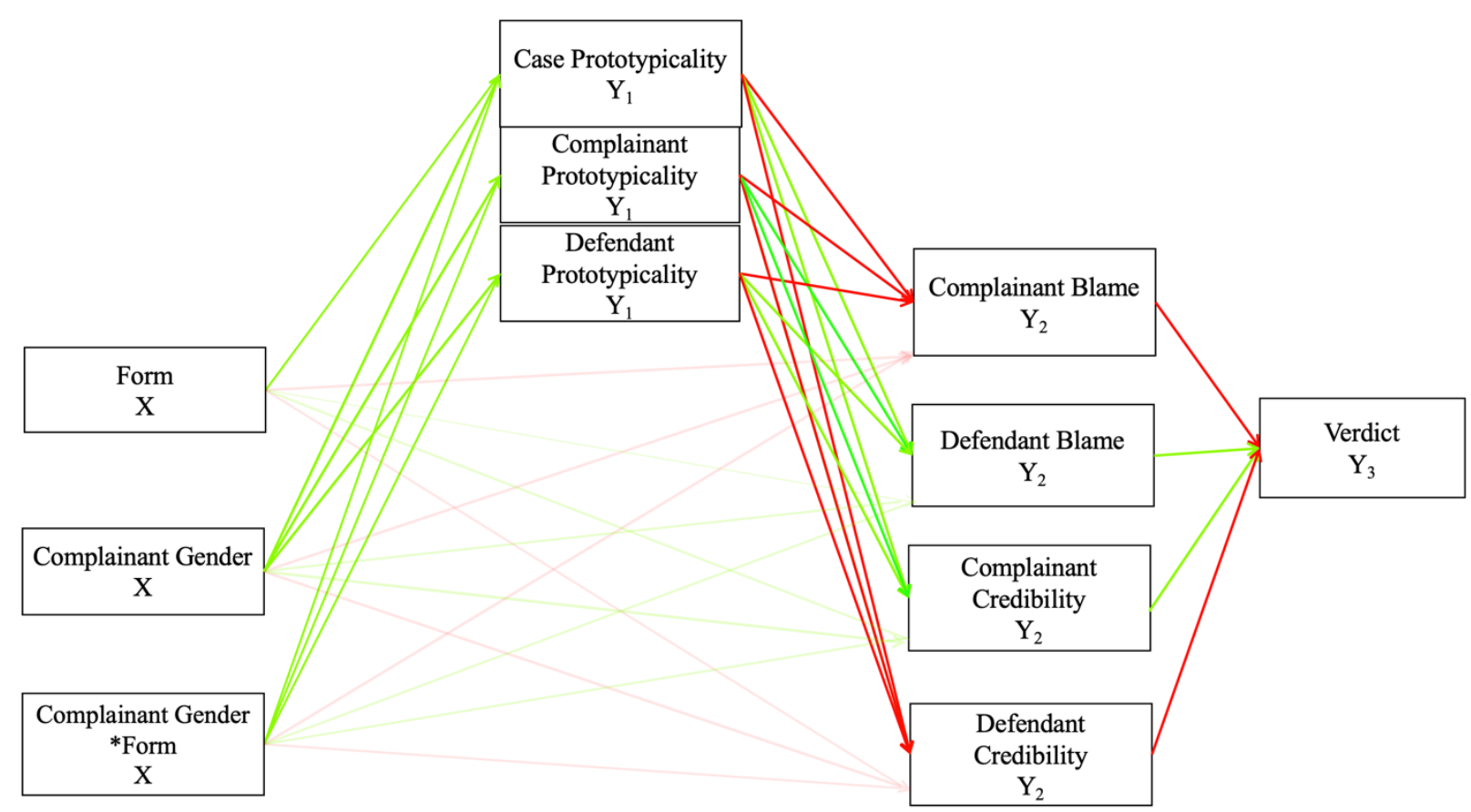

Note. Complainant gender and defendant gender were tied together.

Red line $=$ a negative relationship.

Green line $=$ a positive relationship .

Faded line $=$ reduced direct effect with prototypicality (of the case, complainant, and defendant) as the meditator.

Following the most common psycho-legal research approach (Greene et al., 2004:

Lieberman et al., 2016), my thesis employed a mock juror simulation study. The present study varied the form of the sexual assault (vaginal intercourse, oral sex) and, in accordance with the methodology utilized by Starosta and Schuller (2020), tied the variable of complainant gender to defendant gender whereby complainant gender was a function of defendant gender. 
Therefore, when the complainant was depicted as a man, the defendant was always depicted as a woman, and when the complainant was depicted as a woman, the defendant was always depicted as a man (see method section).

The study measured jurors' prototypicality ratings of a sexual assault case, complainant, and defendant. The study also measured five dependent variables: verdict, defendant and complainant blame, and defendant and complainant credibility. The remaining aspects of the sexual assault were represented to adhere to the specific rape myths that dictate what a "genuine" sexual assault case is (i.e., stranger assault, verbal-resistance, sober, immediately reported the assault), to allow for a focused examination on whether/how the form of the sexual assault and the gender of complainant and the defendant inform mock jurors' sexual assault prototypes.

The goal of the present thesis was to potentially discover one of the mechanisms behind jurors' decisions in sexual assault cases by examining the role of prototypicality on jurors' decisions. The study aimed to add to the conceptualization of the "real rape" prototype (Du Mont et al., 2003) by explicitly measuring mock jurors' perceived prototypicality of a sexual assault case, complainant, and defendant to ascertain how male complainants of female perpetrated sexual assault and oral sex fit within jurors' image of a prototypical sexual assault scenario. The study can potentially add to the Director's Cut Model (Devine, 2012) by providing evidence to suggest that jurors' pre-existing attitudes are also informed by their crime prototypes. Furthermore, this research brought male victims of female perpetrated sexual assault and forced oral sex to the empirical discourse, which can help improve our understanding of the multifaceted role gender of the complainant/defendant and form of the sexual assault play in judicial decision-making in sexual assault cases. It is essential to study 
juror bias as it relates to each aspect of our current sexual assault laws, which portray a broad spectrum of who is involved in a sexual assault and what constitutes a sexual assault.

\section{Hypotheses}

\section{1) Sexual assault form}

Direct Effects. a. In line with the rape myth that only vaginal intercourse equates a sexual assault (Lefkovitz et al., 2014; Lefkovitz et al., 2016), and previous empirical findings that sexual assault complainants who deviate from what rape myths prescribe as a "genuine" sexual assault are treated less favourably by jurors (e.g., Abrams et al., 2003; Ellison \& Munro, 2010; McKimmie et al., 2014; Viki et al., 2004), I predicted direct effects from the form of the sexual assault to complainant/defendant blame and credibility. The vaginal intercourse condition was expected to negatively predict complainant blame, positively predict complainant credibility, positively predict defendant blame, and negatively predict defendant credibility, as compared to the oral sex conditions. These direct effects were predicted to be reduced in size with the introduction of prototypicality assessments as the partial mediator.

Indirect Effects. b. In line with the rape myth that only vaginal intercourse equates a sexual assault (Lefkovitz et al., 2014; Lefkovitz et al., 2016), I predicted that the vaginal intercourse form of sexual assault would positively predict the prototypicality of the case, the complainant, and the defendant.

c. In association with prototype theory (Rosch, 1978), The Director's Cut Model contention that jurors rely on their pre-existing attitudes to make their decisions (Devine, 2012), and crime prototype literature (Smith, 1991), I hypothesized case, complainant and defendant prototypicality to negatively predict complainant blame, positively predict complainant credibility, positively predict defendant blame, and negatively predict defendant credibility. 
Therefore, sexual assault form was expected to indirectly predict jurors' complainant/defendant blame and credibility assessments by directly predicting jurors' prototypicality assessments of the sexual assault case, complainant, and defendant, which were then expected to predict jurors' complainant/defendant blame and credibility assessments.

d. Based on research examining the relationship between jurors' complainant/defendant blame and credibility assessments and their verdict decisions (Ellison \& Munro, 2009; Finch \& Munro, 2005), I expected that complainant/defendant blame and credibility would predict jurors' verdict decisions, as depicted in Figure 1. Therefore, sexual assault form was expected to indirectly predict jurors' verdict decisions by directly predicting their prototypicality assessments, which were expected to predict their complainant/defendant blame and credibility assessments, which were then expected to predict their verdict decisions.

Path analysis: The vaginal intercourse condition was predicted to be seen as more prototypical of a sexual assault case, complainant and defendant, which was expected to lead to lower complainant blame, lower defendant credibility, higher complainant credibility, and higher defendant blame, which in turn was expected to lead to more guilty verdicts compared to the oral sex condition (see Figure 2). 


\section{Figure 2}

Hypothesized path analysis for the indirect and direct effect of form of the sexual assault on jurors' verdict decisions in sexual assault cases

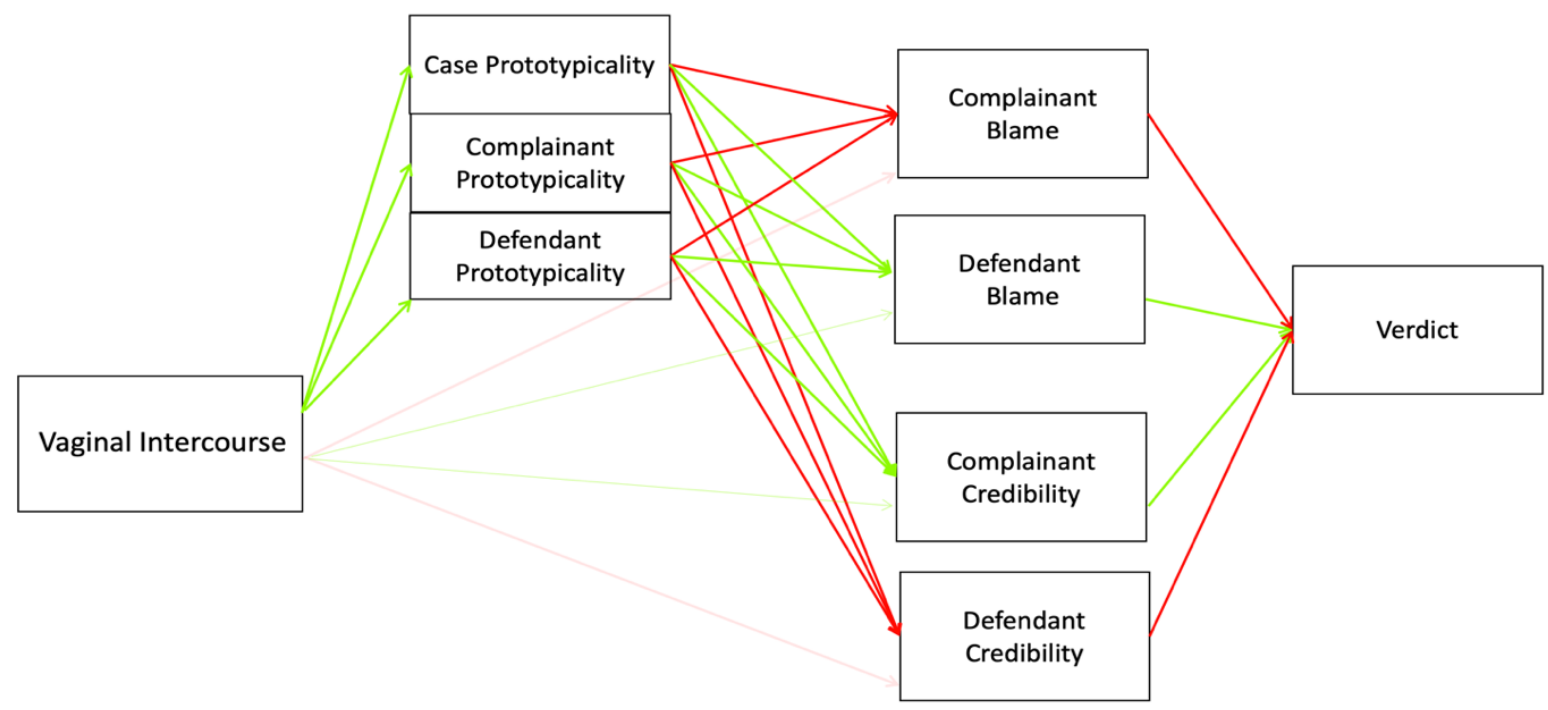

Note. Red line = a negative relationship.

Green line $=$ a positive relationship.

Faded line $=$ reduced direct effect with prototypicality (of the case, complainant, and defendant) as the meditator.

\section{2) Complainant (and defendant) gender}

Direct Effects. a. In line with the rape myths that men cannot be sexually assaulted (Anderson, 2007) and women cannot sexually assault men (Anderson, 2007), along with previous empirical findings surrounding rape myths and complainant/defendant blame and credibility (e.g., Abrams et al., 2003; Ellison \& Munro, 2010; McKimmie et al., 2014; Viki et al., 2004), I predicted direct effects from the complainant (and defendant) gender to complainant/defendant blame and credibility. The female complainant-male defendant condition was expected to negatively predict complainant blame, positively predict complainant credibility, positively predict defendant blame, and negatively predict defendant credibility, as compared to the male complainant-female defendant condition. The direct effects from complainant gender to 
complainant/defendant blame and credibility were predicted to be reduced in size with the introduction of prototypicality assessments as the partial mediator.

Indirect Effects. b. In line with the rape myths that men cannot be sexually assaulted (Anderson, 2007) and women cannot sexually assault men (Anderson, 2007), I hypothesized that the female complainant-male defendant condition would positively predict the prototypicality of the case, the complainant, and the defendant.

c. Following prototype literature (Rosch, 1978), Director's Cut Model (Devine, 2012), crime prototype literature (Green, 2004; Smith, 1991), previous research concerning individuals' mental representation of sexual assault cases (Anderson, 2007; Ferrone, 2018; Horvath \& Brown, 2013), Gender Stereotype Theory (Kachel et al., 2016), and the preceding literature examining male victims of female-perpetrated sexual assaults (Anderson, 2007; Pica et al., 2018; Starosta \& Schuller, 2020), I predicted that jurors' perceptions of the prototypicality of the case, complainant, and defendant would negatively predict complainant blame, positively predict complainant credibility, positively predict defendant blame, and negatively predict defendant credibility. To this end, the complainant (and defendant) gender was expected to indirectly predict jurors' defendant/complainant blame and credibility assessments by directly predicting jurors' prototypicality assessments, which were then expected to predict jurors' complainant/defendant blame and credibility assessments.

d. Based on research examining the relationship between jurors' complainant/defendant blame and credibility assessments and their verdict decisions (Ellison \& Munro, 2009; Finch \& Munro, 2005), I hypothesized that jurors'defendant/complainant credibility and blame assessments would predict jurors' verdict decisions, as depicted in Figure 1. Accordingly, the complainant (and defendant) gender was expected to indirectly predict jurors' verdict decisions 
by directly predicting jurors' prototypicality assessments, which were expected to predict jurors' complainant/defendant blame and credibility assessments, which, in turn, were expected to predict jurors' verdict decisions.

Path analysis: The female complainant-male defendant combination was expected to be seen as more prototypical of a sexual assault case, complainant, and defendant, leading to lower complainant blame, lower defendant credibility, higher complainant credibility, and higher defendant blame. This was expected to in turn lead to more guilty verdicts compared to the male complainant-female defendant condition (see Figure 3).

\section{Figure 3}

Hypothesized path analysis for the indirect and direct effect of complainant gender (and defendant gender) on jurors' verdict decisions in sexual assault cases

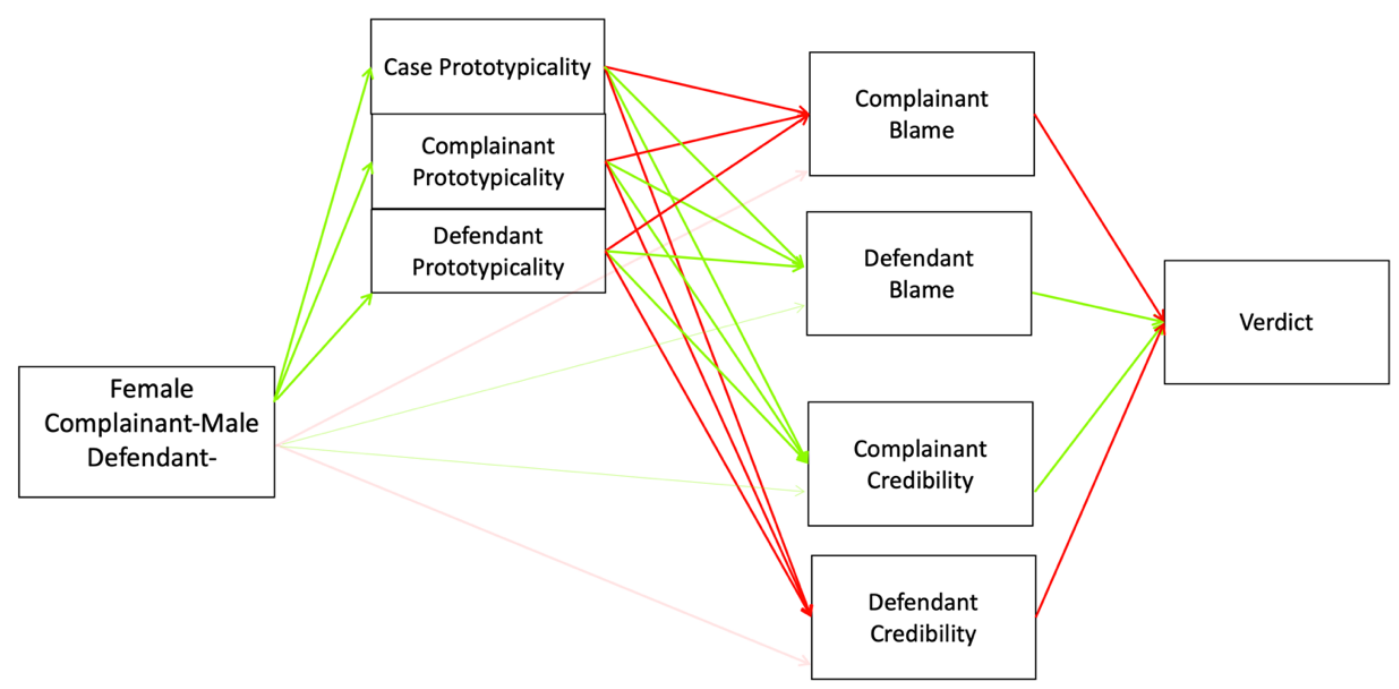

Note. Red line $=$ a negative relationship.

Green line $=$ a positive relationship.

Faded line $=$ reduced direct effect with prototypicality (of the case, complainant, and defendant) as the meditator.

\section{3) Interactions between sexual assault form and complainant (and defendant) gender}


Direct Effects. a. Based on research examining the relationship between rape myths and jurors' complainant/defendant blame and credibility assessments (e.g., Abrams et al., 2003; Ellison \& Munro, 2010; McKimmie et al., 2014; Viki et al., 2004), I predicted direct effects from the hypothesized interaction term of form of the sexual assault and complainant gender (tied to defendant gender). The female complainant-male defendant-vaginal intercourse condition was expected to negatively predict complainant blame, positively predict complainant credibility, positively predict defendant blame, and negatively predict defendant credibility as compared to all the other conditions. These direct effects were predicted to be reduced in size with the introduction of prototypicality assessments as the partial mediator.

Indirect Effects. b. In accordance with the rape myths that only vaginal intercourse equates sexual assault (Lefkovitz et al., 2016; Lefkovitz et al., 2014), men cannot be sexually assaulted (Anderson, 2007), and women cannot sexually assault men (Anderson, 2007), I hypothesized that the female complainant-male defendant-vaginal intercourse condition would positively predict prototypicality of the case, the complainant, and the defendant.

c. Following prototype literature (Rosch, 1978), Director's Cut Model (Devine, 2012), the crime prototype literature (Green, 2004; Smith, 1991), and previous research (Anderson, 2007; Ferrone, 2018; Horvath \& Brown, 2013; Pica et al., 2018; Starosta \& Schuller, 2020), I hypothesized that the prototypicality of the case, the complainant, and the defendant would negatively predict complainant blame, positively predict complainant credibility, positively predict defendant blame, and negatively predict defendant credibility. Consequently, the sexual assault form $\times$ complainant (and defendant) gender interaction term was expected to indirectly predict jurors' complainant/defendant blame and credibility assessments by directly predicting 
jurors' prototypicality assessments, which were then expected to predict jurors' complainant/defendant blame and credibility assessments.

d. Consistent with previous research (Ellison \& Munro, 2009; Finch \& Munro, 2005), I predicted that jurors' defendant/complainant credibility and blame assessments would predict their verdict decisions, as depicted in Figure 1. Thus, the sexual assault form $\times$ complainant (and defendant) gender interaction term was expected to indirectly predict jurors' verdict decisions by directly predicting jurors' prototypicality assessments, which were expected to predict jurors' complainant/defendant blame and credibility assessments, which were then expected to predict jurors' verdict decisions.

Path analysis: The female complainant-male defendant-vaginal intercourse condition was expected to be seen as more prototypical of a sexual assault case, complainant, and defendant in comparison to the male complainant-female defendant-vaginal intercourse, male complainant-female defendant-oral sex, and female complainant-male defendant-oral sex conditions. This was expected to lead to lower complainant blame, lower defendant credibility, higher complainant credibility, and higher defendant blame, which would lead to more guilty verdicts compared to the other conditions (see Figure 4). 


\section{Figure 4.}

Hypothesized path analysis for the interaction between sexual assault form and complainant (and defendant) gender on juror verdict decisions

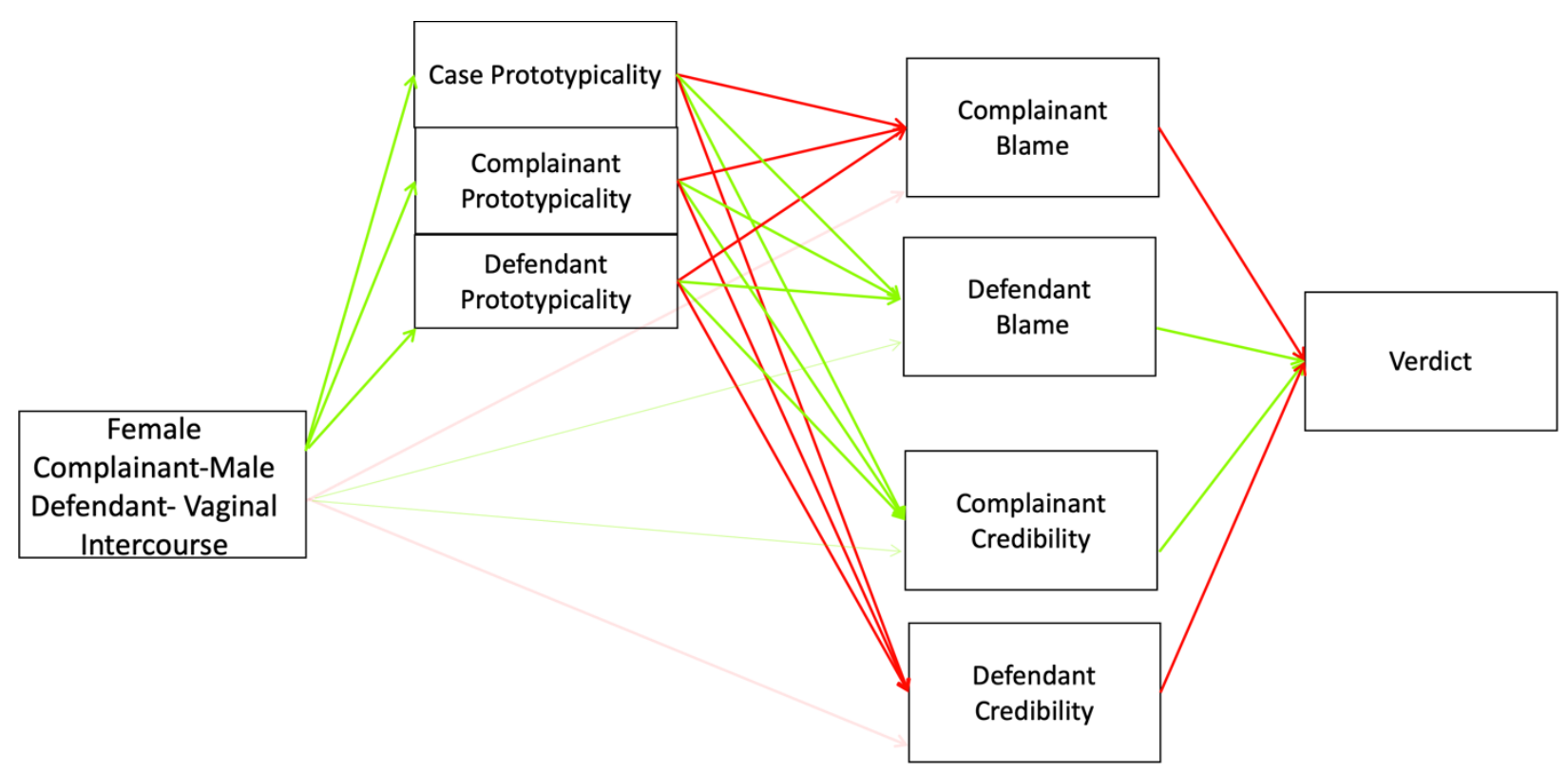

Note. Red line $=$ a negative relationship.

Green line $=$ a positive relationship.

Faded line $=$ reduced direct effect with prototypicality (of the case, complainant, and defendant) as the meditator.

\section{Exploratory Analyses}

Rape Myth Acceptance Scales. Despite previous research suggesting that rape myths inform prototypes (McKimmie et al., 2014) and the empirical support that scores on the rape myth acceptance scale predict participants' case-related decisions (e.g., Klement et al., 2019; Leverick, 2020); to my knowledge, no previous research has examined the role of jurors' rape myth acceptance on jurors' prototype ratings of a sexual assault case, complainant and defendant and the role those prototype ratings have on jurors' decisions. Therefore, the present study considered the role of mock jurors' rape myth acceptance on the predicted paths to be an important exploratory endeavour. 
Juror Gender. Juror gender is a commonly controlled demographic variable because it is well established that there are juror gender differences in the treatment of sexual assault complainants and defendants in sexual assault cases (e.g., Basow \& Minieri, 2011; Grubb \& Harrower, 2008; McKimmie et al., 2014; Simonson \& Subich, 1999). Although juror gender is not the focus of this study, the effect of mock juror gender on the anticipated paths was investigated in an exploratory manner. This was done to help establish if this line of inquiry is warranted for future research investigations.

\section{Methods}

\section{Participants}

The present study used Qualtrics, which is an online platform where researchers can distribute surveys to participants. Research ethics approval was obtained from the Carleton University Research Ethics Board - B (CUREB-B Clearance \# 11196). The rule of thumb for path analysis is to have more than 10 participants per condition, and 400 participants is highly preferred and recommended (Kline, 2005). The present study recruited 440 community members. This allowed room for non-useable data, while still ensuring an appropriate sample size for the path analysis (Kline, 2005; Streiner, 2005).

Participants were recruited through Prolific Academic, an online crowdsourcing platform where researchers can distribute surveys to participants recruited to Prolific Academic through advertisements, referrals, or social media (https:/www.prolific.co/). Participants were randomly assigned to one of the four conditions (see Table 1 for the breakdown of male and female participants in the four conditions). Prolific Academic screened all participants to ensure they are jury eligible within Canadian guidelines (Canadian citizens, 18 years or older, with no prior convictions of an indictable offence for which they have not received a record 
suspension, and fluent in English). As an additional quality measure, I presented participants with a screening questionnaire to ensure the Prolific Academic screening worked properly (see Appendix A).

Four hundred and forty participants were recruited. Three participants failed manipulation checks, and two participants failed attention checks ${ }^{4}$. However, Prolific Academic replaced these submissions with responses from new participants. Three participants did not consent for their data to be used. Therefore, the final sample consisted of 437 participants who responded correctly to all attention-check and manipulation-check questions. Participants' ages in the final sample ranged from 18-74. The mean age was $51.11(S D=15.71)$, which is somewhat higher than the mean age for the Canadian population (40.1; Jeudy, 2021). However, my sample appears representative of the average age of a juror member (50; Mossiere \& Dalby, 2018). The majority of participants identified as White (65.7\%), agnostic (21.7\%), with a bachelor's degree as the highest education obtained (52.4\%). My sample appears to represent the Canadian population as the 2016 census (Statistics Canada, 2016) demonstrates that 55\% of Canadian identified as agnostic, $68 \%$ have a college or university degree, and $72.9 \%$ of Canadians identify as White.

Participants were asked to indicate where their political beliefs fell on a sliding liberal (1) to conservative (10) scale. The results revealed that the sample leaned towards a liberal orientation $(M=3.80, S D=2.11)$. This is fairly representative of the general population as a recent study (Blais et al., 2020) examining Canadians' political affiliation found that $53 \%$ of Canadians identify as liberal compared to $47 \%$ identifying as conservative.

\footnotetext{
${ }^{4}$ Three participants identified the wrong person accusing someone of sexual assault (e.g., believed Lauren was the complainant when they were in the male complainant condition). Two participants did not correctly select " 5 " on the Likert scale.
} 
Table 2 displays an overall summary of the demographic characteristics collected (See Materials, Appendix I). The study took an average of 15 minutes, and participants who completed the study were compensated \$2.50 CAD per Prolific Academic guidelines.

\section{Table 1}

Breakdown of Participants by Gender by Condition

\begin{tabular}{|c|c|c|c|c|c|}
\hline Condition & Men & Women & $\begin{array}{c}\text { Non- } \\
\text { Binary }\end{array}$ & Transgender & Total \\
\hline $\begin{array}{l}\text { Male Complainant- } \\
\text { Female Defendant } \\
\text { Vaginal Intercourse }\end{array}$ & 44 & 59 & 0 & 0 & 103 \\
\hline Oral Sex & 46 & 65 & 1 & 0 & 112 \\
\hline $\begin{array}{c}\text { Female Complainant- } \\
\text { Male Defendant } \\
\text { Vaginal Intercourse }\end{array}$ & 43 & 67 & 1 & 2 & 113 \\
\hline Oral sex & 46 & 60 & 2 & 1 & 109 \\
\hline \multicolumn{6}{|l|}{ Total } \\
\hline & 179 & 251 & 4 & 3 & 437 \\
\hline
\end{tabular}

Table 2

Demographics of Study Sample

Variable

$\mathrm{N}=$

$\%$

\section{Age}

$18-28$

29-39

40-50

51-61

$62-72$

\section{Ethnicity}

South Asian (e.g., East Indian,

Pakistani, Sri Lankan, etc)

Chinese

Black 
Filipino 8

White

Latin American

Indigenous Peoples of Canada

(First Nations/Metis/Inuk

Arab

Southeast Asian (e.g.,

Vietnamese, Cambodian,

Laotian, Thai, etc.)

West Asian (e.g., Iranian,

Afghan, etc.

0.5

Korean

Japanese

Not listed

\section{Religion}

Protestant (Baptist, Methodist, Non-denominational, Lutheran, Presbyterian, Pentecostal,

Episcopalian, Reformed, Church of Christ, etc.)

Roman Catholic (Catholic)

Mormon (Church of Jesus Christ of Latter-day Saints/LDS)

Orthodox (Greek, Russina, or another orthodiz church)

Jewish

Muslim

Buddhist

Hindu

1.1

Atheist (do not beleive in God)

Agnostic (not commited to beleiving in existence or non-

existence of God)

Nothing in particular $\quad 80$

\section{Education}

Doctoral or professional degree $\quad 26$

Bachelor's degree

Associate's degree

Postsecondary non-degree award

Some college, no degree

High school diploma or equivalent 


\section{Materials}

\section{Juror Instructions}

Participants were given a set of juror instructions adapted from the National Judicial Council's jury instructions and the Criminal Code of Canada (see Appendix C). Before the trial transcript, participants read the judicial instructions informing them of their duties as a juror, the burden of proof, and the standard of reasonable doubt. At the end of the trial transcript, participants received instructions outlining the Canadian legal definitions of sexual assault and consent, the burden of proof, and the standard of reasonable doubt, and reminding jurors of their duties.

\section{Trial Transcript}

Following a multitude of previous jury research that has presented participants with a vignette depicting a hypothetical sexual assault and asking participants to assume the role of a

juror (Davies \&. Rogers, 2006; Grubb \& Harrower, 2008; McKimmie et al., 2014; Monson et al., 2000; Pica et al., 2018; Schuller et al., 2013), all participants were told to assume the role of a juror in a sexual assault proceeding. Participants were presented with one of four possible trial transcripts (see Appendix D) that depicted a summary of the proceedings in a hypothetical sexual assault trial.

The trial vignette was created by Cassandra Starosta and Dr. Evelyn Maeder and was modeled in form after the OBA/OJEN Mock Trials competition's R. v. Delany (2019) case. The four vignettes were identical with the exception of the manipulations of the gender combinations of the complainant and the defendant, and the form of the sexual assault (vaginal intercourse vs oral sex). 
The form of sexual assault varied. The act in question was either vaginal intercourse or forced oral sex. I decided to use forced oral sex onto the complainant as the comparator sexual act because of the high rates of male victims of female perpetrated sexual assault who report being sexually assaulted this way (Chapleau et al., 2008).

The present study was a 2 (Form of the SA: vaginal intercourse, oral sex) by 2 (Gender combination: female complainant/male defendant, male complainant/female defendant) design.

\section{Juror Questionnaire}

I presented participants a questionnaire (See Appendix E) based on the questions used in Starosta and Schuller's (2020) study and some questions I created on my own. This questionnaire was designed to measure participants' case, complainant, and defendant prototypicality perceptions and participants' decisions (verdict, blameworthiness, and credibility of both the complainant and defendant). Unless otherwise indicated, I measured the variables using 7-point bipolar scales with the endpoints defined by either the wording of the item (not at all appropriate to completely appropriate) or participants' degree of agreement (not at all to completely). All measures are discussed more fully below.

Verdict. Participants were asked to render a dichotomous verdict (guilty, not guilty).

Prototypicality Assessments. Participants were asked a total of eight questions designed to measure how typical they perceive the current sexual assault case, complainant, and defendant to be. For example, "how typical is the complainant of people who have been sexually assaulted". The three items designed to measure complainant typicality demonstrated strong internal consistency $(\alpha=.799$; Santos, 1999) and were combined to create a composite of complainant typicality. The three items designed to measure defendant typicality also 
demonstrated strong internal consistency $(\alpha=.816$; Santos, 1999) and were combined to create a composite of defendant typicality. The two items designed to measure the typicality of the sexual assault case did not demonstrate strong internal consistency $(\alpha=.114$; Santos, 1999), and so the questions were added into the model individually.

Case Judgments. I asked participants separate questions designed to measure the degree of blame and credibility allocated towards the complainant and the defendant. All participants received identical questions, but the complainant and defendant's names (Jim/Lauren) varied depending on the condition. Two sample questions were: "To what extent is the complainant credible?" and "to what extent is the defendant to blame for the events described?" (Schuller \& Starosta, 2020). Four items were combined to create a composite measure of complainant blame $(\alpha=.792$; Santos, 1999), and four items were combined to create a composite measure of defendant blame $(\alpha=.876$; Santos, 1999). Two items were combined to create a composite measure of complainant credibility ( $\alpha=.947$; Santos, 1999), and two items were combined to create a composite measure of defendant credibility ( $\alpha=.907$; Santos, 1999).

Rape Myth Acceptance Scale. Participants completed 22 items from the Illinois Rape Myth Acceptance Scale (IRMA; McMahon \& Farmer, 2011; See Appendix F), which assesses a person's endorsement of various rape myths (e.g., When girls get raped, it's often because the way they said "no" was unclear). The scale is, to my knowledge, the most up-to-date version to assess rape myth acceptance. However, the scale did come out in 2011, and I found some of the item wording to be outdated. For instance, all the questions referred to women as girls. Recently, there has been a push to stop this reference due to its sexist undertones (Richardson, 2018). Following this push, I decided to change the questions' wording to state "woman" in place of "girl." Additionally, one question originally asked, "When girls go to 
parties wearing slutty clothes, they are asking for trouble." I anticipated that the word slut might be a loaded term (Borah et al., 2012). To avoid such limitations, I instead asked participants, "When women go to parties wearing revealing clothes, they are asking for trouble." All questions were scored on a 7-point Likert scale. A previous Cronbach alpha of .93 and a test-retest reliability of .87 has been reported for this scale (McMahon \& Farmer, 2011). Within the present study, I created a composite measure of IRMA, by combining the 22 items of the IRMA scale ( $\alpha=.909$; Santos, 1999).

Male Rape Myth Acceptance Scale. Participants completed 22 items from the Male Rape Myth Acceptance Scale (MRMA) that measures false or stereotypical beliefs about male rape (Anderson, 2007; See Appendix G). This scale was originally developed by Anderson (2007), and response scales are from 1 (strongly disagree) to 6 (strongly agree). Total scores are summated with higher scores indicating a greater acceptance of male rape myths. Three items were reverse coded. A previous Cronbach alpha of .90 and a test-retest reliability of .89 has been reported for this scale (Anderson, 2007). A Cronbach alpha of .94 (Santos, 1999) was found for this study. A composite measure of MRMA was created by combining the 22 items of the MRMA scale. An example of one of the male rape myth items is "A man can enjoy sex even if it is being forced on him."

Oral Sex Scale. Despite the rape myth that only vaginal intercourse equates a sexual assault (Lefkowitz et al., 2014; Lefkowitz et al., 2016), to my knowledge, no previous scale exists that assess this rape myth. Therefore, in the present study I created three questions to tap jurors' acceptance of this rape myth (See Appendix H). These questions were all scored on a 7-point Likert Scale. The three questions demonstrated strong internal reliability $(\alpha=.78$; Santos, 1999), and a composite measure of the Oral Sex Scale was created by combining these 
three questions. An example of one of the oral sex items is, "One cannot be forced to give oral sex."

Severity. The present study's focus was to ascertain if prototypicality mediates the relationship between form of the sexual assault, gender of the complainant, and gender of the defendant on jurors' decision-making. Through this aspect of investigation, it was recognized that jurors could potentially rate the sexual assault differently due to their perceptions of the severity of the form of the sexual assault, rather than the inquiry of interest, namely, if form of the sexual assault informs mock jurors' sexual assault prototypes and decisions. This issue was identified in Vallano, Winter and Charman's (2012) study that examined the effects of sexual harassment severity on jurors' decision-making. Their study highlighted that more severe charges rendered more guilty verdicts and higher victim support, whereas less severe accusations resulted in less guilty verdicts and more victim blaming behaviours. In an effort to try and account for the role of severity on my predicted relationships, I followed Bornstein and colleagues' (2007) recommendation to measure jurors' perception of the severity of the case, assess if severity is significantly related to your variable of interest, and if so, treat it as a covariate. To this end, participants were asked to rate how severe they considered the incident to be for the complainant on a 7-point bipolar scale with endpoints defined as not at all severe to completely severe. Exploratory analysis of this question on the form of the sexual assault variable was conducted to ascertain if severity should be used as a covariate within the path analysis (see results).

Manipulation Checks. To ensure participants were paying attention to the case, and that the manipulations were being perceived correctly (e.g., if a participant was in the male complainant condition, they realized the complainant was a man), participants in the present 
study were asked three questions regarding the manipulations of the independent variables (the gender of the complainant, the gender of the defendant, and the form of the sexual assault; see Appendix E).

Memory Checks. To ensure participants were paying attention to the case, two questions were asked about facts that were constant in all conditions. For instance, the trial vignettes directly stated that both the complainant and the defendant abstained from drinking on the night in question, and the complainant and defendant did not know each other previously. I asked participants if either the complainant and defendant had been drinking that night, and if the complainant and defendant knew each other before the night in question. Hauser and colleagues (2018) argue that due to the limitations of memory, participants who fail memory checks should not automatically be excluded. Applying this suggestion to the present study, I made the preliminary decision to keep participants' data who get all other manipulation/attention checks correct but believed alcohol was involved, and/or the targets knew each other, as this will also shed light on the magnitude these rape myths have on jurors' perceptions of a sexual assault case.

Attention Checks. To assess if participants were paying attention, random responding items were inserted throughout the questionnaire instructing participants to select a particular number on the 7-point scale.

Demographics Questionnaire. Participants were asked to complete a questionnaire concerning their demographic information (age, race, religion, etc.; see Appendix I).

\section{Procedure}

Participants were community members recruited through Prolific Academic. This platform allows a Qualtrics survey link to be integrated and for the researcher to select demographic and 
participation criteria. The Prolific Academic database is made up of 3000 Canadian workers who were recruited through online advertisements, referrals, or social media. Prolific Academic provided the Qualtrics survey link to interested participants who met the demographic and participation criteria. Participants were told that the study involved "jury decision-making." However, they were not specifically informed about the research questions or manipulations. Once participants opened the survey, they were presented with the screening form to ensure they were eligible to participate (see Appendix A). Once they passed all the screening questions, they were presented with the consent form (see Appendix B), which informed them that they may withdraw from participation at any time without penalty. Once consent was obtained, participants were randomly assigned (done through Qualtrics) to one of four trial transcript summaries of a sexual assault case (see Appendix D). All jurors were given relevant legal instructions both before (see Appendix C) and after reading the transcript (see Appendix D). Following the post transcript instructions, participants responded to a juror questionnaire (see Appendix E), the IRMA (see Appendix F), MRMA (see Appendix G) and the oral sex scale (see Appendix H), as well as a number of manipulation/memory checks (see Appendix E) and demographic questions (see Appendix I). Upon completion, participants were presented with the debriefing form that provided the study's details (goals of the research, its design, hypotheses, and why deception was necessary), the contact information of the researchers, and additional resources to learn more about the topic (see Appendix J). It also provided resources if they found the study emotionally draining (i.e., crisis center contact information) and thanked them for their participation. Following the debrief form, participants were presented with a consent-to-keep- data form to ensure they still wanted to participate in the study now that they knew the study's true purpose (see Appendix K). 


\section{Path Analysis}

I ran a path analysis to analyze whether: (a) the form of the sexual assault (vaginal intercourse, oral sex) and the gender combination (female complainant-male defendant, male complainant- female defendant) influenced jurors' perception of the prototypicality of: 1) the case, 2) the complainant, and 3) the defendant; (b) jurors' perceptions of the prototypicality of the sexual assault case, complainant, and defendant had a role in jurors' complainant/defendant credibility and blameworthiness assessments; and (c) if there was a relationship between jurors' complainant/defendant credibility and blameworthiness assessments and their verdict decisions in a sexual assault case.

I chose to conduct a path analysis for my thesis to examine the mechanism behind jurors' verdict decisions because I expected to find a multitude of relationships that I did not think could properly be examined without considering how the variables relate to each other and the potential influence of one variable on another. Furthermore, path analysis greatly reduces the experiment-wise error by testing several of my research questions simultaneously rather than individually (Kline, 2005). 


\section{Figure 5}

Hypothesized conceptual model

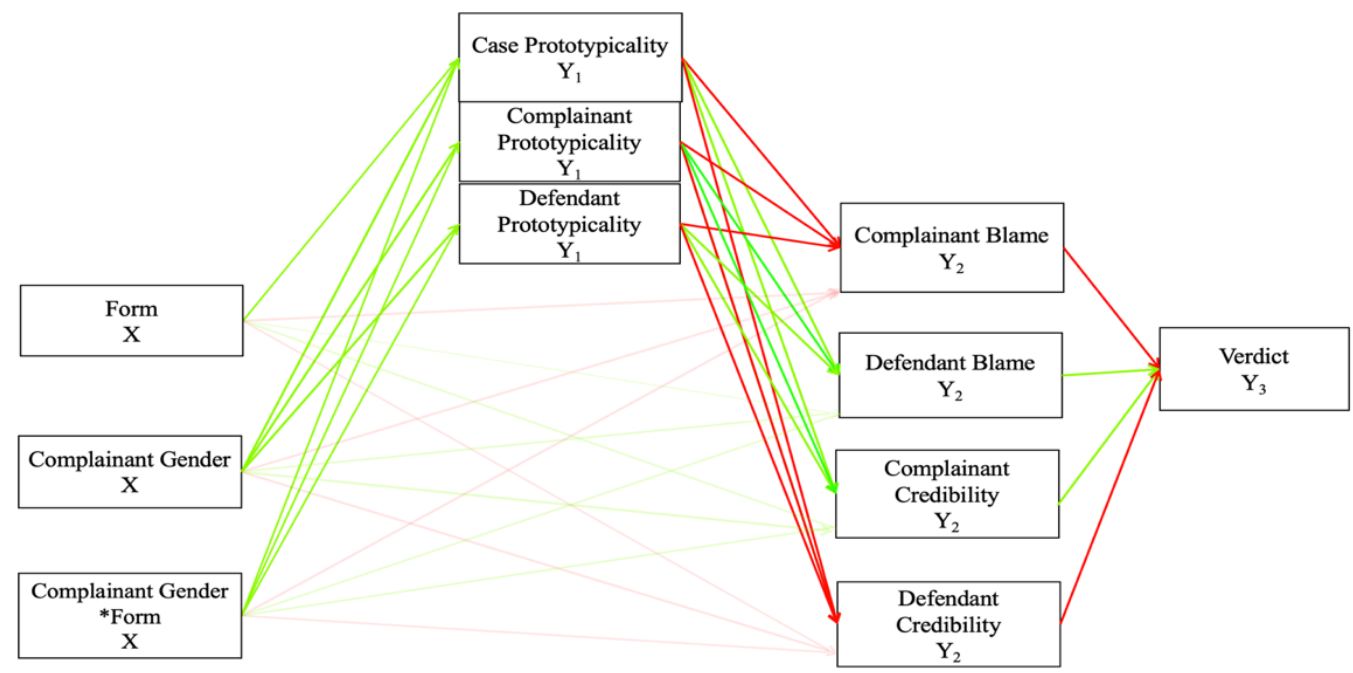

Independent variables are Exogenous $(\mathrm{X})$ variables and dependent variables are Endogenous $(\mathrm{Y})$ variables within a path analysis. Exogenous $(\mathrm{X})$ variables represent the causal sources whereby arrows and paths can project from them but cannot lead into them (Kline, 2005). Within my thesis, my Exogenous variables were the form of the sexual assault and the gender combination (i.e., complainant gender tied to defendant gender). Endogenous (Y) variables have straight lines leading to them, but they also project straight lines from them. With respect to my thesis, prototypicality of the case, the complainant, and the defendant were Y1. Y2 was complainant/defendant blame and credibility, and verdict was Y3. Within a path analysis there are two kinds of arrows. One is a straight arrow which represents a "causal" relationship between variables. The other is a curved arrow, which represents covariances.

In SPSS, I dummy coded each of my Exogenous variables (X). Gender of the complainant was dummy coded (1-woman, 0-man). The same occurred for form of the sexual assault (1vaginal intercourse, 0-oral sex). In SPSS, I created a 2-way interaction term (form $\times$ 
complaint gender). Once I dummy coded and cross multiplied to create interaction variables, I ran the analysis using the software Mplus (Version 8; Muth'en \& Muth'en, 2010). I used Mplus to run the analysis because my verdict variable is a categorical variable. In contrast, my other dependent variables, such as complainant blame, are continuous variables, and Mplus can run both categorical and continuous variables.

I added the code "stdyx" to my output to provide me with standardized path coefficients to allow me to see the full impact of my Exogenous variable(s) (X) on my Endogenous variable (s) (Y; Kline, 2005). I added the code "Missing = all (-9)" to make the model believe that there is no missing information in order to ensure the model can run efficiently. There were no missing data/values within my data, so this line of the code simply did nothing.

I tested all relevant path analysis assumptions to ensure these assumptions were met (Weston \& Gore, 2006). These assumptions include: the data must be categorical or continuous, normally distributed variables, and the variables contain no outliers (Kline, 2005; see result section)).

An identified limitation of path analysis is its sensitivity to sample size (Streiner, 2005), where large sample sizes are more likely to produce significant fit indices, while small sample sizes are likely to produce non-significant fit indices, regardless of the proposed relationship between the variables (Streiner, 2005). As mentioned, the rule of thumb for path analysis is to have more than 10 participants per condition, and 400 participants is highly preferred and recommended (Kline, 2005). The present study had 437 participants with 100-110 participants per condition (see Table 2 for breakdown). In line with past recommendations, if the model has the anticipated relationships, this sample size is appropriate to allow significant fit indices to be recognized (Kline, 2005; Streiner, 2005). 


\section{Results}

\section{Preliminary Analyses}

\section{Attention and Manipulation Checks}

I examined all participants' responses to the attention-check and manipulation-check questions. Three participants identified the wrong person accusing someone of sexual assault (e.g., believed Lauren was the complainant when they were in the male complainant condition). Two participants did not correctly select "5" on the Likert scale; these participants were rejected, and Prolific Academic replaced these submissions with responses from new participants. Thus, in the final sample, all participants responded correctly to all attention-check and manipulationcheck questions.

\section{Memory Checks}

Examination of the responses to the memory checks to ensure participants were paying attention to the case revealed that all participants responded correctly to the memory-check question asking if Lauren and Jim knew each other before the alleged event. In contrast, examination of the responses to the question that asked if Lauren and Jim had been drinking that night revealed that five participants believed Lauren and Jim had been drinking despite this information not being mentioned. These five participants answered the remaining memorymanipulation-and attention-check questions correctly. In line with Hauser and colleagues' (2018) contention, I made the preliminary decision to keep participants who answered the memory checks incorrectly, but the manipulation-and attention-checks correctly.

\section{Assumption Checks}

Tests for normality were conducted on all variables involved in the path analyses. Normality was assessed using absolute skewness and kurtosis values. As recommended by West 
et al. (1995), skewness values $>| \pm 2.1|$ and kurtosis values $>| \pm 7.1|$ represent significant deviation from normality. Results for all variables fell within the normal range (maximum skewness $=-1.298$, maximum kurtosis $=1.714$ ), with most skewness and kurtosis values falling below $| \pm 1|$ (See Table 3). A visual inspection of the frequency distributions and Q-Q plots was also performed to assess for normality. The ratings for complainant credibility and defendant blame were quite positively skewed, and the ratings for complainant blame and defendant credibility were quite negatively skewed. To assess if/how the non-normality would impact my data, I ran the model twice. First, I ran the model with each blame and credibility variable transformed to have integer values of 1 to 7 . This allowed me to treat them as categorical variables (which do not require normality) within the model, as recommended by Rhemtulla and colleagues (2018). The second run of the model used the complainant/defendant blame and credibility composites original raw data. The two models were analogous. Therefore, the model was not compromised by the skewness of the continuous version of these variables. As such, I made the decision to test the present study's hypotheses utilizing the original raw data of complainant/defendant blame and credibility. All the prototypicality assessment distributions were normal.

In line with path analysis assumptions, all data within this thesis were either continuous (i.e., prototypicality assessments, blame/credibility assessments) or categorical (verdict). I ran descriptive statistics on all the continuous composites. I used SPSS to check for outliers for the variables. I decided to remove cases with a Z-score of \pm 3 , as recommended by Tabachnick and Fidell (2007), who suggest that any $z$-score greater than 3 or lower than -3 is considered an outlier. All Z-scores were below 3, which suggests the data did not have outliers on any of the variables. Table 3 provides the descriptive statistics for my study's variables. 
Table 3

Descriptive Statistics for Study Variables

\begin{tabular}{lcccccc}
\hline \multicolumn{1}{c}{ Variable } & $M$ & $S D$ & \multicolumn{2}{c}{ Skewness } & \multicolumn{2}{c}{ Kurtosis } \\
\cline { 2 - 7 } & & & Statistic & $S E$ & Statistic & $S E$ \\
\hline Complainant typicality & 4.239 & 1.290 & -0.187 & 0.118 & -0.362 & 0.235 \\
Defendant typicality & 4.624 & 1.312 & -0.489 & 0.117 & 0.058 & 0.238 \\
To what extent are the & 4.580 & 1.596 & -0.428 & 0.114 & -0.484 & 0.234 \\
$\quad$ events in this case like a & & & & & & \\
$\quad$ typical sexual assault? & & & & & & \\
Complainant blame & 2.541 & 1.331 & 0.790 & 0.119 & -0.075 & 0.233 \\
Defendant blame & 5.950 & 1.163 & -1.297 & 0.115 & 1.704 & 0.232 \\
Complainant credibility & 5.479 & 1.425 & -1.112 & 0.116 & 0.821 & 0.231 \\
Defendant credibility & 3.253 & 1.460 & 0.344 & 0.118 & -0.486 & 0.237 \\
\hline
\end{tabular}

${ }^{\mathrm{a}} N=437$

\section{Severity}

As mentioned, I recognized that jurors could potentially rate the sexual assault differently due to their perceptions of the severity of the sexual assault, as discovered in Vallano and colleagues' study (2012). Therefore, I performed an independent-groups $t$-Test to assess if participants rated the oral sex condition as more or less severe than the vaginal intercourse condition. The analysis did not reveal a significant effect of severity on form of the sexual assault, $t(436)=1.294, p=.394$. Oral sex was not perceived as more or less severe than vaginal intercourse by jurors. Therefore, I decided not to use severity as a covariate within the main model. However, the potential role of this variable was investigated in an exploratory fashion.

\section{Hypothesized Conceptual Model}

\section{Path Analyses}

Next, the hypothesized model was tested. I hypothesized that form of the sexual assault (H1b), complainant gender (H2b), and the interaction between complainant gender and form (H3b) would each predict case prototypicality, complainant prototypicality, and defendant prototypicality. I also predicted that case prototypicality, complainant prototypicality, and 
defendant prototypicality would each predict complainant blame, predict defendant blame, predict complainant credibility, and predict defendant credibility (H2b, H2c, H3c). In addition, I expected complainant blame to predict verdict, defendant blame to predict verdict, complainant credibility to predict verdict, and defendant credibility to predict verdict $(\mathrm{H} 1 \mathrm{~d}, \mathrm{H} 2 \mathrm{~d}, \mathrm{H} 3 \mathrm{~d}$; see Figure 5). I used Mplus (Version 8; Muthén \& Muthén, 2010) to run the model.

Many of the paths included in the model were significant (see Figure 6). I had originally anticipated a partial mediation model, whereby when prototypicality was included within the analysis the direct effects from complainant gender, form of the sexual assault and the interaction would equal zero or be significantly reduced. Contrary to this prediction, many of the direct effects were significant but in the opposite direction (See Table 4). Therefore, the model was an inconsistent mediation (MacKinnon et al., 2007). In this case, the mediator (i.e., prototypicality assessments) acts as a suppressor variable. An inconsistent mediation would be present when the direct and mediated effects of an independent variable on a dependent variable have opposite signs (Cliff \& Earleywine, 1994; Tzelgov \& Henik, 1991), as they do in the current study.

Previous researchers have presented hypothetical situations where inconsistent mediation effect is present (MacKinnon et al., 2000). For instance, MacKinnon and colleagues (2000) provide the example of a researcher interested in the interrelationships among workers' intelligence, level of boredom, and the number of errors made on a task. The authors' explained that it could be argued that all else being equal, the more intelligent workers would make fewer errors, the more intelligent workers would exhibit higher levels of boredom, and boredom would be positively associated with the number of errors. Thus, the authors demonstrated that the direct effect of intelligence on errors would be negative, and the indirect effect of intelligence on errors mediated by boredom would be positive (MacKinnon et al., 2000). Combined, MacKinnon et al. 
(2000) revealed that these two hypothetical effects might cancel each other out, resulting in a total effect of intelligence on errors equal to zero. The authors explain that without understanding the existence of inconsistent mediation, one may erroneously conclude that mediation is not present in that situation, but in reality, mediation does exist; it is just acting as a suppressor variable (MacKinnon et al., 2000).

Extrapolating this to my thesis results, when the indirect paths were positive, the direct paths were consistently negative. Analogously, when the indirect paths were negative, the direct paths were always positive. For example, with respect to complainant blame, the indirect path through complainant prototypicality to complainant blame from complainant gender was negative $(1.305 *-.556=-.726)$. In contrast, the direct path from complainant gender to complainant blame was positive $(+1.278)$. The same pattern occurs consistently for all direct and indirect paths for defendant credibility, and the analogous pattern occurs for defendant blame and defendant credibility, where the indirect effects are positive and the direct effects are negative, thus expressing an inconsistent mediation model.

All unstandardized path coefficients, standard errors, standard errors of the estimate, and $p$ values for all direct and indirect effects are provided in Table 4. Male complainant-female defendant and oral sex were the reference groups for the Complainant Gender and Form indicator variables. 


\section{Figure 6}

Hypothesized Conceptual Model Results

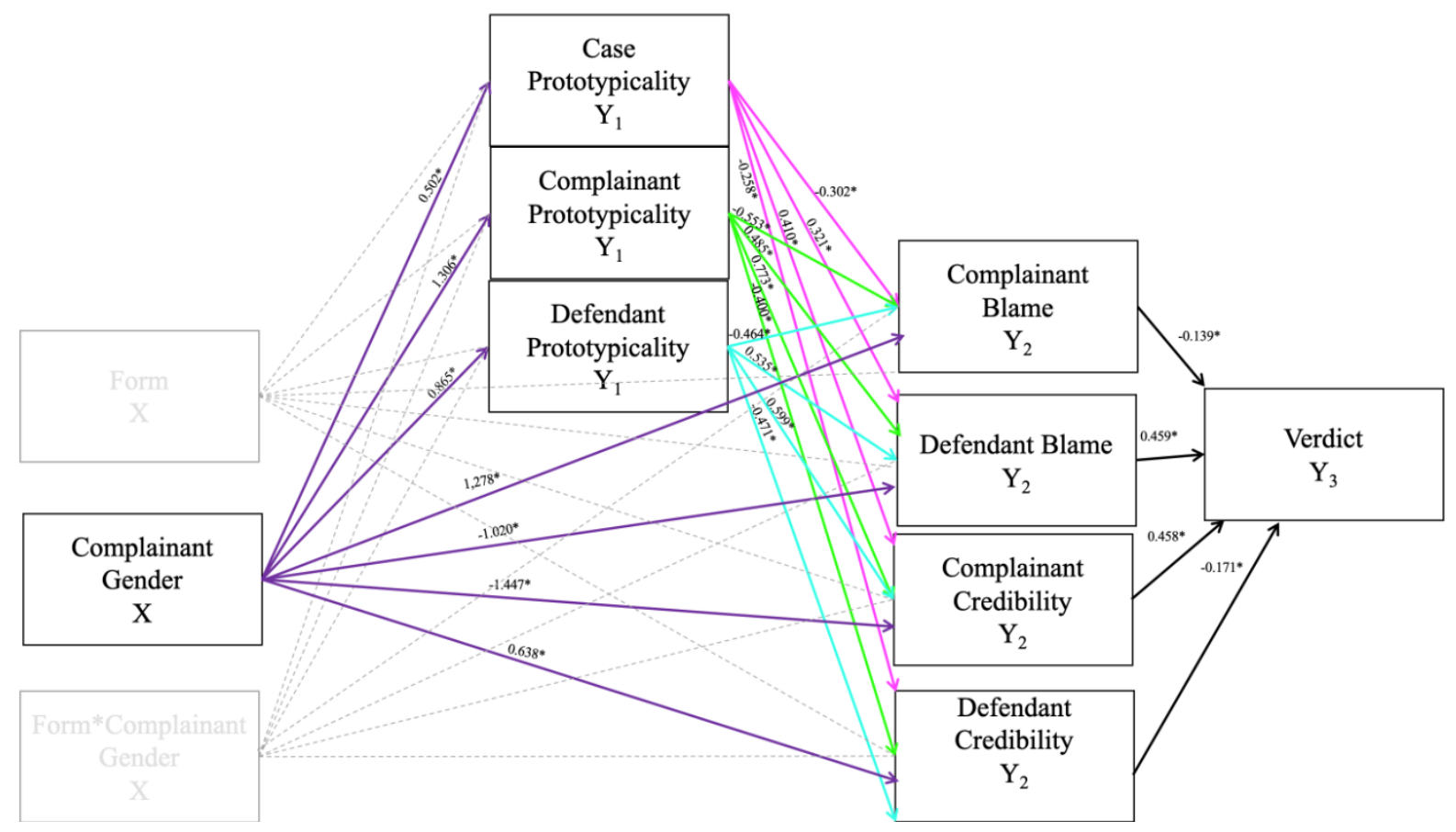

Note. Faded $=$ non-significant findings.

$* p<.05$

\section{Table 4}

Model Results for Study Variables

\begin{tabular}{|c|c|c|c|c|}
\hline Variable & $B$ & $S E$ & $z$ & $p$ \\
\hline \multicolumn{5}{|c|}{ Case typicality } \\
\hline Complainant gender ${ }^{\mathrm{a}}$ & 0.502 & 0.226 & 2.218 & $0.027 *$ \\
\hline Form $^{\text {b }}$ & 0.158 & 0.186 & 0.846 & 0.398 \\
\hline Complainant gender $\times$ form & 0.003 & 0.317 & 0.009 & 0.993 \\
\hline \multicolumn{5}{|c|}{ Complainant typicality } \\
\hline Complainant gender & 1.306 & 0.147 & 8.898 & $<0.001^{*}$ \\
\hline \multirow{2}{*}{$\begin{array}{l}\text { Form } \\
\text { Complainant gender } \times \text { form }\end{array}$} & -0.024 & 0.143 & -0.171 & 0.864 \\
\hline & 0.101 & 0.210 & 0.479 & 0.632 \\
\hline \multicolumn{5}{|c|}{ Defendant typicality } \\
\hline Complainant gender & 0.865 & 0.170 & 5.076 & $<0.001^{*}$ \\
\hline Form & -0.073 & 0.153 & -0.480 & 0.631 \\
\hline Complainant gender $\times$ form & 0.099 & 0.239 & 0.413 & 0.680 \\
\hline \multicolumn{5}{|c|}{ Complainant blame } \\
\hline Complainant gender & 1.280 & 0.227 & 5.626 & $<0.001 *$ \\
\hline
\end{tabular}




\begin{tabular}{|c|c|c|c|c|}
\hline Form & 0.169 & 0.183 & 0.923 & 0.356 \\
\hline Complainant gender $\times$ form & -0.038 & 0.287 & -0.133 & 0.894 \\
\hline Case prototypicality & -0.302 & 0.031 & -9.808 & $<0.001 *$ \\
\hline Complainant prototypicality & -0.553 & 0.045 & -12.312 & $<0.001 *$ \\
\hline Defendant prototypicality & -0.464 & 0.037 & -12.488 & $<0.001^{*}$ \\
\hline \multicolumn{5}{|c|}{ Defendant blame } \\
\hline Complainant gender & -1.038 & 0.199 & -5.206 & $<0.001 *$ \\
\hline Form & -0.159 & 0.159 & -0.996 & 0.319 \\
\hline Complainant gender $\times$ form & 0.039 & 0.251 & 0.154 & 0.877 \\
\hline Case typicality & 0.321 & 0.025 & 12.772 & $<0.001 *$ \\
\hline Complainant prototypicality & 0.485 & 0.038 & 12.824 & $<0.001 *$ \\
\hline Defendant prototypicality & 0.535 & 0.032 & 16.672 & $<0.001 *$ \\
\hline \multicolumn{5}{|c|}{ Complainant credibility } \\
\hline Complainant gender & -1.470 & 0.234 & -6.275 & $<0.001 *$ \\
\hline Form & -0.195 & 0.193 & -1.010 & 0.313 \\
\hline Complainant gender $\times$ form & 0.038 & 0.304 & 0.125 & 0.901 \\
\hline Case prototypicality & 0.410 & 0.030 & 13.583 & $<0.001 *$ \\
\hline Complainant prototypicality & 0.773 & 0.050 & 15.580 & $<0.001 *$ \\
\hline Defendant prototypicality & 0.599 & 0.037 & 16.091 & $<0.001 *$ \\
\hline \multicolumn{5}{|c|}{ Defendant credibility } \\
\hline Complainant gender & 0.645 & 0.234 & 2.764 & $0.006^{*}$ \\
\hline Form & -0.258 & 0.199 & -1.300 & 0.194 \\
\hline Complainant gender $\times$ form & 0.130 & 0.297 & 0.438 & 0.661 \\
\hline Case prototypicality & -0.258 & 0.033 & -7.795 & $<0.001 *$ \\
\hline Complainant prototypicality & -0.400 & 0.048 & -8.421 & $<0.001 *$ \\
\hline Defendant prototypicality & -0.471 & 0.041 & -11.523 & $<0.001^{*}$ \\
\hline \multicolumn{5}{|c|}{ Verdict } \\
\hline Complainant gender & 0.563 & 0.622 & 0.905 & 0.365 \\
\hline Form & -0.091 & 0.164 & -0.555 & 0.579 \\
\hline Complainant gender $\times$ form & 0.107 & 0.219 & 0.489 & 0.625 \\
\hline Complainant blame & -0.139 & 0.079 & -1.771 & $0.076^{*}$ \\
\hline Defendant blame & 0.459 & 0.151 & 3.039 & $0.002 *$ \\
\hline Complainant credibility & 0.458 & 0.184 & 2.493 & $0.013 *$ \\
\hline Defendant credibility & -0.171 & 0.056 & -3.050 & $0.002 *$ \\
\hline Case prototypicality & -0.191 & 0.170 & -1.123 & 0.262 \\
\hline Complainant prototypicality & -0.312 & 0.293 & -1.064 & 0.287 \\
\hline Defendant prototypicality & -0.301 & 0.266 & -1.132 & 0.258 \\
\hline
\end{tabular}

Note. $N=437$.

${ }^{\mathrm{a}}$ Male $=0$, Female $=1$

${ }^{\mathrm{b}}$ Oral sex $=0$, Vaginal intercourse $=1$

$* p<.05$ 
Sexual Assault Form. It was predicted that the vaginal intercourse condition would be regarded as more prototypical of a sexual assault case, complainant, and defendant (H1b), which was expected to lead to lower complainant blame, lower defendant credibility, higher complainant credibility, and higher defendant blame (H1c), which, in turn, was expected to lead to more guilty verdicts compared to the oral sex condition (H1d).

Direct effects from the form of the sexual assault to complainant/defendant blame and credibility were also predicted (H1a). The vaginal intercourse condition was expected to negatively predict complainant blame, positively predict complainant credibility, positively predict defendant blame, and negatively predict defendant credibility, compared to the oral sex conditions. These direct effects were predicted to be reduced in size with the introduction of prototypicality assessments as the partial mediator.

The path model did not support any of these predictions, as shown in Table 4. Mock jurors did not view the vaginal intercourse condition as more prototypical of a sexual assault case $(B=0.158, S E=0.187, z=0.846, p=0.398)$, complainant $(B=-0.024, S E=0.143$, $z=-0.171, p=0.864)$, or defendant $(B=-0.0 .073, S E=0.153, z=-0.480, p=0.631)$ compared to the oral sex condition. Furthermore, there were no significant direct effects (H1a) between form of the assault and complainant blame $(B=-0.169, S E=0.183, z=0.923, p=0.356)$, defendant blame $(B=-0.159, S E=0.159, z=-0.996, p=0.319)$, complainant credibility $(B=$ $0.195, S E=0.193, z=-1.010, p=0.313)$, defendant credibility $(B=-0.258, S E=0.199, z=-$ $1.300, p=0.194)$, or verdict $(B=-0.091, S E=0.164, z=-0.555, p=0.579)$. As part of Baron and Kenny's (1986) steps for mediation, within step 2, the mediator is regressed on the independent variable (IV) to confirm the IV is a significant predictor of the mediator. If it is not associated with the IV, it cannot mediate anything. Applying this step to my results, my mediator 
(prototypicality) was not related to my IV (sexual assault form). Therefore, it cannot mediate the relationship between sexual assault form and blame/credibility. Likewise, the relationship between sexual assault form and verdict through blame/credibility is not possible. Therefore, contrary to my prediction, sexual assault form did not significantly lead to lower complainant blame, lower defendant credibility, higher complainant credibility, or higher defendant blame through the prototypicality assessments, which in turn did not significantly predict jurors' verdict decisions in the predicted directions.

Complainant (and Defendant) Gender. It was predicted that the female complainantmale defendant condition would be regarded as more prototypical of a sexual assault case, complainant, and defendant (H2b), leading to lower complainant blame, lower defendant credibility, higher complainant credibility, and higher defendant blame $(\mathrm{H} 2 \mathrm{c})$. This was expected to predict verdict decisions $(\mathrm{H} 2 \mathrm{~d})$. The path model fully supported this prediction.

As shown in Figure 6, female complainants were associated with increases in prototypicality of the sexual assault case, complainant, and defendant, whereby jurors viewed the female complainant-male defendant condition as more prototypical of a sexual assault case $(B=$ 0.502, $S E=0.226, z=2.218, p=0.027)$, complainant $(B=1.306 ., S E=0.147, z=8.898, p<$ $0.001)$, and defendant $(B=0.865, S E=0.170, z=5.076, p<0.001)$. In line with hypothesis $2 \mathrm{c}$, these prototypicality assessments (i.e., prototypicality of the sexual assault case, complainant, and defendant) each individually significantly predicted complainant blame, defendant credibility, complainant credibility, and defendant blame in the predicted directions, as shown in Table 4.

Moreover, prototypicality of the case, complainant, and defendant each had an effect when controlling for the other two kinds of prototypicality. Therefore, each prototypicality 
assessment is contributing something unique to the prediction of blame and credibility. In support of hypothesis $2 \mathrm{~d}$, complainant and defendant blame and credibility did predict verdict decisions. Contrary to my expectations, direct effects between complainant gender and complainant and defendant blame and credibility were all significant, but in the opposite direction of the indirect effects, and these results are discussed more fully below.

Complainant Blame. In support of my hypothesized conceptual model, jurors’ perceptions of the prototypicality of the case $(B=-0.302, S E=0.031, z=-9.808, p<0.001)$, complainant $(B=-0.553, S E=0.045, z=-12.312, p<0.001)$, and defendant $(B=-0.464, S E$ $=0.037, z=-12.488, p<0.001)$ significantly predicted perceptions of complainant blame. The more prototypical jurors perceived the sexual assault case, complainant, and defendant to be, the less blame they assigned to the complainant. Therefore, the female complainant-male defendant condition was seen as significantly more prototypical of a sexual assault case, complainant, and defendant by jurors than the male complainant-female defendant condition, which led to significantly less blame being assigned to the female than to the male complainant.

In line with my model demonstrating inconsistent mediation, complainant gender had a significant direct effect on complainant blame $(B=1.280, S E=0.227, z=5.626, p<0.001)$ in the opposite direction of the indirect effect of this variable by way of the prototypicality of the case, complainant, and defendant on complainant blame. After controlling for prototypicality of the sexual assault case, complainant, and defendant, female complainants were associated with significant increases in complainant blame. Therefore, when holding the prototypicality assessments constant, mock jurors blamed the female complainant more than they blamed the male complainant. This is in opposition to the indirect effects of complainant gender through prototypicality, which served to reduce complainant blame for female complainant by enhancing 
prototypicality. That is, the more prototypical mock jurors perceived a sexual assault case, complainant, and defendant to be, the less they blamed the complainant, with female complainants being blamed less than male complainants. Therefore, the prototypicality assessments are acting as a suppressor variable within this model, mediating the effect of complainant gender on complainant blame.

Defendant Blame. As predicted by my hypothesized conceptual model, jurors’ perceptions of the prototypicality of the case $(B=-0.321, S E=0.025, z=12.772, p<0.001)$, complainant $(B=0.485, S E=0.038, z=12.824, p<0.001)$, and defendant $(B=0.535, S E$ $=0.032, z=16.672, p<0.001)$ significantly predicted perceptions of defendant blame. The more prototypical jurors perceived the sexual assault case, complainant, and defendant to be, the more blame they assigned to the defendant. Therefore, the female complainant-male defendant condition was seen as significantly more prototypical of a sexual assault case, complainant, and defendant by jurors, which led to significantly more blame being assigned to the male defendant compared to the female defendant.

After controlling for the prototypicality of the case, complainant, and defendant, once again, there was a direct effect of complainant gender on defendant blameworthiness $(\mathrm{B}=$ $1.038, S E=0.199, z=-5.206, p<0.001)$ that was in opposition to the indirect effect of prototypicality assessments on defendant blame. When the prototypicality assessments were held constant, defendant blame was lower for female than for male complainants. Therefore, mock jurors blamed the male defendant less than they blamed the female defendant. This is in opposition to the indirect effects that demonstrate that the female complainant-male defendant is perceived by mock jurors as more prototypical of a sexual assault case, complainant, and 
defendant than are male complainant-female defendants, which positively predicts defendant blame.

Complainant Credibility. The results supported the prediction that jurors' perceptions of the prototypicality of the case $(B=0.410, S E=0.030, z=13.583, p<0.001)$, complainant $(B$ $=0.773, S E=0.050, z=15.580, p<0.001)$, and defendant $(B=0.599, S E=0.037, z=16.091, p$ $<0.001)$ would significantly predict perceptions of complainant credibility. The more prototypical jurors perceived the sexual assault case, complainant, and defendant to be, the more credible they found the complainant. Because the female complainant-male defendant condition was seen as significantly more prototypical of a sexual assault case, complainant, and defendant by jurors, this led to significantly higher credibility ratings being assigned to female than male complainants.

Following the same pattern as complainant and defendant blame, when the prototypicality assessments were held constant, the direct effects between complainant gender and credibility were in the opposite direction of the indirect effects between complainant gender and complainant credibility through the prototypicality assessments. After controlling for the prototypicality assessments, female complainants were associated with significant decreases in complainant credibility $(B=-1.470, S E=0.234, z=-6.275, p<0.001)$. To this end, for a fixed level of prototypicality, jurors perceived the female complainant to be less credible than the male complainant. However, when prototypicality was added to the model, it acted as a suppressor variable, and the more prototypical jurors perceived the sexual assault case, complainant, and defendant to be, the higher the credibility they allocated towards the complainant.

Defendant Credibility. In support of my hypothesized conceptual model, increases in the prototypicality of a sexual assault case $(B=-0.258, S E=0.033, z=-7.795, p<0.001)$, 
complainant $(B=-0.400, S E=0.048, z=-8.421, p<0.001)$, and defendant $(B=-0.471, S E$ $=0.041, z=-11.523, p<0.001)$ were associated with significant decreases in defendant credibility. The more prototypical jurors perceived the sexual assault case, complainant, and defendant to be, the less credible they found the defendant. Therefore, because the female complainant-male defendant condition was seen as significantly more prototypical of a sexual assault case, complainant, and defendant by jurors, this led to significantly lower credibility ratings being assigned to male defendant than female defendants.

Analogously to complainant and defendant blame and complainant credibility, the direct effects of complainant gender was opposite to the indirect effect. To this end, for fixed levels of prototypicality (in terms of case, complainant, and defendant) defendant credibility is higher for male defendants than for female defendants. However, the effects of the prototypicality with complainant gender held constant signify that the more prototypical jurors perceive the case, complainant, and defendant to be, the less credible they find the defendant, with jurors in this study judging a scenario involving a female complainant and male defendant as more prototypical of a sexual assault case, complainant, and defendant and therefore ascribing the defendant in this condition less credibility than the defendant in a scenario involving a male complainant and female defendant.

Verdict. The model significantly supported hypothesis $2 \mathrm{~d}$ that jurors' assessments of defendant and complainant credibility and blame would predict their verdict decisions, in line with Figure 3. As predicted, increases in complainant blame and defendant credibility were associated with a significantly lower probability of a guilty verdict for complainant blame $(B=$ 0.139, $S E=0.079, z=-1.771, p=0.076)$ and defendant credibility $(B=-0.171, S E=0.056, z=$ 3.050, $p=0.002$. Increases in defendant blame $(B=0.459, S E=0.151, z=3.039, p=0.002)$ and 
complainant credibility $(B=0.458, S E=0.184, z=2.493, p=0.013)$ were associated with a significantly higher probability of a guilty verdict. Moreover, the effect of each of these four variables (complainant blame, defendant blame, complainant credibility, and defendant credibility) on the verdict is significant when controlling for the other three variables. These effect of these four variables on verdict is also significant when controlling for prototypicality assessments and the independent variables of complainant gender, form of the assault, and the hypothesized interaction. To this end, complainant blame, defendant blame, complainant credibility, and defendant credibility are each contributing something unique to the prediction of verdict.

To ensure the model was accounting for all direct and indirect effects, I regressed the prototypicality assessments on the verdict to examine if there were any further direct effects of the prototypicality assessments on verdict decisions. The results reveled no significant direct effects for prototypicality of the case $(B=-0.191, S E=0.170, z=-1.123, p=0.262)$, complainant $(B=-0.312, S E=0.293, z=-1.064, p=0.287)$, or defendant $(B=-0.301, S E=$ $0.266, z=-1.132, p=0.258)$ on verdict.

To examine the prediction that after controlling for blame and credibility jurors would return more guilty verdicts for the female complainant-male defendant condition compared to the male complainant-female complainant condition, I also ran the model with direct paths to verdict from complainant gender to assess the significance of this path. No further direct effects were found for complainant gender on verdict.

\section{Interactions between Sexual Assault Form and Complainant (and Defendant) Gender}

It was predicted that the female complainant-male defendant-vaginal intercourse condition would be seen as more prototypical of a sexual assault case, complainant, and 
defendant in comparison to the male complainant-female defendant-vaginal intercourse, male complainant-female defendant-oral sex, and female complainant-male defendant-oral sex conditions (H3b). This was expected to lead to lower complainant blame, lower defendant credibility, higher complainant credibility, and higher defendant blame $(\mathrm{H} 3 \mathrm{c})$ for this condition, which would lead to more guilty verdicts as compared to the other conditions (H3d). Direct effects were also predicted to occur between the hypothesized interaction term and complainant and defendant blame and credibility assessments (H3a). As demonstrated in Table 4, the model did not support this prediction.

There were no significant interactions between complainant gender and form of the sexual assault on the prototypicality of the case $(B=0.003, S E=0.317, z=-0.009, p=0.993)$, complainant $(B=0.101, S E=0.210, z=0.479, p=0.632)$, or defendant $(B=0.099, S E=0.239$, $z=0.431, p=0.680)$. Similarly, there were no significant direct effects for this hypothesized interaction term on complainant blame $(B=-0.038, S E=0.287, z=-0.133, p=0.894)$, defendant blame $(B=0.039, S E=0.251, z=0.154, p=0.877)$, complainant credibility $(B=$ $0.038, S E=0.304, z=0.125, p=0.901)$, or defendant credibility $(B=0.130, S E=0.297, z=$ 0.438, $p=0.661)$. Following Baron and Kenny's (1896) steps for mediation, step 2 was not satisfied for this interaction, where the mediator is not directly associated with the independent $\operatorname{variable(s).~}$

\section{Exploratory Analysis}

In an exploratory fashion, I added jurors' scores on the IRMA, MRMA, Oral Sex Scale, and jurors' severity rating of the sexual assault case into the model to explore if and where they fit in the model. I also examined how the model would differ based on the jurors' gender (see figure 7). 
Figure 7

Exploratory Model

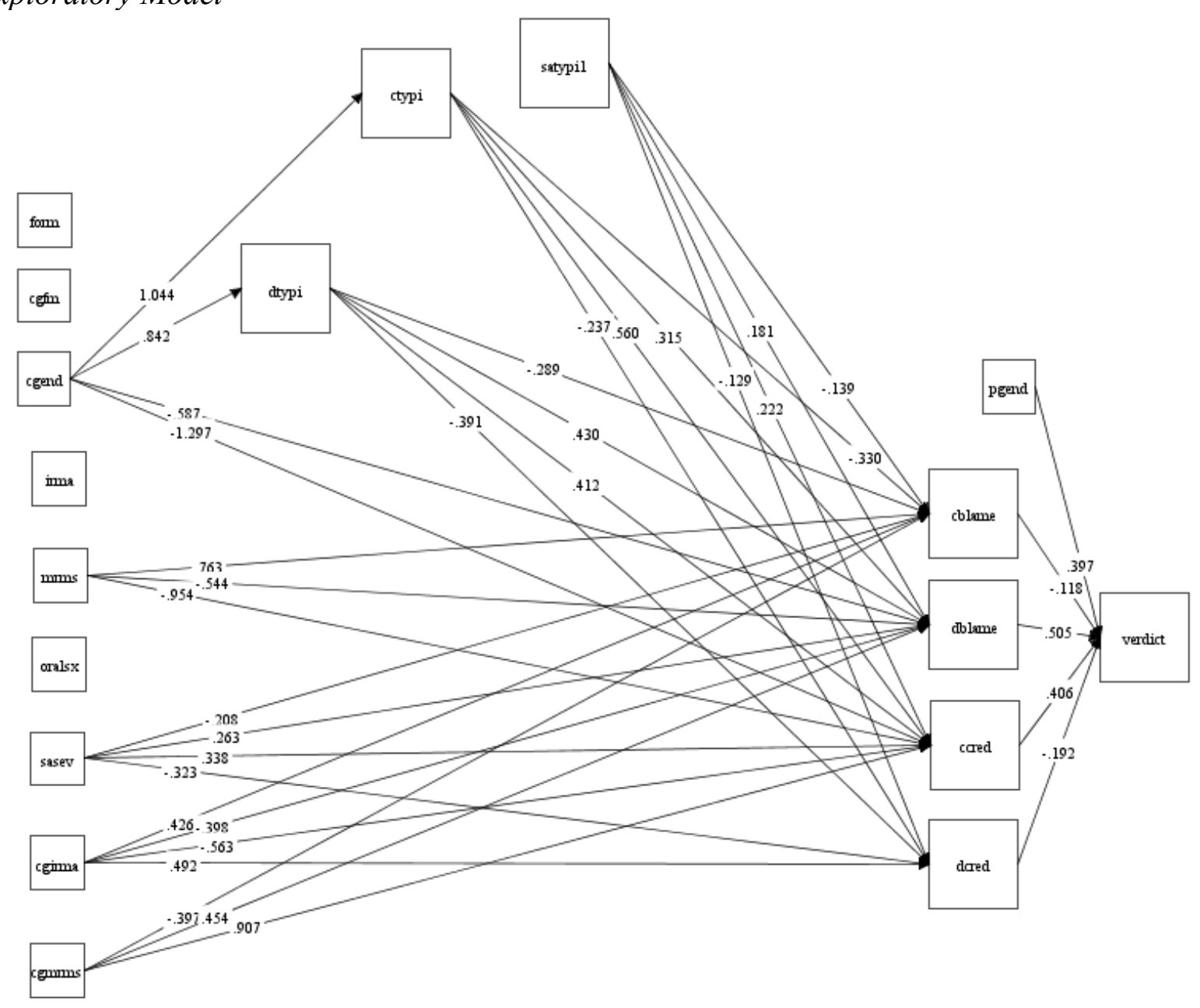

Note. Only significant paths are shown.

cgfm $=$ Complainant gender $\times$ Form

form $=$ form of the sexual assault

cgend $=$ complainant gender

irma $=$ Illinois Rape Myth Acceptance Scale

mrma $=$ Male Rape Myth Acceptance Scale

oralsx $=$ Oral sex scale

cgirma $=$ complainant gender $\times$ Illinois Rape Myth Acceptance Scale

cgMRMA = complainant gender $\times$ Male Rape Myth Acceptance Scale

Rape Myth Acceptance Scales and Severity as Covariates. To examine what role the inclusion of the IRMA, MRMA, Oral Sex Scale, and severity would have on the direct effects of complainant gender on blame and credibility variables found within my main model, I added severity, and the composite measures of IRMA, MRMA, and the Oral Sex Scale to my Mplus code. Prior to this, I examined severity, IRMA, MRMA and Oral Sex Scales' normality through 
visual inspection of histograms and Q-Q plots. The results revealed that the rating for severity was positively skewed. For the three scales, the results demonstrated negative skew, which is not surprising because when I examined the means for the rape myth acceptance scales to ascertain the general acceptance of rape myths within my sample, the results suggested that my sample had a low acceptance for all three of the rape myths scales (i.e., MRMA, IRMA, and oral sex), as highlighted in Table 5. I performed an inverse transformation on all of these variables to try and account for their skewness, as recommended by Tabachnick and Fidell (2007). Fortunately, the data appeared to be normal following these transformations.

As shown in Table 6, with the inclusion of these covariates, complainant gender no longer had an effect on the prototypicality of the sexual assault case. However, complainant gender was still associated with increases in the prototypicality of the complainant and defendant. Additionally, the direct main effects of complainant gender on complainant blame and defendant credibility were no longer significant. Similarly, the effect of complainant blame on the verdict was no longer significant. However, all the other paths remained significant, even with the inclusion of these scales and severity as covariates.

RMA Scales as Predictors. To examine the role of jurors' rape myth acceptance on jurors' prototype ratings of a sexual assault case, complainant and defendant and the role those prototype ratings have on jurors' decisions, I included the IRMA, MRMA, and Oral Sex Scale as predictors in the exploratory model. As demonstrated by Table 6, including these scales as predictors in the model illustrated that both the Oral Sex Scale and the IRMA did not uniquely predict anything in the model. On the contrary, the MRMA scale had significant direct effects on complainant/defendant blame and credibility. To this end, higher male rape myth scores uniquely 
predict significant increases in complainant blame and defendant credibility and significant decreases in defendant blame and complainant credibility.

In light of the significant direct paths between the MRMA and complainant/defendant blame and credibility, I wanted to explore the role of the MRMA further and investigate if it would interact with complainant gender (and further if this interaction would reduce the significant direct effects of complainant gender on defendant blame and complainant credibility). To ensure the model was accounting for all direct and indirect effects, I decided to test all of the rape myth scales (i.e., IRMA, and the Oral Sex Scale) as a function of gender. To do this, I created three interaction terms, the first between IRMA and complainant gender $(C G \times$ IRMA), the second between MRMA and complainant gender $(\mathrm{CG} \times \mathrm{MRMA})$, and the third between Oral Sex Scale and complainant gender $(\mathrm{CG} \times$ Oral $)$. I added these interaction terms to the model in order to observe their impact on the paths. No significant results were found as a result of the CG $\times$ Oral interaction. However, the $\mathrm{CG} \times \mathrm{IRMA}$ and the $\mathrm{CG} \times \mathrm{MRMA}$ interaction terms yielded significant unique effects on the paths, as illustrated by Table 6.

Firstly, as mentioned, higher male rape myth scores uniquely predicted significant increases in complainant blame and defendant credibility and decreases in defendant blame and complainant credibility. However, this happens to a much lesser extent (if at all) when the complainant is female. For example, the slope relating MRMA to complainant blame was 0.900 for male complainants but is only $0.376(0.900-0.524)$ for female complainants. Intuitively, this makes sense, as the MRMA measures male rape myths. Secondly, as mentioned, higher IRMA did not on its own significantly predict blame or credibility, unless the complainant was female and the defendant male, as revealed by the significant interaction between complainant and defendant blame and credibility. In this case, increases in rape myth beliefs are associated with 
increases in complainant blame and defendant credibility, and with decreases in defendant blame and complainant credibility for the female complainant-male defendant condition.

Severity as a Predictor. I wanted to explore the role of severity further to ensure the model was accounting for all direct and indirect effects. Therefore, I added severity as a predictor into the exploratory model. The results revealed that the rating for severity was positively skewed. I therefore performed inverse transformations, which made the variable normally distributed. The results revealed that severity had significant direct effects on complainant and defendant blame and credibility (see Table 6). The more severe jurors perceived the sexual assault to be, the less blame they attributed to the complainant, and the more blame they attributed towards the defendant. Similarly, when jurors rated the incident as more severe, they found the complainant more credible and the defendant less credible.

Mock Juror Gender. To explore if mock juror gender had any effect on the path model and if it could explain the presence of the significant direct effects, I re-ran the original path analyses with the data separated into two files: one with only female participants and the other with data from the male participants. Unfortunately, non-binary and transgender individuals could not be considered within this analysis, due to their small sample size in my thesis $(N=7)$. As shown in Table 7, although there were slight differences in men and women's judgements for the typicality of the case, defendant blame, and credibility, the differences did not warrant further investigation. In contrast, men and woman's verdict decisions appeared to be drastically different from each other, and this difference warranted further investigation. Therefore, I conducted a multiple group path analysis, which allowed me to create one model per analysis group (in this case, all the variables going into verdict). In a normal path analysis, the paths are equal across all groups, but a multiple group path analysis allows the path values to be free across all groups, and 
this meant I could examine if the paths to verdict were significantly different for male and female jurors. However, the results revealed no evidence that any of the paths in the model were significantly different for male and female participants.

I was curious if the effects of rape myth acceptance on the paths would differ depending on the jurors' gender. I therefore separated the data to have a file with only female participants' data and another file with only male participants' data and ran the exploratory model with the inclusion of rape myth acceptance scales and the $\mathrm{CG} \times \mathrm{IRMA}, \mathrm{CG} \times \mathrm{MRMA}, \mathrm{CG} \times$ Oral interaction terms as covariates. The results did not reveal significant differences between men and female jurors on their rape myth acceptance (see Table 8). I once again conducted a multiple group path analysis and assessed whether the model's fit significantly deteriorated. The results again revealed that in no case did the fit significantly deteriorate. Therefore, there is no evidence that any of the model paths are significantly different for male and female participants.

\section{Table 5}

Means for IRMA, MRMA, and The Oral Sex Scale

\begin{tabular}{ccccccc}
\hline Variable & $N$ & Range & Min & Max & Mean & $\begin{array}{c}\text { Std. } \\
\text { Deviation }\end{array}$ \\
\hline IRMA & 437 & $\begin{array}{c}1 \text { (strongly } \\
\text { disagree) }-6 \\
\text { (strongly agree) } \\
1 \text { (strongly }\end{array}$ & 1 & 6 & 2.0362 & .89074 \\
MRMA & 436 & $\begin{array}{c}\text { disagree) }-6 \\
\text { (strongly agree) } \\
1 \text { (strongly } \\
\text { disagree) }-6\end{array}$ & 1 & 5 & 1.7708 & .78078 \\
$\begin{array}{c}\text { The Oral } \\
\text { Sex Scale }\end{array}$ & 437 & 4 & 1.6938 & 1.27171 \\
\hline
\end{tabular}

Table 6

RMA Scales and Severity included in Path Model

\begin{tabular}{lcccc}
\hline & Variable & $B$ & $z$ & $p$ \\
\hline & \multicolumn{3}{c}{ Case typicality } & \\
CG & 0.118 & 0.410 & 0.288 & 0.773 \\
Form & 0.213 & 0.183 & 1.163 & 0.245 \\
CG $\times$ form & -0.054 & 0.310 & -0.174 & 0.862 \\
\hline
\end{tabular}

Complainant typicality 


\begin{tabular}{|c|c|c|c|c|}
\hline $\mathrm{CG}$ & 1.068 & 0.254 & 4.209 & $<0.001^{*}$ \\
\hline Form & 0.024 & 0.141 & 0.169 & 0.866 \\
\hline $\mathrm{CG} \times$ form & 0.085 & 0.201 & 0.422 & 0.673 \\
\hline \multicolumn{5}{|c|}{ Defendant typicality } \\
\hline $\mathrm{CG}$ & 0.768 & 0.315 & 2.438 & $0.015^{*}$ \\
\hline Form & -0.025 & 0.146 & -0.174 & 0.862 \\
\hline $\mathrm{CG} \times$ form & 0.050 & 0.230 & 0.215 & 0.830 \\
\hline \multicolumn{5}{|c|}{ Complainant blame } \\
\hline IRMA & 0.166 & 0.166 & 1.433 & 0.152 \\
\hline $\mathrm{CG} \times \mathrm{IRMA}$ & 0.517 & 0.164 & 3.147 & $0.002 *$ \\
\hline MRMA & 0.900 & 0.123 & 7.294 & $<0.001^{*}$ \\
\hline $\mathrm{CG} \times \mathrm{MRMA}$ & -0.524 & 0.167 & -3.130 & $0.002 *$ \\
\hline Oral sex & 0.042 & 0.055 & 0.763 & 0.446 \\
\hline $\mathrm{CG} \times$ oral sex & -0.074 & 0.077 & -0.964 & 0.335 \\
\hline $\mathrm{CG}$ & 0.566 & 0.339 & 1.672 & 0.094 \\
\hline Severity & -0.208 & 0.038 & -5.509 & $<0.001 *$ \\
\hline Form & 0.053 & 0.150 & 0.354 & 0.723 \\
\hline $\mathrm{CG} \times$ form & -0.010 & 0.227 & -0.045 & 0.964 \\
\hline Case typicality & -0.170 & 0.027 & -6.304 & $<0.001 *$ \\
\hline Complainant typicality & -0.353 & 0.040 & -8.795 & $<0.001 *$ \\
\hline Defendant typicality & -0.303 & 0.036 & -8.360 & $<0.001 *$ \\
\hline \multicolumn{5}{|c|}{ Defendant blame } \\
\hline IRMA & -0.133 & 0.110 & -1.205 & 0.228 \\
\hline $\mathrm{CG} \times \mathrm{IRMA}$ & -0.458 & 0.135 & -3.382 & $<0.001 *$ \\
\hline MRMA & -0.757 & 0.109 & -6.947 & $<0.001 *$ \\
\hline $\mathrm{CG} \times \mathrm{MRMA}$ & 0.666 & 0.174 & 3.836 & $<0.001 *$ \\
\hline Oral sex & -0.008 & 0.049 & -0.163 & 0.871 \\
\hline $\mathrm{CG} \times$ oral sex & -0.039 & 0.073 & -0.532 & 0.594 \\
\hline $\mathrm{CG}$ & -0.658 & 0.294 & -2.236 & $0.025^{*}$ \\
\hline Severity & 0.263 & 0.032 & 8.122 & $<0.001 *$ \\
\hline Form & -0.069 & 0.142 & -0.487 & 0.626 \\
\hline $\mathrm{CG} \times$ form & -0.003 & 0.208 & -0.014 & 0.989 \\
\hline Case typicality & 0.227 & 0.024 & 9.483 & $<0.001^{*}$ \\
\hline Complainant typicality & 0.353 & 0.035 & 9.941 & $<0.001^{*}$ \\
\hline Defendant typicality & 0.449 & 0.036 & 12.609 & $<0.001 *$ \\
\hline \multicolumn{5}{|c|}{ Complainant credibility } \\
\hline IRMA & -0.104 & 0.117 & -0.883 & 0.377 \\
\hline $\mathrm{CG} \times \mathrm{IRMA}$ & -0.631 & 0.162 & -3.902 & $<0.001$ \\
\hline MRMA & -1.218 & 0.119 & -10.264 & $<0.001 *$ \\
\hline $\mathrm{CG} \times \mathrm{MRMA}$ & 1.166 & 0.182 & 6.415 & $<0.001 *$ \\
\hline Oral sex & 0.032 & 0.057 & 0.561 & 0.575 \\
\hline $\mathrm{CG} \times$ Oral sex & -0.067 & 0.082 & -0.810 & 0.418 \\
\hline CG & -1.357 & 0.339 & -4.006 & $<0.001 *$ \\
\hline Severity & 0.335 & 0.037 & 9.110 & $<0.001 *$ \\
\hline Form & -0.088 & 0.158 & -0.560 & 0.575 \\
\hline $\mathrm{CG} \times$ form & -0.020 & 0.238 & -0.083 & 0.934 \\
\hline Case typicality & 0.275 & 0.028 & 9.782 & $<0.001 *$ \\
\hline
\end{tabular}




\begin{tabular}{lcccc} 
Complainant typicality & 0.598 & 0.043 & 14.002 & $<0.001^{*}$ \\
Defendant typicality & 0.454 & 0.038 & 11.878 & $<0.001^{*}$ \\
\hline & \multicolumn{2}{c}{ Defendant } & credibility & \\
IRMA & 0.115 & 0.165 & 0.698 & 0.485 \\
CG $\times$ IRMA & 0.580 & 0.225 & 2.578 & $0.010^{*}$ \\
MRMA & 0.548 & 0.183 & 2.988 & $0.003^{*}$ \\
CG $\times$ MRMA & -0.709 & 0.264 & -2.690 & $0.007^{*}$ \\
Oral sex & -0.027 & 0.073 & -0.370 & 0.711 \\
CG $\times$ Oral sex & 0.017 & 0.117 & 0.147 & 0.883 \\
CG & 0.267 & 0.382 & 0.698 & 0.485 \\
Severity & -0.323 & 0.049 & -6.640 & $<0.001^{*}$ \\
Form & -0.302 & 0.189 & -1.595 & 0.111 \\
CG $\times$ form & 0.169 & 0.282 & 0.599 & 0.549 \\
Case typicality & -0.187 & 0.035 & -5.376 & $<0.001^{*}$ \\
Complainant typicality & -0.315 & 0.051 & -6.210 & $<0.001^{*}$ \\
Defendant typicality & -0.426 & 0.046 & -9.171 & $<0.001^{*}$ \\
\hline & & & & \\
CG & 0.276 & 0.367 & 0.752 & 0.452 \\
Form & -0.177 & 0.163 & -1.085 & 0.278 \\
CG $\times$ form & 0.142 & 0.234 & 0.607 & 0.544 \\
Case typicality & -0.054 & 0.056 & -0.978 & 0.328 \\
Complainant typicality & -0.059 & 0.101 & -0.587 & 0.557 \\
Defendant typicality & -0.105 & 0.096 & -1.093 & 0.274 \\
Complainant blame & -0.081 & 0.057 & -1.413 & 0.158 \\
Defendant blame & 0.449 & 0.079 & 5.675 & $<0.001^{*}$ \\
Complainant credibility & 0.354 & 0.079 & 4.499 & $<0.001^{*}$ \\
Defendant credibility & -0.169 & 0.055 & -3.048 & $0.002^{*}$ \\
\hline Note $N=437$. & & &
\end{tabular}

Note. $N=437$.

$\mathrm{CG}=$ complainant gender

IRMA = The Illinois. Rape Myth Acceptance Scale

MRMA = Male Rape Myth Acceptance Scale

$* p<.05$

Table 7

Gender Differences for Predicted Relationships

\begin{tabular}{|c|c|c|c|c|c|c|c|c|}
\hline \multirow[t]{2}{*}{ Variable } & \multicolumn{4}{|c|}{ Female jurors } & \multicolumn{4}{|c|}{ Male jurors } \\
\hline & $B$ & $S E$ & $z$ & $p$ & $B$ & $S E$ & $z$ & $p$ \\
\hline \multicolumn{9}{|c|}{ Complainant gender } \\
\hline Case typicality & 0.558 & 0.321 & 1.738 & .082 & 0.565 & 0.343 & 1.649 & 0.099 \\
\hline Complainant typicality & 1.233 & 0.184 & 6.682 & $<0.001$ & 1.457 & 0.238 & 6.109 & $<0.001$ \\
\hline Defendant typicality & 0.976 & 0.203 & 4.800 & $<0.001$ & 0.797 & 0.301 & 2.648 & 0.008 \\
\hline Complainant blame & 1.203 & 0.286 & 4.212 & $<0.001$ & 1.430 & 0.356 & 4.019 & $<0.001$ \\
\hline Defendant blame & -1.172 & 0.237 & -4.948 & $<0.001$ & -0.781 & 0.325 & -2.405 & 0.016 \\
\hline $\begin{array}{l}\text { Complainant } \\
\text { credibility }\end{array}$ & -1.488 & 0.278 & -5.344 & $<0.001$ & -1.412 & 0.383 & -3.686 & $<0.001$ \\
\hline Defendant credibility & 0.645 & 0.286 & 2.253 & 0.024 & 0.751 & 0.397 & 1.892 & 0.059 \\
\hline Verdict & -0.705 & 0.912 & -0.773 & 0.439 & 1.607 & 0.775 & 2.072 & 0.038 \\
\hline
\end{tabular}




\begin{tabular}{lcccccccc}
\hline & \multicolumn{7}{c}{ Verdict } \\
Case typicality & 0.180 & 0.220 & 0.816 & 0.414 & -0.642 & 0.256 & -2.510 & 0.012 \\
Complainant typicality & 0.372 & 0.412 & 0.901 & 0.367 & -0.938 & 0.373 & -2.514 & 0.012 \\
Defendant typicality & 0.238 & 0.355 & 0.671 & 0.502 & -0.862 & 0.364 & -2.371 & 0.018 \\
$\begin{array}{l}\text { Complainant blame } \\
\text { Defendant blame }\end{array}$ & 0.026 & 0.095 & 0.269 & 0.788 & -0.343 & 0.138 & -2.485 & 0.013 \\
$\begin{array}{l}\text { Complainant } \\
\quad \text { credibility }\end{array}$ & 0.234 & 0.212 & 1.104 & 0.270 & 0.750 & 0.230 & 3.256 & 0.001 \\
Defendant credibility & 0.048 & 0.306 & 0.156 & 0.876 & 0.744 & 0.216 & 3.449 & 0.001 \\
\hline
\end{tabular}

Note. $N=430$

$* p<.05$

\section{Table 8}

Gender differences for rape myth acceptance scales and the predicted relationships

\begin{tabular}{|c|c|c|c|c|c|c|c|c|}
\hline Variable & $\mathrm{B}$ & SE & $\mathrm{Z}$ & $\mathrm{p}$ & $\mathrm{B}$ & SE & $\mathrm{Z}$ & $\mathrm{p}$ \\
\hline \multicolumn{9}{|c|}{ Complainant Blame } \\
\hline & \multicolumn{4}{|c|}{$\underline{\text { Female Jurors }}$} & \multicolumn{4}{|c|}{$\underline{\text { Male Jurors }}$} \\
\hline IRMA & 0.293 & 0.167 & 1.760 & 0.078 & -0.131 & 0.193 & -0.677 & 0.499 \\
\hline IRMA*CG & 0.183 & 0.219 & 0.836 & 0.403 & 0.697 & 0.294 & 2.371 & $0.018^{*}$ \\
\hline MRMA & 0.724 & 0.180 & 4.026 & $<0.001^{*}$ & 0.777 & 0.215 & 3.608 & $<0.001^{*}$ \\
\hline $\begin{array}{l}\mathrm{MRMA} * \mathrm{C} \\
\mathrm{G}\end{array}$ & -0.377 & 0.215 & -1.755 & 0.079 & -0.377 & 0.332 & -1.136 & 0.256 \\
\hline \multicolumn{9}{|c|}{ Defendant Blame } \\
\hline IRMA & -0.071 & 0.165 & -0.430 & 0.667 & 0.066 & 0.161 & 0.412 & 0.681 \\
\hline IRMA*CG & -0.194 & 0.209 & -0.925 & 0.355 & -0.631 & 0.212 & -2.973 & $0.003^{*}$ \\
\hline MRMA & -0.480 & 0.170 & -2.821 & $0.005^{*}$ & -0.592 & 0.175 & -3.384 & $0.001 *$ \\
\hline $\begin{array}{l}\mathrm{MRMA} * \mathrm{C} \\
\mathrm{G}\end{array}$ & 0.502 & 0.235 & 2.140 & $0.032 *$ & 0.410 & 0.276 & 1.488 & 0.137 \\
\hline \multicolumn{9}{|c|}{ Complainant Credibility } \\
\hline IRMA & -0.130 & 0.147 & -0.882 & 0.378 & 0.214 & 0.205 & 1.048 & 0.295 \\
\hline IRMA*CG & -0.338 & 0.204 & -1.655 & 0.098 & -0.727 & 0.280 & -2.596 & $0.009^{*}$ \\
\hline MRMA & -0.805 & 0.151 & -5.322 & $<0.001^{*}$ & -1.131 & 0.209 & -5.413 & $<0.001 *$ \\
\hline $\begin{array}{l}\mathrm{MRMA}{ }^{*} \mathrm{C} \\
\mathrm{G}\end{array}$ & 1.043 & 0.209 & 4.987 & $<0.001^{*}$ & 0.854 & 0.312 & 2.738 & $0.006^{*}$ \\
\hline \multicolumn{9}{|c|}{ Defendant Credibility } \\
\hline IRMA & 0.290 & 0.207 & 1.402 & 0.161 & -0.384 & 0.284 & -1.352 & 0.176 \\
\hline IRMA*CG & 0.184 & 0.280 & 0.659 & 0.510 & 0.852 & 0.388 & 2.192 & $0.028^{*}$ \\
\hline MRMA & 0.110 & 0.240 & 0.457 & 0.647 & 0.510 & 0.341 & 1.496 & 0.135 \\
\hline $\begin{array}{l}\text { MRMA*C } \\
\text { G }\end{array}$ & -0.413 & 0.328 & -1.260 & 0.208 & -0.529 & 0.480 & -1.102 & 0.270 \\
\hline
\end{tabular}

Note. $N=430$

$*_{p}<.05$

\section{Discussion}

This study examined whether the form of sexual assault and complainant and defendant gender (i.e., male complainant-female defendant vs. female complainant-male defendant) 
influence mock jurors' perceptions of the prototypicality of a sexual assault case, complainant, and defendant. I also examined the role of prototypicality of the case, complainant, and defendant on mock jurors' complainant/defendant blame and credibility assessments. Finally, I investigated the relationship between mock jurors' complainant/defendant blame and credibility assessments and their verdict decisions. Several important findings emerged from these analyses. The path model for complainant gender (tied to defendant gender) supported my hypotheses, whereas the model for form of the sexual assault did not.

\section{Indirect Effects of Complainant Gender tied to Defendant Gender}

As predicted, the gender of the complainant/defendant informed mock jurors' prototypes of what constitutes a sexual assault case, complainant, and defendant. Also, in line with my predictions, mock jurors' complainant/defendant blame and credibility assessments were informed by their sexual assault prototypes, and these assessments, in turn, affected their verdict decisions. My results provide evidence to suggest that because male complainants-female defendants do not fit within mock jurors' prototypes of a sexual assault case, complainant, or defendant, the male complainant is blamed more and seen as less credible by mock jurors, while his female defendant is perceived as more credible and less blameworthy. Because of this, the probability of mock jurors rendering a guilty verdict in this condition was reduced.

The present study helps extend psycho-legal research by providing evidence to suggest that in addition to scripts and stereotypes informing mock jurors' mental representation of a case, as contended in the Director's Cut model (Devine, 2012), mental representations appear to be formulated by mock jurors' sexual assault prototypes as well. The results of the current study fit well with previous studies (e.g., Du Mont et al., 2003; McKimmie et al., 2014; Stuart et al., 2019) and serve to extend their scope by providing evidence to suggest that, in addition to rape 
myths, participants' sexual assault prototypes are one of the mechanisms underpinning their assessments of complainant/defendant blame and credibility. Additionally, my findings support previous research demonstrating that complainant/defendant blame and credibility are related to mock jurors' verdict decisions (Ellison \& Munro, 2009; Finch \& Munro, 2005). My thesis expands on these findings and provides a model that offers evidence to suggest one of the phenomena behind mock jurors' verdict decisions is their sexual assault prototypes. Specifically, mock jurors' sexual assault prototypes inform their complainant/defendant blame and credibility assessments, which, in turn predict their verdict decisions.

My results are broadly in line with the growing body of research examining judicial decisions involving male complainants of female-perpetrated sexual assault. In my study, the male complainant was viewed as more blameworthy and less credible than his female complainant counterpart, consistent with previous studies (Anderson, 2007; Pica et al., 2018; Starosta \& Schuller, 2020). My results go beyond previous reports by empirically demonstrating the mediating role of prototypicality of the sexual assault case, complainant, and defendant, which may help explain the aforementioned studies' findings.

My results can also add to the conceptualization of the 'real rape' prototype (Du Mont et al., 2003) because by explicitly measuring mock jurors' perceived prototypicality of a sexual assault case, complainant, and defendant, it provides evidence to suggest that mock jurors' 'real rape' prototype includes a female complainant-male defendant pairing, and that male complainant-female defendant pairings do not appear to fit within this conception.

Consistent with the growing body of research examining jurors' decisions for male complainant-female defendants compared to female complainant-male defendants (Anderson, 2007; Pica et al., 2018; Starosta \& Schuller, 2020), complainant gender was not directly related 
to mock jurors' verdict decisions. However, this is reasonably because all of the effect complainant gender has on verdict is due to its effects on blame and credibility (either indirectly or directly), which then affect verdict. Subsequently, there is nothing left after that for complainant gender to affect verdict directly. More research is warranted to confirm this supposition and ascertain if this process could explain why previous research found that mock jurors' verdict decisions did not differ for a male complainant-female defendant or a female complainant-male defendant.

\section{Direct Effects of Complainant Gender as Related to Defendant Gender}

Contrary to my prediction, the direct effects of complainant gender on complainant/defendant blame and credibility remained significant when including prototypicality assessments, and the model demonstrated inconsistent mediation. The present study's findings revealed that for fixed levels of prototypicality, the female complainant was blamed more and seen as less credible than the male complainant. The male defendant was viewed as more credible and less blameworthy than the female defendant. These findings contrast previous research demonstrating that a male complainant of female-perpetrated sexual assault was blamed more and seen as less credible than the female complainant of male-perpetrated assaults (Anderson, 2007; Pica et al., 2019; Starosta \& Schuller, 2020).

These results may be explained by hindsight bias, which is the tendency to overestimate the foreseeability of an outcome once it is known (Fischhoff, 1975). Perhaps participants believed that because the female complainant-male defendant condition is more prototypical of a sexual assault case, complainant, and defendant, in hindsight, she should have "known better" and avoided her victimization. Hindsight bias has implications for decision-making within the legal system. Previous research has suggested that when mock jurors are presented with a case 
describing aggression (not exclusive to sexual assault), they dissect whether the victim could have foreseen the outcome (Casper et al., 1989; Roese et al., 2006). This research suggests that mock jurors, in accordance with the hindsight bias, overestimate the foreseeability of the aggression because they are unable to judge the situation as if they had not known the outcome. Due to this overestimation, mock jurors believe that the victim could have changed their behavior to avoid the aggression (Casper et al., 1989). Harley (2007) suggests that this hindsight bias leads mock jurors to believe that the complainant was partially responsible for the outcome because they did not foresee how risky their behavior was, despite the complainant not having access to this hindsight. It, therefore, stands to reason that mock jurors may not be able to empathize with the information available to the complainant at the time of the alleged assault, which appears to diverge from rational decision-making (Russ et al., 1996). From this standpoint, perhaps the mock jurors in the present study relied on their knowledge of the outcome (i.e., the sexual assault occurred) to inform their assessments of blame and credibility.

The contention that a female complainant should have "known better" seems plausible due to the suggestion that because women are at a higher risk of sexual assault by men (Department of Justice, 2019), women are consistently taught how to avoid being sexually assaulted in the form of prevention tips such as (a) only walk during the day or well-lit places, (b) wear nonrevealing clothing to avoid sending the wrong message, (c) do not talk to male strangers, and (d) keep an eye on your beverage at all times to avoid the unwanted consumption of drugs (Bedera \& Nordmeyer, 2015). Researchers suggest these prevention strategies are rooted in rape myths (Bedera \& Nordmeyer, 2015). For instance, Bedra and Nordemeyer (2015) note that the strategy to "avoid wearing revealing clothing" has a strong resemblance to the rape 
myth that "when girls go to parties wearing slutty clothes, they are asking for trouble" (Burt, 1991; McMahon \& Farmer, 2011).

Researchers suggest that when participants are exposed to these prevention strategies and then read and evaluate a sexual assault case, they blame the victim and view her as more responsible because they believe the woman should have known how to protect herself based on the prevention tips, they assume she has been exposed to (Cherniawsky \& Morrison, 2020). Perhaps, participants believed that since women are more likely to be sexually assaulted by men and provided with prevention tips (Cherniawsky \& Morrison, 2020), in hindsight, she should have "known better" how to avoid her victimization. However, because my participants did not view the male complainant of female-perpetrated sexual assault as prototypical of a sexual assault case, complainant, or defendant, they may not have relied on this hindsight bias and believed that the male complainant should have "known better" how to avoid the assault, especially since victim-prevention strategies are not usually targeted towards men (DeGue et al., 2014). Therefore, participants found the female complainant as more to blame and less credible than the male complainant in the present study. These assumptions provide a starting point for discussion and further investigation.

Previous research has consistently demonstrated that female complainants who deviate from what rape myths prescribe as a "genuine" sexual assault complainant (e.g., intoxicated complainant, lack of complainant's physical resistance, the defendant was known to the complainant) receive more blame from mock jurors and are seen as less credible compared to complainants who are seen as "genuine", as defined by rape myths (e.g., McKimmie et al., 2014; Sims et al., 2007; Wall \& Schuller, 2002). In the present study, the female complainant was portrayed as a "genuine" sexual assault complainant in accordance with these rape myths (e.g., 
stranger assault, verbal-resistance, sober, immediately reported the assault), yet for fixed levels of prototypicality, she was still blamed more and seen as less credible than the male complainant. It appears from my results that mock jurors may have a propensity to blame female complainants of sexual assault and it remains unclear to what degree these rape myths contribute to mock jurors' decisions in sexual assault cases. Research has suggested that due to social movements such as \#Metoo and Slutwalk that advocate for an end to victim blame and, more broadly, rape culture (Nicholls, 2021), individuals have a broader understanding of sexual assault and are debunking rape myths (Henry et al., 2020). While there may be a paradigm shift away from established rape myths, other factors appear to be informing mock jurors' evaluation of a female complainant of sexual assault, as demonstrated by my participants endorsing low levels of rape myth acceptance, but still blaming and viewing the female complainant as less credible. Further work is required to disentangle the complexity of these findings.

\section{Form of Sexual Assault}

To my knowledge, this study was the first to empirically investigate mock jurors' decisions for a sexual assault involving forced oral sex. Contrary to my predictions, the form of sexual assault did not affect participant responses, with no significant differences found between the oral sex and the vaginal intercourse condition. It therefore seems that the "only vaginal intercourse equates to sexual assault" rape myth (Leftkovitz et al., 2014; Lefkovitz et al., 2016) did not play a significant role in mock jurors' evaluations of the complainant or defendant. This is contrary to previous research finding that sexual assault complainants who deviate from what rape myths prescribe as a "genuine" sexual assault are treated less favourably by jurors (e.g., Ellison \& Munro, 2010; McKimmie et al., 2014; Persson et al., 2018). 
The "only vaginal intercourse equates to sexual assault" rape myth was first identified by Lefkovitz and colleagues in 2014 and was re-examined in 2016. However, since 2016, many high-profile sexual assault cases involving forced oral sex on a victim have occurred. In 2017, Harvey Weinstein was accused of forcing oral sex onto a woman (Wagmeister, 2017). This case was published in numerous news outlets and received heavy media focus (e.g., NYTimes, Washington Post). Additionally, Matt Lauer, who previously hosted the popular morning talk show, The Morning Show, was publicly accused of performing unwanted oral sex on his female victims. These allegations were published by The Washington Post on April 25, 2018 (Ellison, 2018). Likewise, there has been media attention on male victims being forced to receive oral sex. In 2018, the well-known male actor Shia Labeouf publicly disclosed being sexually assaulted by a female fan who forced oral sex on him (Beaumont-Thomas, 2018).

Mastro and Kopacz (2010) suggest that the media is one of the primary ways that prototypes are created. It is therefore reasonable that due to the increase in media attention on forced oral sex onto victims, this form of sexual assault is now perceived as a "genuine" and typical form of a sexual assault, despite the rape myth against it. This supposition is consistent with the findings of Kessler et al. (2019), who investigated whether features of a workplace sexual harassment charge that gained media attention during the \#MeToo movement would increase people's perceptions of the type of behaviours that are involved in sexual harassment. The results demonstrated that behaviours inconsistent with media stories were not perceived as sexual harassment. Although this line of inquiry appears to be testing prototypes, prototypicality was never measured. Regardless, the results suggest that the media affects individuals' perceptions (Kessler et al., 2019) and, arguably, their prototypes. Therefore, it seems likely that due to the increase in media attention on oral sex (with both male and female complainants), this 
form of sexual assault is now seen as a "typical" form of sexual assault. This may explain why, in the present study, no significant effects were found for sexual assault form on prototypicality assessments, complainant and defendant blame and credibility assessments, and verdict decisions.

I found no significant difference between participants' severity ratings for the oral sex or vaginal intercourse condition, which may support the assumption that increased media focus on forced oral sex onto a complainant has added this form of sexual assault to peoples' prototypes of a "genuine" sexual assault case. However, due to the scant research investigating the influence of the form of the sexual assault on juror decisions, this study alone cannot be used to derive firm conclusions about the role of sexual assault form on judicial decisions. Future research should replicate this study and include other forms of sexual assault, such as anal sex, forced oral sex onto a defendant, and/or forced digital penetration (i.e., hand job/fingering) onto the complainant/defendant, to enable a more extensive understanding of the role of this variable on judicial decisions in sexual assault cases.

\section{Exploratory Model}

\section{RMA Scales as Predictors}

Contrary to previous research (e.g., Chapleau et al., 2008; Davies et al., 2012), in the present study, the rape myth acceptance scales only predicted complainant/defendant blame and credibility for the complainant gender the scale was targeting. For instance, the IRMA targets rape myths against women, and in the present study, the IRMA only predicted complainant blame or credibility when the complainant was female. Similarly, the MRMA targets rape myths against men, and in the present study, the MRMA only predicted male complainant blame and credibility. These inconsistent findings may be explained by the fact that previous research 
studied participants with high scores for both the IRMA and MRMA (e.g., Chapleau et al., 2008;

Davies et al., 2012), while my participants generally had low rape myth acceptance. These conflicting results suggest that further research concerning the role of jurors' rape myth acceptance on their blame and credibility assessments towards both male and female complainants and defendants are required.

MRMA. Consistent with previous research, higher MRMA scores were significantly associated with increases in male complainant blame and female defendant credibility and decreases in male complainant credibility and female defendant blame (e.g., Davies et al., 2012; Sleath \& Bull, 2010). In my study, even though participants had low MRMA acceptance scores in general, any acceptance of male rape myths predicted negative perceptions of the male complainant. Believing in male rape myths appeared to inform participants' assessments and decision-making, potentially resulting in unfair proceedings and outcomes for male complainants. This is problematic because potential jurors for sexual assault cases are not screened as to where they fall on rape myth acceptance scales prior to trial in Canada.

IRMA. When I partialed out the effect of complainant gender through the prototypicality assessments, mock jurors, regardless of their level of rape myth acceptance, were more likely to blame the female complainant than the male complainant. Because previous research has not examined prototypicality, this may explain why previous studies have not found these effects and have instead found that those higher in rape myth acceptance tend to blame complainants more than those with lower rape myth acceptance (e.g., Klement et al., 2019; Krahe et al., 2007). These results may be due to mock jurors in my study having low rape myth acceptance in general. Alternatively, these results could suggest that there may have been an implicit bias towards female complainants that the scale did not measure, evidenced by the finding of an 
effect of complainant gender on complainant credibility, even when controlling for mock jurors' rape myth acceptance and the interaction between IRMA or MRMA and complainant gender. More research is warranted to confirm these findings. This is an important line of inquiry due to the high rate of women sexually assaulted each year (Statistics Canada, 2017). If there is an implicit bias to view female sexual assault complainants as less credible, further investigations on why this is occurring and how to attenuate this bias are required.

Oral Sex Scale. The three questions I created to gauge jurors' acceptance of the "only vaginal intercourse equates sexual assault" (Lefkovitz et al., 2014; Lefkovitz et al., 2016) rape myth did not significantly predict complainant/defendant blame or credibility. As previously noted, this rape myth may no longer be salient for jurors due to the increased media attention on this form of sexual assault, which could have taught individuals that forced oral sex onto a complainant equates sexual assault.

\section{Sexual Assault Severity as a Predictor}

Consistent with previous research (e.g., Pickle \& Gentry, 2017; Vallano et al., 2013), the more severe participants in the current study perceived the alleged sexual assault to be for the complainant, the lower blame and higher credibility were attributed to the complainant, while higher blame and lower credibility were attributed to the defendant. Therefore, future investigations are encouraged to further delve into the relationship between severity, jurors' prototypes, and their decisions.

\section{Rape Myth Acceptance Scales and Severity as Covariates}

I explored if the inclusion of the IRMA, MRMA, Oral Sex Scale, and severity would have a role on the direct effects of complainant gender on blame and credibility variables found within my main model. Within the present study, The Oral Sex Scale had no significant role in 
these direct effects. However, using severity, IRMA, and MRMA together as control variables attenuated the direct effects of complainant blame on verdict, and their inclusion resulted in the direct effects of complainant gender on prototypicality of the sexual assault case, complainant blame, and defendant credibility to no longer be significant in the model. Exact understanding of why this occurred may not be possible because these findings occurred in conjunction with the statistical combination of multiple control variables in the exploratory model—for instance, the inclusion of severity, RMA, MRMA, and the Oral Sex Scale. As preliminary analysis yielded promising results for the role of severity, IRMA, and MRMA as covariates in the model, researchers are encouraged to look into this further.

\section{Juror Gender}

Contrary to what has been found in the literature (e.g., Basow \& Minieri, 2011; Grubb \& Harrower, 2008; McKimmie et al., 2014; Simonson \& Subich, 1999), my study did not find significant juror gender differences for any of the predicted relationships. In my study, male participants did not blame the complainant more than female participants did. Male participants did not have a lower probability of rendering a guilty verdict than the female participants, and men did not score higher on rape myth acceptance scales than women. These results are potentially due to my sample participants largely self-identifying as liberal, non-religious, and highly educated. Previous studies have demonstrated that men who are conservative (Silver \& Silver, 2017), Roman Catholic or Protestant (Barnett et al., 2018), and less educated (Esposito et al., 2020) are more punitive towards sexual assault complainants, especially male complainants (Walfield, 2018), compared to their liberal, more educated, and agnostic or atheistic male counterparts. My sample, as mentioned, was fairly representative of the Canadian population. However, it remains an empirical question how results would differ with a more conservative, 
religious, or less educated sample. The present study provides some evidence to suggest that mock jurors' characteristics (e.g., religion, political ideology, and education) may modify the effect of participants' gender on assessments and verdicts. More research concerning the effects of participants' gender, juror characteristics and perceptions of sexual assault complainants, including rape myth acceptance, on jurors' decision-making in sexual assault cases is therefore required. This line of inquiry would provide valuable information to Crown and defence lawyers on which jurors, based on their characteristics, may be more punitive towards sexual assault complainants, especially male complainants.

\section{Implications}

My thesis demonstrates that complainant gender (tied to defendant gender) and mock jurors' perceived prototypicality of the sexual assault case, complainant, and defendant play a multifaceted role in shaping mock jurors' perceptions of sexual assault and legal decisions. The present study endeavored to include male victims of female-perpetrated and forced oral sexual assault in empirical discourse in the hopes of opening the door to more research about these underrepresented populations. My results demonstrate that prototypicality is one of the mechanisms behind mock jurors' decisions and provides evidence to suggest that mock jurors appear to have an image of what genders are involved in a prototypical sexual assault case, complainant, and defendant, with practical implications for sexual assault cases, the field of psychology, and the criminal justice system.

This is the first study to directly measure mock jurors' perceived prototypicality of the sexual assault case, complainant, and defendant. In the past, research has varied how prototypical a sexual assault scenario is based on to what degree the case adheres to salient rape myths. However, the results of the present study highlight that the relationship between complainant 
(tied to) defendant gender on mock jurors' case-related decisions is not as straightforward as previously hypothesized, and only by directly measuring mock jurors' perceived prototypicality of the sexual assault case, complainant, and defendant can this complex relationship be understood. For example, without measuring prototypicality directly, it would have been thought that the female complainant was blamed more and seen as less credible than the male complainant. However, by directly measuring mock jurors' perceived prototypicality of the sexual assault case, complainant, and defendant, we now understand that this actually only occurs for fixed levels of prototypicality. When prototypicality is included in the model, mock jurors actually blame the male complainant more and view him as less credible than the female complainant. The same nuanced relationships were also seen with defendant blame/credibility and mock jurors' verdict decisions. It is only with the knowledge of the intricacies of these relationships that resources can effectively be implemented to counter this prototype-based bias. Furthermore, given the importance of directly measuring prototypicality, the present study provides a methodological basis for psycho-legal researchers to investigate prototypes and their role on judicial decision-making in sexual assault cases.

With regards to the specifics of countering this prototype-based bias, the results of the present study suggest a male complainant of female-perpetrated sexual assault may face a disadvantage if he pursues his claims at trial because his is not the prototypical sexual assault scenario. The consequences of the male complainant-female defendant deviating from jurors' narrow prototypes of whom a complainant/defendant should be appear to be severe. As seen in this study, although mock jurors were provided with the Canadian legal definitions of sexual assault as defined in Bill C-51 (i.e., gender neutral terms such as "complainant" and "defendant" rather than "she" or "he"), they still appeared to have a prototype of what genders are involved in 
a sexual assault case, complainant, and defendant and used this prototype to guide their decisions. Future studies should investigate how to inform jurors that men can be victims of sexual assaults perpetrated by a female to prevent the deleterious belief that men cannot be sexually assaulted and that this gender combination is counter-prototypical of a sexual assault case, complainant, and defendant. This is particularly important because this prototype-based bias, found within the present study, can add to the low attrition rates sexual assault cases face once they make it to court (Bureau of Justice Statistics, 2017) and can prevent fair and just trials for all. Therefore, Crown and defence lawyers, as well as trial judges, should take steps to mitigate this potential bias.

Future research should also be devoted to discovering what other elements might comprise jurors' sexual assault prototypes, what is informing these prototypes, and ways to mitigate them to ensure fair trials. This line of inquiry is essential because how prototypical a sexual assault scenario is perceived to be has no bearing on whether a complainant gave consent. Prototypes should therefore not be related to mock jurors' decisions.

To this end, it would be of empirical interest to replicate the previous research examining the role of rape myths in jurors' decisions (e.g., Du Mont et al., 2003; McKimmie et al., 2014; Schuller et al., 2010) with the inclusion of measurements that empirically examine jurors' sexual assault prototypes. Such studies could disentangle, for instance, whether sexual assault victims who knew their assailant are seen as more blameworthy by jurors because they are not adhering to what rape myths prescribe as a "genuine" sexual assault case, or whether jurors' prototypical image of a sexual assault complainant is someone assaulted by a stranger, so deviations from this image increase victim blaming. This inquiry line would aid in further understanding the drivers of juror complainant/defendant blame and credibility assessments and verdict decisions. 
For female complainants, the present study's findings provide additional information about the multifaceted role of complainant gender (tied to defendant gender) on mock jury decision-making in sexual assault cases. This study suggests that a female complainant will be blamed regardless of whether her sexual assault adheres to salient rape myths and regardless of whether she is the prototypical sexual assault image. This has negative consequences for our legal system because one in three women have experienced sexual assault at some point in their lives (Statistics Canada, 2017). Intuitively then, there should be a high rate of individuals being charged with sexual assault each year. However, sexual assault has the highest attrition rate of any crime (Bureau of Justice Statistics, 2017). Research suggests that jurors' conceptions play a key role in the high attrition rates found between trial and conviction (Schuller et al., 2010). If jurors (regardless of their level of rape myth acceptance) tend not to believe female complainants, then not all individuals are being treated equally under the court of law. Further research will be essential to replicate this study to confirm my findings. If confirmed, future research should be conducted to understand why jurors tend to hold negative evaluations of female sexual assault complainants and mitigate this bias.

My study further extends the current literature by encompassing a wider range of persons affected by sexual assault rather than solely focusing on female complainants, male defendants, and vaginal penetrative assault, thereby broadening current psycho-legal research to novel populations. This study provides a methodological basis for future studies to investigate other gender influences on jurors' sexual assault prototypes and their role on decision making in sexual assault cases. This is necessary because jurors' tendency to underestimate assault that does not involve a female complainant-male defendant promotes the marginalization of male, female, and transgender complainants of female-perpetrated sexual assault. All of these situations are 
understudied but prevalent within society (Ibrahim, 2019; Rotenberg, 2017). For instance, in 2011 it was estimated that $50 \%$ of transgender individuals reported being sexually assaulted (EGALE Canada, 2011). These statistics, along with my findings, provide evidence to suggest that systemic education of the public on different genders involved in sexual assaults is warranted. Future research is necessary to further understand the biasing role of complainant gender on jurors' decisions in sexual assault cases and examine ways to mitigate against this bias to ensure fair and just trials for all.

In the present study, null results demonstrated that mock jurors do not appear to have a prototypical image of sexual assault form in terms of forced oral sex onto the complainant compared to vaginal intercourse. As this thesis is the first to examine sexual assault forms outside of normative vaginal penetration, more research is warranted to examine all variations of the forms of a sexual assault to understand the full impact of this variable on jurors' decisions.

Severity was not the main focus of the present study. However, the exploratory results provide evidence that participants rely on their assessment of how severe they perceived the alleged sexual assault to be for the complainant to inform their blame/credibility assessments, which then inform their verdict decisions. In opposition to the informative knowledge obtained from how severe a complainant perceived the sexual assault to be for themselves, jurors' subjective perceptions of severity should not have a role in their case-related decisions. Future examinations on the role of severity on jurors' decisions and ways to mitigate its occurrences are required to further understand the role of severity on jurors' decision-making in sexual assault cases.

Similarly, my exploratory model provides evidence to suggest that the rape myth acceptance scales only predicted complainant/defendant blame and credibility for the 
complainant gender the scale was targeting. Because more than just men and women can be sexually assaulted, it is of research interest to design a scale that measures rape myths in general, and is more generalizable to various complainant/defendant gender combinations. However, because previous research has suggested a positive relationship between the IRMA and MRMA scales (e.g., Chapleau et al., 2008; Davies et al., 2012), further research concerning the correlation between the IRMA and MRMA scales is required.

As my exploratory model provides evidence to support previous findings that participants' belief in male rape myths appear to inform their case-related decisions (Davies et al., 2012; Sleath \& Bull, 2010), future examination of ways to reduce male rape myth acceptance is warranted. Lastly, my male and female jurors did not significantly differ in their prototypicality assessments or case-related decisions, thus allowing for cautious optimism surrounding gender differences, among jurors, in the treatment of sexual assault complainants and defendants in sexual assault cases. However, future replication is required to better understand the role of jurors' gender in Canadian sexual assault cases.

\section{Limitations and future directions}

The current study was conducted in a manner that follows previous jury decision-making research, specifically in Canada (Hans, 2013). Because Canadian jurors cannot legally disclose the reasons for their decisions (Criminal Code, s. 649; 1985), jury simulations provide an opportunity to examine the effect of extralegal information on juror decision-making. Several caveats of the present study must, however, be noted.

Firstly, the study used mock jurors and a simulated trial. It is possible that participants knowing that their responses had no consequences for a defendant may have influenced their decision-making process and/or outcome (Bornstein et al., 2017; Bornstein \& McCabe, 2005). 
Therefore, the present study may not fully represent what would occur in a courtroom, lowering my ecological validity. Secondly, the use of a written trial transcript instead of an audio recording or video/live presentation may also have lowered the ecological validity of the present study, as real jurors hear and view a case and do not read it. However, research has demonstrated few (if any) differences in results between various modes of presentation (Bronstein, 1999; Pezdek et al., 2010). Additionally, this study lacked a deliberation component. Mock jurors' verdict decisions were rendered individually rather than through group discussion and therefore may not represent how a jury considers this extralegal information (Nunez et al., 2011). Despite these limitations, the simulated nature of this study provided a high degree of experimental control.

Online data collection provides the researcher easier access to a geographically diverse (i.e., participants were from all over Canada) and representative community sample. However, this process does have its limitations. For instance, online participants may fail to pay attention to all questions, which is a challenge to monitor when the researcher is not physically present during their participation. The inclusion of attention checks throughout ones' study can help mitigate this problem (Goodman et al., 2013). Within my final sample, all participants responded correctly to all attention-check and manipulation-check questions, providing some confidence that participants included in the final sample attended to the materials and instructions.

Another important limitation of this study was that the complainant and defendant depicted were not representative of the diversity of all sexual assault cases. For the scope of this thesis, I only examined male complainant-female defendant and female complainant-male defendant conditions. As a result, my findings may not be generalizable to how jurors would consider female complainant-female defendant or male complainant-male defendant conditions. 
The form of the sexual assault was described as either oral sex onto the complainant or vaginal intercourse, which is not reflective of the full range of sexual forms that could be present in a sexual assault. Despite this limitation, this study provides, for the first time, an examination of how the form of sexual assault and gender of the complainant and defendant influence mock jurors' prototypes and decisions in sexual assault cases. This study therefore provides a first step for future research to replicate and extend this analysis with the inclusion of other gender combinations and other forms of sexual assault to allow for a more comprehensive understanding of the diversity of sexual assault cases.

An additional limitation may be present within the IRMA, MRMA and the three questions I created to gauge participants' acceptance of the "only vaginal intercourse equates a sexual assault" rape myth. These questions were an explicit measure of participants' attitudes. Due to issues with response bias and social desirability (Furnham, 1986), participants may not have answered truthfully but instead wanted to appear favourably to the researcher. Although online surveys may reduce social desirability (Booth-Kewley et al., 1992), future researchers investigating the role of rape myths and forced oral sex on jurors' decisions should consider creating an implicit measure to understand the role of these attitudes on jurors' decisions.

It is important to note that the use of the names "Lauren" and "Jim" may have led participants to assume that the characters in the vignette were white. Complainant/defendant race was not within the scope of this thesis, although it is known to have a role in juror decisions (e.g., Mitchell et al., 2005). Future studies should focus on the intersection of different identity statuses, such as gender, sexual orientation, race, class, cultural background, religious beliefs, ability, and age, to capture more thoroughly the complex factors that may contribute to how jurors perceive the prototypicality of a sexual assault situation and their decisions. 
My study gauged participants' rape myth acceptance levels and their role on the predicted relationships. However, other scales exist that have been known to play a role in jurors' decisions in sexual assault cases, and future studies should replicate this study with the inclusion of those scales to see if results would differ. For instance, the Ambivalent Sexism Scale (Glick \& Fiske, 1999) predicts ambivalent attitudes toward women. Previous research has identified that the higher mock jurors score on the Ambivalent Sexism Scale, the more positively they view the male sexual assault defendant (Abrams et al., 2003; Viki et al., 2004). An additional scale of interest would be the Need for Cognition scale (Cacioppo \& Petty, 1982). This scale measures individuals' intrinsic motivation for, and enjoyment of, effortful cognitive activities (Cacioppo \& Petty, 1982). As prototype research suggests that prototypes are employed to reach quick, effortless decisions (Rosch \& Brooks, 1978), it remains an empirical question if jurors who enjoy cognitive activities (as measured by the Need for Cognition scale; Cacioppo \& Petty, 1982) would be less likely to rely on prototypes to reach their decisions, compared to jurors with lower enjoyment of cognitive activities.

Finally, the present study did not examine whether mock jurors' severity assessments were a function of complainant/defendant gender, as this was outside the current project's scope. As such, future studies should explore if juror's severity rating of a sexual assault case differs depending on the complainant/defendant's gender.

\section{Conclusion}

The current study was the first to explicitly measure mock jurors' perceived prototypicality of a sexual assault case, complainant, and defendant. The present study also serves as a first examination of the impact of the form of sexual assault and complainant gender (tied to defendant gender) on mock jurors' sexual assault prototypes and, in turn, their 
assessments and decisions. This study illustrates the multifaceted role of complainant gender (tied to defendant gender) and prototypicality on judicial decision-making. Findings indicate that form of sexual assault was not significantly predictive of mock jurors' sexual assault prototypes, and in turn, their decisions. Factors that contribute to formulating a prototype, such as media focus about forced oral sex onto male and female complainants, may explain this lack of relationship between this form of sexual assault and mock jurors' sexual assault prototypes. This study contributes to the literature on juror bias in sexual assault cases. It provides evidence to suggests that mock jurors' sexual assault prototypes are one of the mechanisms behind their case-related decisions. Simultaneously, the study demonstrates that for fixed levels of prototypicality, mock jurors perceived the female complainant as more blameworthy and less credible than the male complainant and the male defendant to be more credible and less blameworthy than the female defendant, resulting in fewer guilty verdicts in the female complainant-male defendant condition than in the male complainant-female defendant condition. Collectively, this study contributes to the literature on jurors' decision-making in sexual assault cases and suggests that complainant gender, mock jurors' sexual assault prototypes, complainant/defendant blame and credibility, rape myth acceptance, and severity ratings may be essential considerations in mock juror decision-making.

Jurors are legal gatekeepers; they are trusted to decide if an assault occurred, and they are trusted to understand and apply the law and determine if the law was followed in any given case. They are expected to do this by not being swayed by extra-legal information such as gender or their own prototypes. Yet, the present study provides evidence to suggest that prospective jurors may not be able to set aside their own biases. The recognition of this bias, and the future research extending these results, will help notify our legal system of factors that contribute to the high 
attrition rates sexual assault complainants experience within our justice system once a sexual assault case makes it to court (Bureau of Justice Statistics, 2017). The Canadian Human Rights Act states that all Canadians have the right to equality, fair treatment, and an environment free of discrimination on the basis of sex; these goals must extend and be observed in Canadian courtrooms as well. 


\section{References}

Abbey, A., Clinton, A. M., McAuslan, P., Zawacki, T., \& Buck, P. O. (2002). Alcoholinvolved rapes: Are they more violent? Psychology of Women Quarterly, 26(2), 99109.

Abrams, D., Viki, G. T., Masser, B., \& Bohner, G. (2003). Perceptions of stranger and acquaintance rape: The role of benevolent and hostile sexism in victim blame and rape proclivity. Journal of Personality and Social Psychology, 84(1), 111-125. https://doi.org/10.1037/0022-3514.84.1.111

Anderson, I. (2004). Explaining negative rape victim perception: Homophobia and the male rape victim. Current Research in Social Psychology, 10(4), 43-57.

Anderson, I. (2007). What is a typical rape? Effects of victim and participant gender in female and male rape perceptions. British Journal of Social Psychology, 46(1), 225-245.

Ask, K., \& Landstrom, A. (2017). Investigators' decision making. In Par Granhag (Eds.), Forensic Psychology in Context: Nordic and International Approaches (1st ed., pp. 21- 52). Willan.

Baker, M., Fox, P., \& Wingrove, T. (2016). Crowdsourcing as a forensic psychology research tool. American Journal of Forensic Psychology, 34(1). 37-50.

Bates, E. A., Klement, K. R., Kaye, L. K., \& Pennington, C. R. (2019). The Impact of Gendered Stereotypes on Perceptions of Violence: A Commentary. Sex Roles, 81,3443. https://doi.org/10.1007/s11199-019-01029-9

Barnett, M. D., Sligar, K. B., \& Wang, C. D. C. (2018). Religious Affiliation, Religiosity, Gender, and Rape Myth Acceptance: Feminist Theory and Rape Culture. Journal of Interpersonal Violence, 33(8), 1219 1235. https://doi.org/10.1177/0886260516665110 
Baron, R. M., \& Kenny, D. A. (1986). The moderator-mediator variable distinction in social psychological research: Conceptual, strategic and statistical considerations. Journal of Personality and Social Psychology, 51, 1173-1182.

Basow, S. A., and Minieri, A. (2011). "You owe me": effects of date cost, who pays, participant gender, and rape myth beliefs on perceptions of rape. J. Interpers. Violence 26, 479-497. doi: 10.1177/0886260510363421

Beaumont-Thomas, B. (2018, November 28). Shia LaBeouf: I was raped during performance art project. The Guardian. https:/www.theguardian.com/film/2018/nov/28/shialabeouf-raped-performance-art-project-dazed.

Bedera, N., \& Nordmeyer, K. (2015). "Never Go Out Alone”: An Analysis of College Rape Prevention Tips. Sexuality \& Culture, 19(3), 533-542. https://doi.org/10.1007/s12119015-9274-5

Bill C-127, Act to amend the Criminal Code in relation to sexual offences and other offences against the person and to amend certain other Acts in relation thereto or in consequence thereof, S.C. 1980-81-82-83, c. 125.

Blais, J., Pruysers, S., \& Dunham., M.D. (2020) Personality and political identification: An examination of the HEXACO and dark triad. [Unpublished manuscript]. Carleton University.

Blank, H., Musch, J., \& Pohl, R. F. (2007). Hindsight Bias: On Being Wise After the Event. Social Cognition, 25(1), 1-9. https://doi.org/10.1521/soco.2007.25.1.1

Borah, R., \& Nandi, S. (2012). Reclaiming the Feminist Politics of 'SlutWalk.' International Feminist Journal of Politics, 14(3), 415-421.

https://doi.org/10.1080/14616742.2012.699776 
Bornstein, B. H. (1999). The ecological validity of jury simulations: Is the jury still out? Law and Human Behavior, 23(1), 75.

Bornstein, B. H., Golding, J. M., Neuschatz, J., Kimbrough, C., Reed, K., Magyarics, C., \& Luecht, K. (2017). Mock juror sampling issues in jury simulation research: A metaanalysis. Law and Human Behavior, 41(1), 13-28. doi: 10.1037/lhb0000223

Bornstein, B. H., Kaplan, D. L., \& Perry, A. R. (2007). Child abuse in the eyes of the beholder: Lay perceptions of child sexual and physical abuse. Child Abuse \& Neglect, 31(4), 375-391. https://doi.org/10.1016/j.chiabu.2006.09.007

Bornstein, B. H., \& McCabe, S. G. (2005). Jurors of the absurd? The role of consequentiality in jury simulation research. Florida State University Law Review, 32(2), 443-467. doi: 10.1037/lhb0000223

Booth-Kewley, S., Edwards, J., \& Rosenfeld, P. (1992). Impression management, social desirability, and computer administration of attitude questionnaires: Does the computer make a difference? Journal of Applied Psychology, 77(4), 562-566. https://doi.org/10.1037/0021-9010.77.4.562

Bowers, W. J., \& Pierce, G. L. (1978). Arbitrariness and discrimination under post- Furman capital statutes. Crime \& Delinquency, 26(4), 563-632.

Brooks, J. A., Stolier, R. M., \& Freeman, J. B. (2018). Stereotypes bias Visual prototypes for sex and emotion categories. Social Cognition, 36(5), 481-493. https://doi.org/10.1521/soco.2018.36.5.481

Brooks, L. R., \& Rosch, E. (1978). Nonanalytic cognition: Memory, perception, and concept learning. In G.Y. Bower (Eds.), Psychology of Learning and Motivation (Vol. 18, pp.1- 47). Academic Press. https://doi.org/https://doi.org/10.1016/S0079 
7421(08)60358-8

Brown, A. L., Testa, M., \& Messman-Moore, T. L. (2009). Psychological consequences of sexual victimization resulting from force, incapacitation, or verbal coercion. Violence Against Women, 15(8), 898-919. https://doi.org/10.1177/1077801209335491

Burt, M. R. (1980). Cultural myths and supports for rape. Journal of Personality and Social Psychology, 38(2), 217-230. https://doi.org/10.1037/0022-3514.38.2.217

Burt, D. L., \& DeMello, L. R. (2002). Attribution of rape blame as a function of victim gender and sexuality, and perceived similarity to the victim. Journal of Homosexuality, 43(2), 39-57. https://doi.org/10.1300/j082v43n02_03

Cacioppo, J. T., \& Petty, R. E. (1982). The need for cognition. Journal of Personality and Social Psychology, 42(1), 116-131. https://doi.org/10.1037/0022-3514.42.1.116

Caleo, S. (2016). Are organizational justice rules gendered? Reactions to men's and women's justice violations. Journal of Applied Psychology, 101(10), 1422-1435. https://doi.org/10.1037/ap10000131

Canadian Centre for Justice Statistics. (1994). Criminal justice processing of sexual assault cases. Ottawa, Canada: Statistics Canada.

Canadian Charter of Rights and Freedoms, s 7, Part 1 of the Constitution Act, 1982, being Schedule B to the Canada Act 1982 (UK), 1982, c 11.

Carli, L. L. (1999). Cognitive Reconstruction, Hindsight, and Reactions to Victims and Perpetrators. Personality and Social Psychology Bulletin, 25(8), 966979. https://doi.org/10.1177/01461672992511005 
Carlson, K. A., \& Russo, J. E. (2001). Biased interpretation of evidence by mock jurors. Journal of Experimental Psychology: Applied, 7(2), 91-103. https://doi.org/10.1037/1076-898X.7.2.91

Carlsson, R., \& Sinclair, S. (2017). Prototypes and same-gender bias in perceptions of hiring discrimination. The Journal of Social Psychology, 158(3), 285-297. https://doi.org/10.1080/00224545.2017.1341374

Casavant, L., Charron-Tousignant, M., MacKay, R., Nicol, J., \& Shaw, E. (2018). Research publications. Retrieved from: https://lop.parl.ca/sites/PublicWebsite/default/en_CA/ResearchPublications/Legislative Summaries/421C51E

Casper, J. D., Benedict, K., \& Perry, J. L. (1989). Juror decision making, attitudes, and the hindsight bias. Law and Human Behavior, 13(3), 291-310. https://doi.org/10.1007/BF01067031

Chapleau, K. M., \& Oswald, D. L. (2010). Power, sex and rape myth acceptance: Testing two models of rape proclivity. The Journal of Sex Research, 47, 66-78.

Chapleau, K. M., Oswald, D. L., \& Russell, B. L. (2008). Male rape myths: The role of gender, violence, and sexism. Journal of Interpersonal Violence, 23(5), 600-615. https://doi.org/10.1177/0886260507313529

Chambers, W. C. (2007). Oral sex: Varied behaviors and perceptions in a college population. Journal of Sex Research, 44(1), 28-42. https://doi.org/10.1207/s15598519jsr4401_4 Cherniawsky, S., \& Morrison, M. (2020). "You Should Have Known Better": The Social Ramifications of Victimization-Focused Sexual Assault Prevention Tips. Journal of 
interpersonal violence, 886260520913650 . Advance online publication.

https://doi.org/10.1177/0886260520913650

Cislaghi, B., \& Heise, L. (2019). Gender norms and social norms: Differences, similarities and why they matter in prevention science. Sociology of Health and Illness, 42(2), 407422. https://doi.org/10.1111/1467-9566.13008

Cliff, N., \& Earleywine, M. (1994). All predictors are "mediators" unless the other predictor is a "suppressor." Unpublished manuscript.

Connell, R., \& Pearse, R. (2014). Gender norms and the economy: Insights from social research. Feminist Economics, 22(1), 30-53. https://doi.org/10.1080/13545701.2015.1078485

Conroy, S., \& Cotter, A. (2017). Self-reported sexual assault in Canada. Juristat: Canadian Centre for Justice Statistics https://www150.statcan.gc.ca/n1/en/pub/85-002 x/2017001/article/14842-eng.pdf?st=GYOSmUJW

Cossins A. (2020) Factors That Predict Outcomes in Sexual Assault Trials. In: Closing the Justice Gap for Adult and Child Sexual Assault. Palgrave Macmillan, London. https://doi.org/10.1057/978-1-137-32051-3_3

Craig, E. (2018). Putting trials on trial: sexual assault and the failure of the legal profession. McGill-Queens University Press.

Criminal Code - R.S.C., 1985, c. C-46 (Section 606)

Daly, K. (2006). Restorative justice and sexual assault: An archival study of court and conference cases. British Journal of Criminology, 46(2), 334-356. https://doi.org/10.1093/bjc/azi071 
Danube, C. L., Vescio, T. K., \& Davis, K. C. (2014). Male role norm endorsement and sexism predict heterosexual college men's attitudes toward casual sex, intoxicated sexual contact, and casual sex. Sex Roles, 71, 219-232. https://doi.org/10.1007/s11199-0140394-4

Davies, M., \& Boden, S. J. (2012). Examining the sexual preference effect in depicted male sexual assault. Journal of Aggression, Conflict and Peace Research, 4(3), 136-143. https://doi.org/10.1108/17596591211244148

Davies, M., Gilston, J., \& Rogers, P. (2012). Examining the relationship between male rape myth acceptance, female rape myth acceptance, victim blame, homophobia, gender roles, and ambivalent sexism. Journal of Interpersonal Violence, 27(14), 2801-2823. https://doi.org/10.1177/0886260512438281

Davies, M., \& Hudson, J. (2011). Judgments toward male and transgendered victims in a depicted stranger rape. Journal of Homosexuality, 58(2), 237-247. https://doi.org/10.1080/00918369.2011.540179

Davies, M., \& Mccartney, S. (2003). Effects of gender and sexuality on judgements of victim blame and rape myth acceptance in a depicted male rape. Journal of Community and Applied Social Psychology, 13(5), 391-398. https://doi.org/10.1002/casp.741

Davies, M., Pollard, P., \& Archer, J. (2001). The influence of victim gender and sexual orientation on judgments of the victim in a depicted stranger rape. Violence and Victims, 16(6), 607-619.

Davies, M., \& Rogers, P. (2006). Perceptions of male victims in depicted sexual assaults: A review of the literature. Aggression and Violent Behavior, 11(4), 367-377. https://doi.org/https://doi.org/10.1016/j.avb.2006.01.002 
DeGue, S., Valle, L. A., Holt, M. K., Massetti, G. M., Matjasko, J. L., \& Tharp, A. T. (2014). A systematic review of primary prevention strategies for sexual violence perpetration. Aggression and Violent Behavior, 19(4), 346-362.

DeJong, C., Morgan, S. J., \& Cox, A. (2020). Male rape in context: measures of intolerance and support for male rape myths (MRMA). Criminal Justice Studies, 33(3), 195-212. https://doi.org/10.1080/1478601X.2020.1786278

Department of Justice. (2017). What we heard - Transforming Canada's criminal justice system. Retrieved from https://www.justice.gc.ca/eng/rp-pr/other-autre/tcjsDepartment of Justice (2019). The Impact of Trauma on Adult Sexual Assault Victims. https://www.justice.gc.ca/eng/rp-pr/jr/trauma/trauma_eng.pdf

DeSantis, A (2020). This Is Not Your Parents' Greek Life: Prototypes in the Ongoing Evolution of Fraternities and Sororities. Rapid Prototypying Journal. 14(1).

Devine, D. J. (2012). Jury decision making: The state of the science. New York, NY: NY Press.

Devine, D. J., \& Caughlin, D. E. (2014). Do they matter? A meta-analytic investigation of individual characteristics and guilt judgments. Psychology, Public Policy, and Law, 20(2), 109-134

Dowler, K., Fleming, T., \& Muzzatti, S. L. (2006). Constructing Crime: Media, Crime, and Popular Culture. Canadian Journal of Criminology and Criminal Justice, 48(6), 837850. https://doi.org/10.3138/cjecj.48.6.837

Duke, L. M., \& Desforges, D. M. (2007). Mock juror decision-making in sexual abuse cases. Applied Psychology in Criminal Justice, 3(2), 96-116. 
Dufraimont, L. (2019). The problem of the jury in sexual assault trials. Queen's Law Journal, 44(2). https://doi.org/10.5040/9781472564320.ch-003

Du Mont, J., Miller, K.-L., \& Myhr, T. L. (2003). The role of "real rape" and "real victim" stereotypes in the police reporting practices of sexually assaulted women. Violence Against Women, 9(4), 466-486. https://doi.org/10.1177/1077801202250960

EGALE Canada Human Rights Trust. (2011). Queering the Sustainable Development Goals in Canada Not Leaving LGBTQI2S Communities Behind. Egale Canada Human Rights Trust. https://egale.ca/wp-content/uploads/2017/10/SDG-eng-1.pdf.

Ellison, S. (2018, April 25). Matt Lauer accused of raping a former colleague in Ronan Farrow's new book. The Washington Post. https://www.washingtonpost.com/artsentertainment/2019/10/09/matt-lauer-accused-raping-former-colleague-ronan-farrowsnew-book/.

Ellison, L., \& Munro, V. E. (2010). A stranger in the bushes, or an elephant in the room? Critical reflections upon received rape myth wisdom in the context of a mock jury study. New Criminal Law Review, 13(4), 781-801. https://doi.org/10.1525/nclr.2010.13.4.781

Ellison, L., \& Munro, V. E. (2009). Reacting to rape: Exploring mock jurors' assessments of complainant credibility. The British Journal of Criminology, 49(2), 202-219. https://doi.org/10.1093/bjc/azn077

Esposito, C., Di Napoli, I., Esposito, C., Carnevale, S., \& Arcidiacono, C. (2020). Violence Against Women: A Not in My Back Yard (NIMBY) Phenomenon. Violence and Gender, 7(4), 150-157. https://doi.org/10.1089/vio.2019.0067

Estrich, S. (1987). Real rape. Cambridge, MA: Harvard University Press. 
Faul, F., Erdfelder, E., Lang, A. G., \& Buchner, A. (2007). G*Power 3: A flexible statistical power analysis program for the social, behavioral, and biomedical sciences. Behavior Research Methods. https://doi.org/10.3758/BF03193146

Ferrone, C. J. (2018). The role of schema congruence in mock jurors' judgments of sexual assault cases (Unpublished master's thesis). Appalachian State University.

Finch, E., \& Munro, V. E. (2005). Juror stereotypes and blame attribution in rape cases involving intoxicants: The findings of a pilot study. The British Journal of Criminology, 45(1), 25-38. https://doi.org/10.1093/bjc/azh055

Fischhoff, B. (1975). Hindsight is not equal to foresight: The effect of outcome knowledge on judgment under uncertainty. Journal of Experimental Psychology: Human Perception and Performance, 1(3), 288-299. https://doi.org/10.1037/0096-1523.1.3.288

Fisher, N. L., Pina, A. (2013). An overview of the literature on female-perpetrated adult male sexual victimization. Aggression and Violent Behavior, 18, 54-61

Foti, R. J., \& Lord, R. G. (1987). Prototypes and scripts: The effects of alternative methods of processing information on rating accuracy. Organizational Behavior and Human Decision Processes, 39(3), 318-340

Frese, B., Moya, M., \& Megías, J. L. (2004). Social perception of rape: how rape myth acceptance modulates the influence of situational factors. Journal of interpersonal violence, 19(2), 143-161.

Furnham, A. (1986). Response bias, social desirability and dissimulation. Personality and Individual Differences, 7(3), 385-400. https://doi.org/https://doi.org/10.1016/01918869(86)90014-0

Geeraerts, D. (2008). Prototypes, stereotypes, and semantic norms. In G. Kristiansen \& R. 
Dirven (Eds.), Cognitive Sociolinguistics (pp. 21-44). De Gruyter Mouton. https://doi.org/doi:10.1515/9783110199154.1.21

George, S., \& Spohn, C. (2019). Liberating discretion: The effect of rape myth factors on prosecutors' decisions to charge suspects in penetrative and non-penetrative sex offenses. Justice Quarterly, 35(7), 1280-1308. https://doi.org/10.1080/07418825.2018.1529251

Gerger, H., Kley, H., Bohner, G., \& Siebler, F. (2007). The acceptance of modern myths about sexual aggression scale: Development and validation in German and English. Aggressive Behavior, 33(5), 422-440. https://doi.org/10.1002/ab.20195

Gerber, E., \& Carroll, M. (2012). The psychological experience of prototyping. Design Studies, 33(1), 64-84. https://doi.org/10.1016/j.destud.2011.06.005

Glick, P., \& Fiske, S. T. (1996). The Ambivalent Sexism Inventory: Differentiating hostile and benevolent sexism. Journal of Personality and Social Psychology, 70(3), 491512. https://doi.org/10.1037/0022-3514.70.3.491

Goodman, J.K., Cryder, C.E. and Cheema, A. (2013), Data Collection in a Flat World: The Strengths and Weaknesses of Mechanical Turk Samples. J. Behav. Dec. Making, 26: 213-224. https://doi.org/10.1002/bdm.1753

Gollom, M. (2016, March 25). Jian Ghomeshi to take time to 'reflect and move forward' following acquittal $\mid$ CBC News. CBCnews. https://www.cbc.ca/news/canada/toronto/jian-ghomeshi-sexual-assault-trial-ruling1.3505446 . 
Gotell, L. (2012). The ideal victim, the hysterical complainant, and the disclosure of confidential records: The implications of the charter for sexual assault law. Osgoode Hall Law Journal.

Government of Canada, S. C. (2019, August 9). Census Profile, 2016 Census Canada. /https://www12.statcan.gc.ca/census-recensement/2016/dp $\mathrm{pd} /$ prof/details/page.cfm?Lang $=\mathrm{E} \& \mathrm{Geo} 1=\mathrm{PR} \&$ Code $1=01 \& \mathrm{Geo} 2=\&$ Code $2=\&$ SearchT ext $=$ Canada\&SearchType $=$ Begins $\&$ SearchPR $=01 \& B 1=$ All\&TABID=1\&type $=0$.

Government of Canada, D. of J. (2020, January 7). Bill C-46: Records Applications PostMills, A Caselaw Review. 3. Statistics on Sexual Assault (cont'd) - Bill C-46: Records Applications Post-Mills, A Caselaw Review. https://www.justice.gc.ca/eng/rp-pr/csjsjc/ccs-ajc/rr06_vic2/p3_4.html.

Government of Canada, S. C. (2020). Uniform Crime Reporting Survey-Selected police reported crime statistics - Special COVID-19 report to Statistics Canada

Graham, R. (2006). Male Rape and the Careful Construction of the Male Victim. Social \& Legal Studies, 15(2), 187-208. https://doi.org/10.1177/0964663906063571

Gravelin, C. R., Biernat, M., \& Bucher, C. E. (2018). Blaming the victim of acquaintance rape: Individual, situational, and sociocultural factors. Frontiers in Psychology, 9, 2422. https://doi.org/10.3389/fpsyg.2018.02422

Green, S. P. (2000). Prototype Theory and the classification of offenses in a revised model penal code: A general approach to the special part. Buffalo Criminal Law Review, 4(1),301-339. https://doi.org/10.1525/nclr.2000.4.1.301

Green, S. P. (2004, April 24). Cognitive prototypes and narrative thinking [Conference session]. Collaborative European Research Conference 2012, Germany, Europe. 
Greene, E., \& Ellis, L. (2008). Decision-making in Criminal Justice. In D. Carson, B. Milne, F. Pakes, K. Shalev, \& A. Shawyer (Eds.), Applying Psychology to Criminal Justice (pp.183-200). Chichester: Wiley. doi:10.1002/9780470713068.ch11

Grubb, A., \& Harrower, J. (2008). Attribution of blame in cases of rape: An analysis of participant gender, type of rape and perceived similarity to the victim. Aggression and Violent Behavior, 13(5), 396-405. https://doi.org/10.1016/j.avb.2008.06.006

Hans, V. P. (2013). Canadian Jury Research. Canadian Journal of Criminology and Criminal Justice, 55(4), 533-548. https://doi.org/10.3138/cjccj.2012.ES07

Harley, E. M. (2007). Hindsight bias in legal decision-making. Social Cognition, 25, 48-63.

Harrison, L. A., Howerton, D. M., Secarea, A. M., \& Nguyen, C. Q. (2008). Effects of ingroup bias and gender role violations on acquaintance rape attributions. Sex Roles, 59(9), 713- 725. https://doi.org/10.1007/s11199-008-9472-9

Haskell, L., \& Randall. (2019). The Impact of Trauma on Adult Sexual Assault Victims. https://www.justice.gc.ca/eng/rp-pr/jr/trauma/trauma_eng.pdf.

Hastie, R., \& Pennington, N. (1991). Cognitive and social processes in decision-making. In L. B. Resnick, J. M. Levine, \& S. D. Teasley (Eds.), Perspectives on socially shared cognition (p.308-327). American Psychological Association. https://doi.org/10.1037/10096-013

Hauser, D. J., Ellsworth, P. C., \& Gonzalez, R. (2018). Are Manipulation Checks Necessary? Frontiers in Psychology, 9, 998. https://doi.org/10.3389/fpsyg.2018.00998

Hayes-Roth, B., \& Hayes-Roth, F. (1977). Concept learning and the recognition and classification of exemplars. Journal of Verbal Learning and Verbal Behavior, 16(3), 321- 338. https://doi.org/10.1016/S0022-5371(77)80054-6 
Heller, K. J. (2006). The Cognitive Psychology of Circumstantial Evidence. Michigan Law Review, 105(5), 241-305.

Henry, A., Perillo, A., Reitz-Krueger, C., \& Perillo, J. T. (2020). Reflecting the Times?

Reexamining the Effect of Alcohol Intoxication on Perceptions of Campus Sexual Assault. https://doi.org/10.31234/osf.io/2k3wh

Horvath, M., \& Brown, J. (Eds.). (2009). Rape: Challenging Contemporary Thinking (1st ed.). Willan. https://doi.org/10.4324/9781843927129

Ibrahim, D. (2019, March 20). Police-reported violence among same-sex intimate partners in Canada, 2009 to 2017. Statistics Canada: Canada's national statistical agency / Statistique Canada : Organisme statistique national du Canada. https://www150.statcan.gc.ca/n1/pub/85-002-x/2019001/article/00005-eng.htm.

Jacobs, S. (2020, March 12). Harvey Weinstein sentenced to 23 years in prison for sexually assaulting two women in New York. The Washington Post. https://www.washingtonpost.com/lifestyle/harvey-weinstein-sentence-trial-sexual assault/2020/03/11/398f2cf6-630b-11ea-acca-80c22bbee96f_story.html.

Jaffray, B. (2020). Experiences of violent victimization and unwanted sexual behaviours among gay, lesbian, bisexual and other sexual minority people, and the transgender population, in Canada, 2018. Juristat: Canadian Centre for Justice Statistics.https://proxy.library.carleton.ca/login?url=https:// www.proquest.com/schola rly- journals/experiences-violent-victimization-unwanted sexual/docview/2443867303/se- 2?accountid $=9894$ 
Javaid, A. (2017). The unknown victims: Hegemonic masculinity, masculinities, and male sexual victimisation. Sociological Research Online, 22(1), 28-47. https://doi.org/10.5153/sro.4155

Jeudy, L. (2021, July 6). Canada - median age of population by province 2020. Statista. https://www.statista.com/statistics/444816/canada-median-age-of-resident-populationby-province/.

Johnson, H. (2012). Limits of a criminal justice response: Trends in police and court processing of sexual assault. In Sheehy, E. A. (Ed.), Sexual assault in Canada: Law, legal practice and women's activism. Les Presses de l'Université d'Ottawa| University of Ottawa Press. Retrieved from http://books.openedition.org/uop/592

Kachel, S., Steffens MC., \& Niedlich C. (2016). Traditional masculinity and femininity: Validation of a new scale assessing gender roles. Front. Psychol, 7 :956. doi: 10.3389/fpsyg.2016.00956

Kannanayakal, T. (2020, October 28). The Role of Crown Prosecutors in our Criminal Justice.LawNow Magazine. https://www.lawnow.org/the-role-of-crown-prosecutors-inour- criminal-justice-system/.

Kantor, J., \& Twohey, M. (2017, October 5). Harvey Weinstein Paid Off Sexual Harassment Accusers for Decades. The New York Times. https://www.nytimes.com/2017/10/05/us/harvey-weinstein-harassmentallegations.html.

Kaplan, M. F., \& Miller, C. E. (1987). Group decision-making and normative versus informational influence: Effects of type of issue and assigned decision rule. Journal of 
Personality and Social Psychology, 53(2), 306-313. https://doi.org/10.1037/00223514.53.2.306

Kessler, A. M., Kennair, L. E. O., Grøntvedt, T. V., Bjørkheim, I., Drejer, I., \& Bendixen, M. (2020). The effect of prototypical \#MeToo features on the perception of social-sexual behavior as sexual harassment. Sexuality and Culture, 25(5), 12271-1291. https://doi.org/10.1007/s12119-019-09675-7

Klement, K. R., Sagarin, B. J., \& Skowronski, J. J. (2019). Accusers lie and other myths: Rape myth acceptance predicts judgments made about accusers and accused perpetrators in a rape case. Sex Roles: A Journal of Research, 81(1-2), 16-33. https://doi.org/10.1007/s11199-018-0950-4

Kline, R. B. (2005). How to Fool Yourself with SEM. In Principles and practice of structural equation modeling (1st ed., Vol. 81, pp. 560-780). essay, The Guilford Press.

Klippenstine, M. A., \& Schuller, R. (2012). Perceptions of sexual assault: expectancies regarding the emotional response of a rape victim over time. Psychology, Crime \& Law, 18(1), 79- 94, DOI: 10.1080/1068316X.2011.589389

Knoop., J., \& Maeder, E. (2019). Compounding Prejudice? Investigating Canadian Mock Juror Perceptions of Victim Race and Work in the Sex Trade. (Unpublished master's thesis). Carleton University.

Koehler, Jonathan (2006). Train our jurors. Faculty Working Papers. Paper 141. http://scholarlycommons.law.northwestern.edu/facultyworkingpapers/141

Koenig, A. M. (2018). Comparing prescriptive and descriptive gender stereotypes about children, adults, and the elderly. Frontiers in Psychology, 9, 1086. https://doi.org/10.3389/fpsyg.2018.01086 
Krahé, B., Temkin, J., Bieneck, S. (2007). Schema-driven information processing in judgements about rape. Applied Cognitive Psychology, 21, 601-619. doi:10.1002/acp.1297

Kurinec, C., \& Weaver, C. (2018). Do Memory-Focused Jury Instructions Moderate the Influence of Eyewitness Word Choice? Applied Psychology in Criminal Justice, 14(1), 55-66

Laub, C., \& Bornstein, B. H. (2008). Juries and Eyewitnesses. Encyclopedia of Psychology and Law, Faculty Publications, Department of Psychology. https://doi.org/10.4135/9781412959537.n153

Lawrence, S. (2010). Reflections: on judicial diversity and judicial independence, in A. Dodek \& L. Sossin (Eds) Judicial Independence in Context (pp. 193-217). Irwin Law.

Lindsey, L. (2016). Gender development the socialization process. In L. Lindsey (Eds) Gender Roles (6th ed., pp. 64-96). Routledge.

Lieberman, J. D., Krauss, D. A., Heen, M., \& Sakiyama, M. (2016). The good, the bad, and the ugly: Professional perceptions of jury decision-making research practices. Behavioral Sciences and the Law, 34(4), 495-514. https://doi.org/10.1002/bs1.2246

Lefkowitz, E. S., Shearer, C. L., Gillen, M. M., \& Espinosa-Hernandez, G. (2014). How gendered attitudes relate to women's and men's sexual behaviors and beliefs. Sexuality \& Culture, 18(4), 833-846. https://doi.org/10.1007/s12119-014-9225-6

Lefkowitz, E. S., Vasilenko, S. A., \& Leavitt, C. E. (2016). Oral vs. vaginal sex experiences and consequences among first-year college students. Archives of Sexual Behavior, 45(2), 329-337. https://doi.org/10.1007/s10508-015-0654-6 
Leverick, F. (2020). What do we know about rape myths and juror decision-making? The International Journal of Evidence \& Proof, 24(3), 255-279. https://doi.org/10.1177/1365712720923157

Levin, A. \& Alkoby, A. (2017) Shouldn't the bench be a mirror? The diversity of the Canadian Judiciary. Oñati Socio-legal Series [online], 7(4), pp. 1-35. Available at: http://ssrn.com/ abstract=3034201

Little, W. (2016). Introduction to Sociology: 2nd Canadian Edition. Victoria, BC: Bccampus.https://opentextbc.ca/introductiontosociology2ndedition/

Lonsway, K.A., \& Fitzgerald, L.F. (1999). Rape myths: In review. Psychology of Women Quarterly, 18, 133-164.

Lord, R. G., \& Foti, R. J. (1986). Schema theories, information processing and organizational behavior. In H. P. Sims, Jr., \& D. A. Gioia (Eds.), Social cognition in organizations.

Lord, C. G., Lepper, M. R., \& Mackie, D. (1984). Attitude prototypes as determinants of attitude-behavior consistency. Journal of Personality and Social Psychology, 46(6), 1254-1266. https://doi.org/10.1037/0022-3514.46.6.1254

MacKinnon, D. P., Krull, J. L., \& Lockwood, C. M. (2000). Equivalence of the mediation, confounding and suppression effect. Prevention science: the official journal of the Society for Prevention Research, 1(4), 173-181. https://doi.org/10.1023/a:1026595011371

MacKinnon, D. P., Fairchild, A. J., \& Fritz, M. S. (2007). Mediation Analysis. Annual Review of Psychology, 58(1), 593-614. https://doi.org/10.1146/annurev.psych.58.110405.085542 
Mann, O. (2018). (Bi)Sexuality and victim blame: How observer sexuality affects attributions of blame in a case of acquaintance sexual assault with a heterosexual female victim. [Unpublished master's thesis]. University of South Dakota.

Masser, B., Lee, K., \& Mckimmie, B. M. (2010). Bad woman, bad victim? Disentangling the effects of victim stereotypicality, gender stereotypicality and benevolent sexism on acquaintance rape victim blame. Sex Roles, 62(7-8), 494-504. doi:

10.1007/s11199- 009-9648-y

Mastro, D. E., \& Kopacz, M. A. (2010). Media Representations of Race, Prototypicality, and Policy Reasoning: An Application of Self-Categorization Theory. Journal of Broadcasting \& Electronic Media, 50(2), 305-322. https://doi.org/10.1207/s15506878jobem5002_8

Marx, B. P., Forsyth, J. P., Gallup, G. G., Fusé, T., \& Lexington, J. M. (2008). Tonic immobility as an evolved predator defense: Implications for sexual assault survivors. Clinical Psychology: Science and Practice, 15(1), 74-90. https://doi.org/10.1111/j.1468- 2850.2008.00112.x

Mccolgan, A. (1996). Common law and the relevance of sexual history evidence. Oxford Journal of Legal Studies, 16(2), 275-308. https://doi.org/10.1093/ojls/16.2.275

McCreary, D.R. (1994). The male role and avoiding femininity. Sex Roles, 31, 517-531 https://doi.org/10.1007/BF01544277

McKimmie, B. M., Masser, B. M., \& Bongiorno, R. (2014). What counts as rape? The effect of offense prototypes, victim stereotypes, and participant gender on how the complainant and defendant are perceived. Journal of Interpersonal Violence, 29(12), 2273-2303. https://doi.org/10.1177/0886260513518843 
McGlynn, C. (2017). Rape trials and sexual history evidence: Reforming the law on thirdparty evidence. The Journal of Criminal Law, 81(5), 367-392. https://doi.org/10.1177/0022018317728824

McMahon, S., \& Farmer, G. L. (2011). An Updated Measure for Assessing Subtle Rape Myths. Social Work Research, 35(2), 71-81. https://doi.org/10.1093/swr/35.2.71 me too. Movement. (2021, April 14). https://metoomvmt.org/.

Mirmirani P. (2020). It's time to stop calling our office staff "the girls". International journal of women's dermatology, 6(4), 346-347. https://doi.org/10.1016/j.ijwd.2020.04.003

Mitchell, T. L., Haw, R. M., Pfeifer, J. E., \& Meissner, C. A. (2005). Racial Bias in Mock Juror Decision-Making: A Meta-Analytic Review of Defendant Treatment. Law and Human Behavior, 29(6), 621-637. https://doi.org/10.1007/s10979-005-8122-9

Monson, C. M., Langhinrichsen-Rohling, J., \& Binderup, T. (2000). Does "no" really mean "no" after you say "yes"?: Attributions about date and marital rape. Journal of Interpersonal Violence, 15(11), 1156-1174. https://doi.org/10.1177/088626000015011003

Morabito, M. S., Pattavina, A., \& Williams, L. M. (2019). It all just piles up: Challenges to victim credibility accumulate to influence sexual assault case processing. Journal of Interpersonal Violence, 34(15), 3151-3170. https://doi.org/10.1177/0886260516669164

Morgan , R., \& Oudekerk, B. (2018). Criminal Victimization, 2018. Office of Justice Programs. https://www.ojp.gov/library/publications/criminal-victimization-2018. 
Mossière, A., \& Dalby, J. T. (2018). The Influence of Gender and Age in Mock Juror Decision-Making. Europe's Journal of Psychology, 4(4).https://doi.org/10.5964/ejop.v4i4.440

Muth'en, L. K., \& Muth'en, B. O. (2010). Mplus user's guide (6th ed.) Los Angeles, CA: Muth'en \& Muth'en.

National Judicial Institute. (2014). Model jury instructions. Retrieved from nji-inm.ca

National Sexual Violence Resource Center. (2015). Statistics about sexual violence. https://www.nsvrc.org/sites/default/files/publications_nsvrc_factsheet_mediapacket_statistics-about-sexual-violence_0.pdf.

Nicholls, T. (2021). And they all lived better than before . . Culture-jamming our way to a better world. In Dismantling rape culture: the peacebuilding power of 'Me too' (1st ed., pp. 175-200). essay, Routledge.

Nunez, N., McCrea, S. M., \& Culhane, S. E. (2011). Jury decision-making research: Are researchers focusing on the mouse and not the elephant in the room? Behavioral Sciences and the Law. 29, 439-451. doi: 10.1002/bs1.967

OBA/OJEN Mock Trials competition's $R$. v. Delany, 2019 case. Retrieved from: http://ojen.ca/wp-content/uploads/2019/01/R-v-Delaney-OOCMT-Case-2019FINAL- VERSION-Jan-15-2019.pdf

Pack, L. (2019). Rape myth effects on juror decisions in deliberations of rape Cases: How rape myths affect jury deliberations. Critique: a Worldwide Student Journal of Politics.

Parkinson, H. J. (2015, July 8). Stop calling women 'girls'. It's either patronising or sexually suggestive. The Guardian. 
https://www.theguardian.com/commentisfree/2015/jul/08/stop-calling-women-girlsits-either-patronising-or-sexually-suggestive.

Payne, D. L., Lonsway, K. A., \& Fitzgerald, L. F. (1999). Rape Myth Acceptance: Exploration of Its Structure and Its Measurement Using the Illinois Rape Myth Acceptance Scale. Journal of Research in Personality, 33(1), 27-68. https://doi.org/10.1006/jrpe.1998.2238

Pennington, D. C. (1981). Being wise after the event: an investigation of hindsight bias. Current Psychology, 1(3-4), 271-282. https://doi.org/10.1007/bf03186737

Pennington, N., \& Hastie, R. (1992). Explaining the evidence: Tests of the story model for juror decision-making. Journal of Personality and Social Psychology, 62(2), 189-206. https://doi.org/10.1037/0022-3514.62.2.189

Persson, S., Dhingra, K., \& Grogan, S. (2018). Attributions of victim blame in stranger and acquaintance rape: A quantitative study. Journal of Clinical Nursing, 27(13-14), 26402649. https://doi.org/10.1111/jocn.14351

Petersson, C. C., \& Plantin, L. (2019). Breaking with norms of masculinity: Men making sense of their experience of sexual assault. Clinical Social Work Journal, 47(4), 372383. https://doi.org/10.1007/s10615-019-00699-y

Pezdek, K., Avila-Mora, E., \& Sperry, K. (2010). Does trial presentation medium matter in jury simulation research? Evaluating the effectiveness of eyewitness expert testimony. Applied cognitive psychology, 24(5), 673-690

Pica, E., Sheahan, C. L., \& Pozzulo, J. (2018). Mock jurors' perceptions of sexual assault on a university campus. Journal of Interpersonal Violence. Advance online publication. https://doi.org/10.1177/0886260518800316 
Pickel, K. L., \& Gentry, R. H. (2017). Mock jurors' expectations regarding the psychological harm experienced by rape victims as a function of rape prototypicality. Psychology, Crime \& Law, 23, 254-273.

Posner, M. I., \& Keele, S. W. (1968). On the genesis of abstract ideas. Journal of Experimental Psychology, 77(3), 353-363. https://doi.org/10.1037/h0025953

Purdie-Vaughns, V., \& Eibach, R. P. (2008). Intersectional invisibility: The distinctive advantages and disadvantages of multiple subordinate-group identities. Sex Roles: $A$ Journal of Research, 59(5-6), 377-391. https://doi.org/10.1007/s11199-008 9424-4

r/MenGetRapedToo. reddit. (2013, July). https://www.reddit.com/r/MenGetRapedToo/. r/sex Was this rape? [forced oral sex]. reddit. (2008).

https://www.reddit.com/r/sex/comments/54beq2/was_this_rape_forced_oral_sex/.

R. v. Ewanchuk, 1999 SCC 330

R. v. Find, [2001] 1 S.C.R. 863, 2001 SCC 32

R. v. Seaboyer; R. v. Gayme, [1991] 2 S.C.R. 577

Randall, M. (2010). Sexual assault law, credibility, and ideal victims: Consent, resistance, and victim blaming. Canadian Journal of Women and the Law, 22(2), 398-433. https://doi.org/10.3138/cjwl.22.2.397

Raitt, F. \& Zeedyk , S. ( 1997 ), Rape Trauma Syndrome: Its Corroborative and Educational Roles. Journal of Law and Society, 24, $552-68$

Reed, S. K. (1972). Pattern recognition and categorization. Cognitive Psychology, 3(3), 382407. https://doi.org/https://doi.org/10.1016/0010-0285(72)90014-X

Reed, R. A., Pamlanye, J. T., Truex, H. R., Murphy-Neilson, M. C., Kunaniec, K., P., Newins, A. R., \& Wilson, L. C. (2020). Higher rates of unacknowledged rape among men: The 
role of rape myth acceptance. Psychology of Men \& Masculinities, 21(1), 162-

167. https://doi.org/10.1037/men0000230

Roese, N.J., Fessel, F., Summerville, A., Kruger, J., \& Dilich, M.A. (2006). The Hindsight effect: When jurors' hindsight trumps foresight. Psycholgical Science, 17, 305-310

Rhemtulla, M., Brosseau-Liard, P. É., \& Savalei, V. (2018). When can categorical variables be treated as continuous? A comparison of robust continuous and categorical SEM estimation methods under suboptimal conditions. Psychological methods, 17(3), 354373. https://doi.org/10.1037/a0029315

Richard, F. D., Bond, C. F., \& Stokes-Zoota, J. J. (2003). One hundred years of social psychology quantitatively described. Review of General Psychology, 7(4), 33363. https://doi.org/10.1037/1089-2680.7.4.331

Richardson, Laurel. 2004. "Gender Stereotyping in the English Language,” pp. 89-94, in Feminist Frontiers, 6th Edition, edited by Laurel Richardson, Verta Taylor, and Nancy Whittier. New York: McGraw-Hill

Roberts, J., Grossman, M. (1994). Changing definitions of sexual assault: An analysis of police statistics. In J. Roberts and R. Mohr (Eds.), Confronting Sexual Assault: A Decade of Legal and Social Change, (pp.57-83). University of Toronto Press.

Robichaud, S. (2018, March 20). Sexual assault trials in Canada: what really happens. https://robichaudlaw.ca/what-happens-at-trial-sexual-assault-cases/.

Rosch, E. (1978). Principles of Categorization. Readings in Cognitive Science, 312-322. https://doi.org/10.1016/b978-1-4832-1446-7.50028-5 
Rotenberg, C. (2017). Police-reported sexual assaults in Canada, 2009 to 2014: A statistical profile. Statistics Canada. Retrieved from: https://www150.statcan.gc.ca/n1/pub/85002- x/2017001/article/54866-eng.htm

Ruva, C. L., \& Guenther, C. C. (2017). Keep your bias to yourself: How deliberating with differently biased others affects mock-jurors' guilt decisions, perceptions of the defendant, memories, and evidence interpretation. Law and human behavior, 41(5), 478-493.

Ryan, K. M. (2011). The relationship between rape myths and sexual scripts: The social construction of rape. Sex Roles: A Journal of Research, 65(11-12), 774-782. https://doi.org/10.1007/s11199-011-0033-2

Sakaluk, J. K., Todd, L. M., Milhausen, R., Lachowsky, N. J., \& Undergraduate Research Group In Sexuality URGiS (2014). Dominant heterosexual sexual scripts in emerging adulthood: conceptualization and measurement. Journal of Sex Research, 51(5), 516531. https://doi.org/10.1080/00224499.2012.745473

Santos, J. A. R. (1999). Cronbach's alpha: A tool for assessing the reliability of scales. Journal of Extension, 37, 1-5.

Schank, R. C., \& Abelson, R. P. (1977). Scripts, Plans, Goals, and Understanding. https://doi.org/10.4324/9780203781036

Schuller, R. A., Mckimmie, B. M., Masser, B. M., \& Klippenstine, M. A. (2010). Judgments of sexual assault: The impact of complainant emotional demeanor, gender, and victim stereotypes. New Criminal Law Review, 13(4), 759-780. https://doi.org/10.1525/nclr.2010.13.4.759

Schutte, J. W., \& Hosch, H. M. (1997). Gender Differences in Sexual Assault Verdicts: A 
Meta-Analysis. Journal of Social Behavior and Personality, 12(3), 761.

Sheehy, E. A. (Ed.) 2012. Sexual Assault in Canada: Law, legal pratice and women's activism. Ottawa: Les Presses de 1'Université d'Ottawa | University of Ottawa Press. Retrieved from http://books.openedition.org/uop/535

Silver, J. R., \& Silver, E. (2017). Why are conservatives more punitive than liberals? A moral foundations approach. Law and Human Behavior, 41(3), 258272. https://doi.org/10.1037/lhb0000232

Sims C. M., Noel N. E., Maisto S. A. (2007). Rape blame as a function of alcohol presence and resistance type. Addict. Behav. 32 2766-2775. 10.1016/j.addbeh.2007.04.013

Simon, W., Gagnon, J.H. (2003). Sexual scripts: Origins, influences and changes. Qualitative Sociology, 26, 491-497.

Simonson, K., and Subich, L. M. (1999). Rape perceptions as a function of gender-role traditionality and victim-perpetrator association. Sex Roles 40, 617-634. doi: 10.1023/A:1018844231555

Sleath, E. \& Bull, R. (2010). Male rape victim and perpetrator blaming. Journal of Interpersonal Violence, 25, 969-988

Skeem, J. L., \& Golding, S. L. (2001). Describing jurors' personal conceptions of insanity and their relationship to case judgments. Psychology, Public Policy, and Law, 7(3), 561621

Smith, V. (1991). Prototypes in the Courtroom: Lay Representations of Legal Concept. Personality and Social Psychology, 61, 857-72. 
Sommer, S., Reynolds, J. J., \& Kehn, A. (2016). Mock juror perceptions of rape victims: Impact of case characteristics and individual differences. Journal of Interpersonal Violence, 31(17), 2847-2866. https://doi.org/10.1177/0886260515581907

Spohn, C., Beichner, D., \& Davis-Frenzel, E. (2001). Prosecutorial Justifications for Sexual Assault Case Rejection: Guarding the "Gateway to Justice". Social Problems, 48(2), 206-235. doi:10.1525/sp.2001.48.2.206

Suarez, E., \& Gadalla, T. M. (2010). Stop blaming the victim: A meta-analysis on rape myths. Journal of Interpersonal Violence, 25(11), 2010-2035. https://doi.org/10.1177/0886260509354503

St.Amant, K., (2017). Of Scrips and Prototypes: A Two-Part Approach to User Experience Design for International Contexts Applied Research. Journal of Technical Communications, 64(2), 113-125.

Starosta, C., \& Schuller, R. (2020). Perceptions of sexual assault: Effects of victim physiological arousal and victim gender on jurors' decisions. Journal of Interpersonal Relations, Intergroup Relations and Identity, 13, 48-60.

Streiner, L. D. (2005). Finding our way: An introduction to path analysis. Research Methods of Psychiatry, 50(2), 115-122.

Stemple, L., \& Meyer, I. H. (2017). The sexual victimization of men in America: New data challenge old assumptions. American Journal of Public Health, 104(6), 19-26. https://doi.org/10.2105/ajph.2014.301946.

Stuart, S. M., McKimmie, B. M., \& Masser, B. M. (2019). Rape perpetrators on trial: The effect of sexual assault-related schemas on attributions of blame. Journal of Interpersonal Violence, 34(2), 310-336. 
Tabachnick, B., \& Fidell, S. (2007). Using multivariate statistics (5th edition). Boston: Allyn \& Bacon.

Timasheff, N. (1941). Fundamental problems of the sociology of law. The American Catholic Sociological Review, 2(4), 233-248. doi:10.2307/3706563

Truman, J., \& Langton, L. (2017). Criminal Victimization, 2015. Bureau of Justice Statistics. https://bjs.gov/content/pub/pdf/cv14.pdf

Tzelgov, J., \& Henik, A. (1991). Suppression situations in psychological research: Definitions, implications, and applications. Psychological Bulletin, 109, 524-536

Vallano, J. P., Winter, R. J., \& Charman, S. D. (2013). Is this injury reasonable? Do psychological injury expectations affect mock jurors' legal decisions in a sexual harassment case? Psychiatry, Psychology and Law, 20(6), 834852. https://doi.org/10.1080/13218719.2012.744626

Viki, G. T., Abrams, D., \& Masser, B. (2004). Evaluating stranger and acquaintance rape: The role of benevolent sexism in perpetrator blame and recommended sentence length. Law and Human Behavior, 28(3), 295-303. doi: 10.1023/b:1ahu.0000029140.72880.69

Wagmeister, E. (2017, October 24). Former Weinstein Production Assistant Shares Graphic Account of Sexual Assault. Variety. https://variety.com/2017/film/news/harvey-weinstein-accuser-mimi-haleyi-sexualassault-tampon-period-1202597509/.

Walfield, S. M. (2018). “Men Cannot Be Raped”: Correlates of Male Rape Myth Acceptance. Journal of Interpersonal Violence. https://doi.org/10.1177/0886260518817777 
Wall A., Schuller R. A. (2002). Sexual assault and defendant/victim intoxication: jurors' perceptions of guilt. J. Appl. Psychol. 30 253-274. 10.1111/j.15591816.2000.tb02315.X

Wakelin, A., \& Long, K. M. (2003). Effects of victim gender and sexuality on attributions of blame to rape victims. Sex Roles: A Journal of Research, 49(9-10), 477-487. https://doi.org/10.1023/A:1025876522024

Weare, S. (2018). "I feel permanently traumatized by It": Physical and emotional impacts reported by men forced to penetrate women in the United Kingdom. Journal of Interpersonal Violence. https://doi.org/10.1177/0886260518820815

Wenger, A.A., \& Bornstein, B.H. (2006). The effects of victim's substance use and relationship closeness on mock jurors' judgments in an acquaintance rape case. Sex Roles, 54(7), 547- 555. DOI: 10.1007/s11199-006-9014-2

West SG, Finch JF, Curran PJ. Structural equation models with nonnormal variables: problems and remedies. In: Hoyle RH, editor. Structural equation modeling: Concepts, issues and applications. Newbery Park, CA: Sage; 1995. pp. 56-75

Weston, R., \& Gore, P. A. (2006). A Brief Guide to Structural Equation Modeling. The Counseling Psychologist, 34(5), 719-751. https://doi.org/10.1177/0011000006286345

White, B. H., \& Kurpius, S. E. R. (2002). Effects of victim sex and sexual orientation on perceptions of rape. Sex Roles: A Journal of Research, 46(5-6), 191200. https://doi.org/10.1023/A:1019617920155

White, S., \& Yamawaki, N. (2009). The moderating influence of homophobia and gender-role traditionality on perceptions of male rape victims. Journal of Applied Social Psychology, 39(5), 1116-1136. https://doi.org/10.1111/j.1559-1816.2009.00474.x 
Wiederman, M. W. (2005). The gendered nature of sexual scripts. The Family Journal, 13(4), 496-502. https://doi.org/10.1177/1066480705278729

World Heath Organization. (2019, November 29). Violence against women. Retrieved October, from https://www.who.int/news-room/fact-sheets/detail/violence-against-

Zidenberg, A., Sparks, B., Harkins, L., \& Lidstone, S. K. (2019). Tipping the scales: Effects of gender, rape myth acceptance, and anti-fat attitudes on judgments of sexual coercion scenarios. Journal of Interpersonal Violence, 1(27), 0886260519872978.

doi:10.1177/0886260519872978 


\section{Appendix A}

Screener

Please answer the following questions.

1. Are you a Canadian citizen?

- Yes

○ No

2. Are you able to read, write and understand the English language?

○ Yes

○ No

3. Have you ever been convicted of an indictable offense that you did not receive a formal record suspension for?

○ Yes

$\circ$ No 


\section{Appendix B}

Consent form

Name and Contact Information of Researchers:

Cassandra Starosta, Carleton University, Department of Psychology

Email: cassandrastarosta@cmail.carleton.ca

Supervisor and Contact Information:

Dr. Evelyn Maeder, Carleton University, Institute of Criminology and Criminal Justice/Department of Psychology

Email: evelyn.maeder@carleton.ca

\section{Project Title}

Legal Decision Making

\section{Carleton University Project Clearance}

Clearance \#: 111967

Date of Clearance: February 2, 202

\section{Invitation}

You are invited to participate in a study concerning juror decision-making. The information in this form is intended to help you understand what we are asking of you so that you can decide whether you agree to participate in this study. Your participation in this study is voluntary, and a decision not to participate will not be used against you in any way.

\section{Purpose}

This is a study to evaluate juror decision-making in sexual assault cases.

\section{Task Requirements}

If you agree to participate in this study, we will ask you to:

- Assume the role of a juror.

- Read a trial transcript involving a sexual assault charge.

- Determine a verdict.

- Respond to a series of questions.

This will take approximately 15 minutes.

\section{Who is eligible to participate in this study?}

Prior to reading the trial transcript, participants will be screened to ensure that they are eligible to serve on a Canadian jury (Canadian citizen, at least 18 years old, fluent in English, and have no indictable offenses).

\section{Risks and Inconveniences}

You will be asked to read a trial transcript involving a sexual assault charge. You may be uncomfortable with the nature of the charge or the description of the assault. You will also be asked to answer questions regarding your attitudes about certain sensitive topics and you may become uncomfortable with the nature of the questions. At any time, you may discontinue your involvement in this study. 


\section{Possible Benefits}

You may not receive any direct benefit from your participation in this study. However, your participation may allow researchers to better understand juror decision-making in sexual assault trails.

\section{Compensation/Incentives}

You will be compensated $\$ 2.50$ for your participation.

\section{No waiver of your rights}

By signing this form, you are not waiving any rights or releasing the researchers from any liability.

\section{Right to Withdraw}

At any time, you may discontinue your involvement in this study, and you will still receive compensation; clicking "I wish to withdraw from this study" on any page will take you to the end of the survey. At the end of the study, you will be asked if you would like to withdraw your data from the study and will have the option of doing so immediately if you should so wish.

\section{Withdrawing from the study}

If you withdraw your consent during the course of the study, all information collected from you before your withdrawal will be discarded. If you consent to submit your responses to the study, it will no longer be possible to withdraw your data.

\section{Confidentiality}

The data collected in this experiment is strictly confidential. No identifying information will be collected at any time. We will treat your personal information as confidential although absolute privacy cannot be guaranteed. We collect data through the software Qualtrics, which uses servers with multiple layers of security to protect the privacy of the data (e.g., encrypted websites and password protected storage). Your data will be stored and protected by Qualtrics on Toronto- based servers but may be disclosed via a court order or data breach. Please note that Qualtrics is hosted by a server located in the USA. The United States Patriot Act permits U.S. law enforcement officials, for an anti-terrorism investigation, to seek a court order that allows access to the personal records of any person without that person's knowledge. In view of this we cannot absolutely guarantee the full confidentiality and anonymity of your data. With your consent to participate in this study you acknowledge this.

The results of this study may be published or presented at an academic conference or meeting, but the data will be presented so that it will not be possible to identify any participants.

\section{Data Retention}

After the study is completed, your de-identified data will be retained for future research use.

\section{New information during the study}


In the event that any changes could affect your decision to continue participating in this study, you will be promptly informed.

\section{REB Review and Contact Information:}

This project was reviewed and cleared by the Carleton University Research Ethics Board. If you have any ethical concerns with the study, please contact the Carleton University Research Ethics Board by email at ethics@carleton.ca.

I have read the above form and understand the conditions of my participation. My participation in this study is voluntary, and I understand that if at any time I wish to leave the experiment, I may do so without having to give an explanation and with no penalty whatsoever. Furthermore, I am also aware that the data gathered in this study are confidential and anonymous with respect to my personal identity. By checking this box, I'm indicating that Lagree to participate in this studv.

I have read the above form and understand the conditions of my participation. My participation in this study is voluntary, and I understand that if at any time I wish to leave the experiment, I may do so without having to give an explanation and with no penalty whatsoever. Furthermore, I am also aware that the data gathered in this studyare confidential and anonymous with respect to my personal identity. By checking this box, I'm indicating that Ldo not agree to participate in this studv. 


\begin{abstract}
Appendix C
Juror Instructions

Jim McWilliams has been charged with the crime of sexually assaulting Lauren Robertson. The Crown has the burden of proving this charge beyond a reasonable doubt. It is your duty, as a juror, to read all of the evidence, to decide the facts, and apply the law as given to you at the end of the trial summary. Your decision is to be based on the evidence that follows and the legal rules provided at the end of these materials.
\end{abstract}




\section{Appendix D}

Trial Summary

$\underline{\text { Female Complainant/Male Defendant/Vaginal Intercourse }}$

\section{ONTARIO COURT OF JUSTICE}

DATE:2021-02-03

COURT FILE NO: OTTAWA 10-3631

BETWEEN:

CITATION: $R v$. McWilliams, DATE ONCJ 369

HER MAJESTY THE QUEEN

- AND -

McWilliams

\section{BROWN J.:}

Introduction

[1] Jim McWilliams is charged, that on January 17, 2017, in the City of Ottawa, committed sexual assault against Lauren Robertson.

[2] Members of the jury, you have been chosen to hear this case. You are the sole judge of the facts. You must decide this case only on the evidence presented to you in this courtroom. I am the sole judge of the law, and it is your duty to accept the law as I explain it to you. You must not use your own ideas about what the law is or should be.

Furthermore, you must not rely on information about the law from any other source.

Evidence is the testimony of witnesses and items entered as exhibits. It may also consist of admissions. Evidence includes what each witness says in response to the questions asked. The questions themselves are not evidence, unless the witness agrees that what is asked is correct. Only the answers are evidence. The Crown and the defence may also agree upon certain facts. When this happens, no evidence is required. What they agree upon constitutes as facts for this case. This is called an "admission." You must consider only the evidence put before you in the courtroom.

Keep an open mind as the evidence is being presented. Do not be influenced by sympathy for, or prejudice against, anyone.

[3] The Crown has the burden of proving this charge beyond a reasonable doubt. It is your duty, as a juror, to read all of the evidence, to decide the facts, and apply the law as given to you at the end of the trial summary. Your decision is to be based on the evidence that follows and the 
legal rules provided at the end of these materials.

\section{The information presented below is a summary of the trial proceedings: 1.0: Evidence at Trial \\ $1.1 \quad$ Evidence of Lauren Robertson}

[4] Lauren had just moved to Ottawa from Toronto, and, on the night of January 17 , 2017, she wanted to go to the closest Goodlife gym, since she already had a membership. Lauren reports driving to the gym at around $7 \mathrm{pm}$, parking on a side street nearby. She left the gym around 8:30 pm and proceeded to walk to her car. She reports walking around repeatedly but could not find the street where her car was parked; her cell phone's battery had died and she was still unfamiliar with the area. She was getting nervous, and she reports being very tired and just wanting to go home. She spotted a man in the distance and decided to ask him for directions. The man introduced himself as Jim. He said he was heading that way and could walk her there. Lauren states that she politely declined the offer, but Jim insisted on walking with her, saying that it would not be safe to walk alone in the dark. According to Lauren, she agreed to let him walk her, and the two walked together to her car and exchanged some small talk and a few laughs. Lauren recalls Jim trying to hold her hand, but she moved her hand away. Lauren states that when they got to her car, Jim was in the middle of a story and asked if they could sit in the backseat of her car for a bit so he could finish telling the story. Lauren recalls not wanting this to happen but did not want to appear rude, so she agreed. The two went in the backseat and continued their conversation. Lauren states that Jim kissed her when he finished his story. She testified that she did not feel comfortable, so she asked him to stop. According to Lauren, Jim did not listen to her. He continued to kiss her and got on top of her, and pulled down her pants. Lauren stated that she tried to push Jim off of her, but her body went numb. Lauren testified that she was unable to move. She felt frozen and recalls repeatedly shaking her head from side to side. Lauren reports that Jim forced vaginal intercourse with her /oral sex on her.

[5] According to Lauren, she does not remember how long the sex lasted, but she quickly pulled up her pants as soon as Jim got off her. Before Jim got out of the car, he told her that he had a great time with her and hoped they would see each other again soon. He hugged her before getting out of the car. Lauren testified that she went straight to the police station. 
[4] Lauren testified that she had never seen Jim McWilliams before the night of January 17,2017 , and that the man in court today was indeed the same man she saw on January 17, 2017.

[5] The police officer to whom Lauren reported the allegations of sexual assault was called to the stand to testify. He confirmed that Lauren had reported the same alleged events as given in her testimony. Additionally, the police officer testified that Lauren was emotional when she reported the sexual assault and fully cooperated with the police in their investigations.

[6] In concluding remarks, the Prosecutor, Hamer, argued that Lauren was the victim of a sexual assault that resulted from Jim not listening to Lauren's requests to stop being physically intimate.

\subsection{Evidence of Jim McWilliams}

[4] According to Jim, he was on the street when a woman approached him, asking for directions. He recalled her looking very nervous and tired, so he offered to walk her to her car. According to Jim, while on the walk, they engaged in meaningful conversation, and she laughed at all his jokes. He felt that Lauren was attracted to him, so he tried to hold her hand. Jim recalls that she seemed hesitant but did not say no; he testified that he thought Lauren was just shy. He testified that he believed Lauren was equally attracted to him since she let him into her car. He recalls that when he kissed her, she seemed to enjoy it, so he got on top of her, continued to kiss her, and took off her pants. He testified that Lauren never said no, so he thought she was genuinely comfortable with the sex/oral sex that was occurring.

[5] He further stated that Lauren seemed interested in him. He testified that he hugged her goodbye before he left her car, and she reciprocated the hug.

[6] According to Jim, he mentioned to Lauren that hehad a great time and hoped they could see each other again.

12] Jim maintains that at no time did Lauren indicate that she was unwilling to have sexual relations with him. Jim concluded his testimony by stating that he was shocked to hear that Lauren believed the sex/oral sex was not consensual.

[13] The Defence lawyer, Pacheco, argued that this was not a case of sexual assault because Jim had obtained Lauren's consent. He further argued that Lauren had simply experienced regret or shame about the sexual encounter after the fact and was attempting to claim that she did not consent to make herself feel better about what had happened. 
This brings us to the end of the trial summary. Your job is to decide whether the defendant, Jim McWilliams, is guilty of the charge of sexual assault.

Both parties agree that sexual relations occurred on the evening in question. The central issue in dispute is whether Lauren consented to sexual intercourse with Jim. As the law defines it, sexual assault is any touching of another person without their consent where the touching is of a sexual nature, or where the sexual integrity of the alleged victim is violated. Consent is legally defined as the voluntary agreement of the complainant to engage in the sexual activity in question. There is no consent when (1) the complainant expresses, by words or conduct, a lack of agreement to engage in the activity; (2) the complainant, having consented to engage in sexual activity, expresses, by words or conduct, a lack of agreement to continue to engage in that activity. Belief in consent is not a defence when (1) the accused did not take reasonable steps, in the circumstances known to the accused at the time, to ascertain that the complainant was consenting; or (2) there is no evidence that the complainant's voluntary agreement to the activity was affirmatively expressed by words or actively expressed by conduct. In considering your verdict, the defendant (Jim) is not required to prove his innocence. Rather, it is the Crown's burden to satisfy the juror beyond a reasonable doubt that each element of the charge has been met. The presumption of innocence applies at the beginning and continues throughout the trial,

unless you are satisfied, after considering the whole of the evidence, that the Crown has displaced the presumption of innocence by proof of guilt beyond a reasonable doubt.

1. If, based upon the evidence, you are sure that ( Jim) is guilty of the offence(s) with which he is charged, you must convict him/her of that offence since that demonstrates that you are satisfied of his guilt beyond a reasonable doubt

2. If you have a reasonable doubt whether ( Jim) is guilty of the offence(s) with which he is charged, you must give him/her the benefit of that doubt and find him/her not guilty.

The only evidence you are to consider is the testimony of the witnesses you read.

Please indicate that you have read the above trial summary.

I have read the above information.

You will now be presented with a series of questions specific to the case you just read. For each question you will be asked to either write an answer that best reflects your opinions or select the number on the 7-point scale that reflects your opinion. There are no right or wrong answers. We are interested in what you think.

Please be aware that some of the items that you will be asked to answer may seem unusual as they are instructional and will direct you how to respond. You should simply answer these items as instructed. 


\section{Appendix E \\ Questionnaire \\ Female Complainant- Male Defendant Condition}

*Various attention checks will be asserted throughout the survey asking participants to select a number on a 7-point Likert scale.

1. After reading the judge's instructions, you must now decide upon a verdict. How do you find the accused, Jim McWilliams, on the charge of sexual assault?

○ Guilty

- Not Guilty

2. Please describe how you reached your verdict.

3. How confident are you in your verdict decision?

1. Not at all 2. Not confident 3. Somewhat 4. Neither confident nor confident 5. Somewhat confident 6. Confident 7. Very Confident

Please answer the following questions regarding the complainant (I.e., the person who alleges that they were sexually assaulted), Lauren Robertson:

1. How typical is Lauren of people who have been sexually assaulted?

Not at all

typical (1)
3

4

5

6

Completely

typical (7)

2. How typical is Lauren's behaviour of victims of sexual assault?

Not at all

typical (1) 2

3

4

5

6

Completely

typical (7)

3. How similar is Lauren to a typical sexual assault victim?

Not at all

typical (1)

3

4

5

6

Completely typical (7)

4. To what extent do you believe Lauren's claims?

Not at all (1) 2

3

4

5

6

Completely

5. To what extent is Lauren credible?

Not at all

credible (1) 2

3

4

5

6

Completely credible (7)

6. To what extent is Lauren responsible for the events described?

Not at all responsible

(1)

2

3

4

5

6

Completely responsible

(7) 
1. To what extent is Lauren to blame for the events described?

Not at all

Completel blameworthy 2 3 4 5 6 blamewort (7)

2. To what extent was Lauren's behaviour on the night in question appropriate? (reverse coded)

Not at all

Completel appropriate

(1) 2 3

4

5

6 appropriat (7)

3. To what extent do you sympathize with Lauren? (reverse coded)

Not at all (1) 2

3

4

5

6

Completel

Please answer the following questions regarding the accused (I.e., the person accused of sexual assault), Jim McWilliams:

:

1. How typical is Jim of people who have committed a sexual assault?

Not at all

typical (1)

3

$4 \quad 5$

6

Completel typical (7)

2. How typical is Jim's behaviour of others who have committed a sexual assault? Not at all typical (1) 2 3

4

6

Completel typical (7)

3. How similar is Jim to a typical perpetrator of sexual assault? Not at all typical (1) 2 3

4

5

6

Completel: typical (7)

4. To what extent do you believe Jim's claims?

Not at all (1) 2

3

4

5

6

Completel (7)

5. To what extent is Jim credible?

Not at all credible (1) 2 3

4

5

6

Completel credible $(7$

6. To what extent is Jim responsible for the events described?

Not at all

Completel responsible
(1)
3
4
5

6 responsibl (7) 
1. To what extent is Jim to blame for the events described?

Not at all

blameworthy

(1)

Completel
blamewort

1. To what extent was Jim's behaviour on the night in question appropriate? (reverse coded) Not at all appropriate

(1)
2
3
4
5
Completel appropriat (7)

Please answer the following questions regarding the alleged sexual assault:

1. To what extent are the events in this case like a typical sexual assault? Not at all typical (1) 2

3

4

5

6

Completel typical (7)

2. To what extent are the events in this case like a typical act of consensual sex? Not at all typical (1) 2

3

4

5

6

Completel typical (7)

3. How severe would you consider this incident?

Not at all

Severe (1) 2

3

4

5

6

Completel Severe (7)

4. How traumatic would you consider the incident for the complainant, Lauren Robertson? Not at all Traumatic 2

3

4

5

6

Completel:

(1)

Traumatic

(7) 
The remaining series of questions ask you to recall some details from the case you read. Select the answer that you believe is most accurate.

1. Were the complainant and the accused drinking on the night in question?
1. yes
2. no
3. This information was not provided

2. Did the complainant and the accused know each other before the alleged event?

1. yes

2. no

3. this information was not provided

3. Who is being accused of sexual assault?

1. Lauren

2. Jim

3. Samantha

4. Paul

5. This information was not provided

4. Who is accusing someone of sexual assault?

1. Lauren

2. Jim

3. Samantha

4. Paul

5. This information was not provided

5. What did the complainant claim that the accused did?

1. Forced intercourse

2. Forced oral sex

3. Forced anal sex

4. This information was not provided 


\section{Appendix F}

The Illinois Rape Myth Acceptance Scale

McMahon \& Farmer, 2011

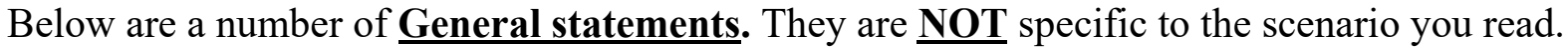

Read each item and select a position on the scale from strongly disagree to strongly agree to indicate YOUR LEVEL OF AGREEMENT with each statement.

\begin{tabular}{|c|c|c|c|c|}
\hline & & Neither & & \\
\hline $\operatorname{tac}$ & & Disagree nor & & Strongly \\
\hline$e(5)$ & Disagree (4) & Agree (3) & Agree (2) & Agr \\
\hline
\end{tabular}

1. If a woman is raped while she is drunk, she is at least somewhat responsible for letting things get out of hand.

2. When women go to parties wearing revealing clothes, they are asking for trouble.

3. If a woman goes to a room alone with a man at party, it is her own fault if she is raped.

4. When women get raped, it's often because the way they said "no" was unclear.

5. If a woman initiates kissing or hooking up, she should not be surprised if a man assumes she wants to have sex.

6. When men rape, it is usually because of their strong desire for sex.

7. Men don't usually intend to force sex on a woman, but sometimes they get too sexually carried away. 
8. Rape happens when a man's sex drive goes out of control.

9. If a man is drunk, he might rape someone unintentionally.

10. It shouldn't be considered rape if a man is drunk and didn't realize what he was doing.

11. If both people are drunk, it can't be rape.

12. If a woman doesn't physically resist sex - even if protesting verbally_it can't be considered rape.

13. If a woman doesn't physically fight back, you can't really say it was rape.

14. A rape probably doesn't happen if a woman doesn't have any bruises or marks.

15. If the accused "rapist" doesn't have a weapon, you really can't call it rape.

16. If a woman doesn't say "no" she can't claim rape.

17. A lot of times, women who say they were raped agreed to have sex and then regret it.

18. Rape accusations are often used as a way of getting back at men.

19. A lot of times, women who say they were raped often led the man on and then had regrets.

20. A lot of times, women who claim they were raped have emotional problems.

21 . Women who are caught cheating on their boyfriends sometimes claim it was rape 


\section{Appendix G}

Male Rape Myth Acceptance Scale

Anderson, 2007

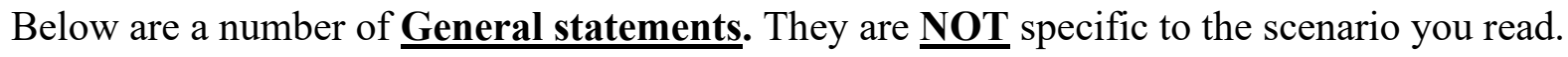

Read each item and select a position on the scale from strongly disagree to strongly agree to indicate YOUR LEVEL OF AGREEMENT with each statement.

Strongly Moderately Slightly

Disagree Disagree Disagree Slightly Moderately Strongly

(1)

(2)

Agree (4) Agree (5) Agree (6)

1. It is a terrible experience for a man to be raped by a woman.

2. The extent of a man's resistance should be a major factor in determining if he was raped.

3. Any healthy man can successfully resist a rapist if he really wants to.

4. If a man obtained an erection while being raped it probably means that he started to enjoy it.

5. A man can enjoy sex even if it is being forced upon him.

6. Most men who are raped by a woman are very upset by the incident.

7. Many men claim rape if they have consented to homosexual relations 
but have changed their minds afterward.

8. Most men who are raped by a woman are somewhat to blame for not escaping or fighting off the woman.

9. Male rape is usually committed by homosexuals.

10. A man who has been raped has lost his manhood.

11. Most men who are raped by a man are somewhat to blame for not escaping or fighting off the man.

12. Most men who are raped by a woman are somewhat to blame for not being more careful.

13. If a man told me that he had been raped by another man, I would suspect that he is homosexual.

14. Most men who have been raped have a history of promiscuity.

15. No self-respecting man would admit to being raped.

16. Women who rape men are sexually frustrated individuals.

17. A man who allows himself to be raped by 
another man is probably homosexual.

18. Most men would not enjoy being raped by a woman.

19. Men who parade around nude in a locker room are asking for trouble.

20. Male rape is more serious when the victim is heterosexual than when the victim is homosexual.

21. I would have a hard time believing a man who told me that he was raped by a woman. 


\section{Appendix H}

Oral Sex Scale

Starosta \& Maeder, 2020

Below are a number of General statements. They are NOT specific to the scenario you read.

Read each item and select a position on the scale from strongly disagree to strongly agree to indicate YOUR LEVEL OF AGREEMENT with each statement

Strongly Disagree

(5)
Neither Disagree

nor Agree (3)
Agree (2)
Strongly Agree

(1)

1. One cannot be forced to give oral sex.

2. Forced oral sex is not sexual assault.

3. Oral sex cannot be forced on to someone else. 


\section{Appendix I}

Demographic Questions

1. What is your age?

2. What is your gender? Please select all that apply.
○ Male
○ Female
o Non-binary
- Transgender
○ Not listed (please specify):

3. What is the highest level of education that you have obtained?
- Doctoral or professional degree
- Master's degree
- Bachelor's degree
- Associate's degree
○ Postsecondary non-degree award
- Some college, no degree
- High school diploma or equivalent
$\circ$ Less than high school

4. Please indicate what your present religion is, if any.

- Protestant (Baptist, Methodist, Non-denominational, Lutheran, Presbyterian, Pentecostal, Episcopalian, Reformed, Church of Christ, etc.)

- Roman Catholic (Catholic)

- Mormon (Church of Jesus Christ of Latter-day Saints/LDS)

- Orthodox (Greek, Russian, or another orthodox church)

- Jewish (Judaism)

○ Muslim (Islam)

○ Buddhist

- Hindu

- Atheist (do not believe in God)

- Agnostic (not committed to believing in existence or non existence of God)

- Nothing in particular

- Not listed (please specify)

5. What is your racial/ethnic background? Please select all that apply.
- South Asian
o Chinese
o Black
○ Filipino
○ White 


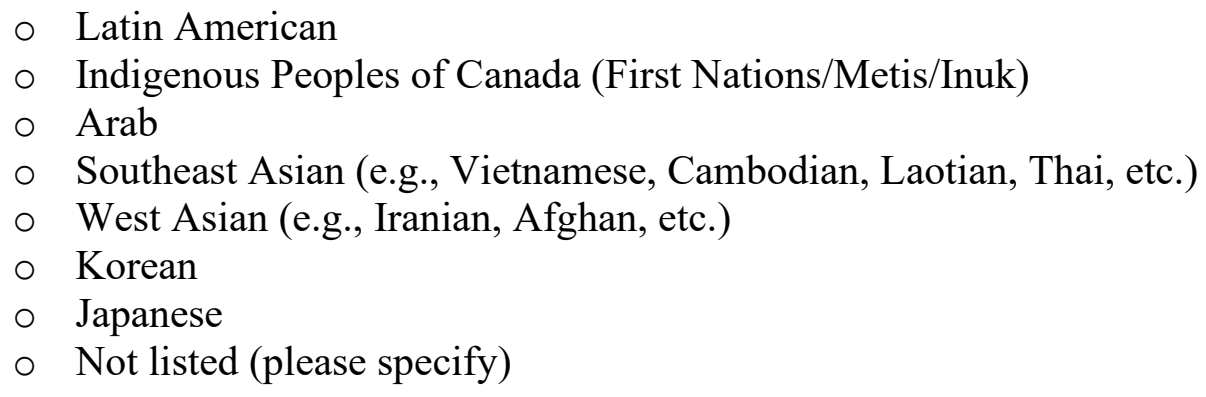

6. Please indicate where your political beliefs fall, using the scale below. Liberal

$\begin{array}{lllllllllll}0 & 1 & 2 & 3 & 4 & 5 & 6 & 7 & 8 & 9 & 10\end{array}$




\section{Appendix $\mathbf{J}$}

Debriefing Form

Thank you for your participation in this study. This is a debriefing form that will clarify the purpose of our study and why we are interested in this issue.

What are we trying to learn in this research and how was this study designed?

The purpose of this study is to understand whether judgments surrounding complainants and defendants of sexual assault are influenced by the complainant's gender, defendant's gender, and the type of sexual assault itself. As such, within the hypothetical sexual assault vignettes the complainant and defendant's gender was manipulated with some participants reading the complainant was a male, and the defendant was a female, and others reading that the complainant was a female, and the defendant was a male. Within the two different conditions participants were briefly either told the sexual assault in question was vaginal intercourse or oral sex. In addition to evaluating a case, participants are also asked to report on their personalbeliefs and attitudes about sexual assault.

Why was the use of deception necessary?

Deception occurs when information is intentionally omitted or when misinformation is intentionally delivered. In our study, we were not able to inform you of the specific purpose of the study. Deception was employed to avoid an effect of social desirability, which is a phenomenon where individuals modify their answers to fit with what they perceive to be socially acceptable. Please be aware that you can withdraw your data from this study if you wish.

What are our hypotheses and predictions?

Previous research suggests that among some individuals, decisions in sexual assault cases are different depending on the victim and accused's gender (Anderson, 2007; Pica et al., 2018; Starosta \& Schuller, 2020). We expect that judgments will be harsher for male complainants of female perpetrated sexual assault than female complainants of male perpetrated sexual assault. We predict that judgments would be harsher for the complainants of oral sex sexual assault compared to vaginal intercourse sexual assault, based on the prevailing myth that only intercourse equates a sexual assault (Lefkovitz et al., 2014; Lefkovitz et al., 2016).

Where can I learn more?

Anderson, I. (2007). What is a typical rape? Effects of victim and participant gender in female and male rape perceptions. British Journal of Social Psychology, 46, 225-245.

Lefkowitz, E. S., Shearer, C. L., Gillen, M. M., \& Espinosa-Hernandez, G. (2014). How gendered attitudes relate to women's and men's sexual behaviors and beliefs. Sexuality \& Culture, 18(4), 833-846. https://doi.org/10.1007/s12119-014 
Lefkowitz, E. S., Vasilenko, S. A., \& Leavitt, C. E. (2016). Oral vs. vaginal sex experiences and consequences among first-year college students. Archives of Sexual Behavior, 45(2), 329-337. https://doi.org/10.1007/s10508-015-0654-6

What if I have questions later?

If you have any remaining concerns, questions, or comments about the experiment, please feel free to contact Cassandra Starosta (Principal Investigator), at: cassandra.starosta@carleton.ca, or Dr. Evelyn Maeder (Faculty Sponsor), at: evelyn.maeder@carleton.ca.

Should you have any ethical concerns with the study, please contact the REB Chair, Carleton University Research Ethics Board-B (by email: ethics@carleton.ca). For all other questions about the study, please contact the researcher."

This study has been cleared by the Carleton University Research Ethics Board - B (CUREB-B Clearance \# 111967).

Is there anything I can do if I found this experiment emotionally draining? If this experiment has caused you any emotional distress, please call 1-800-273-TALK (8255) to connect to a skilled and trained counselor at a crisis center in your area. This service is available $24 / 7$. 


\section{Appendix K}

\section{Consent-to-keep-data Form}

The purpose of a consent-to-keep-data form is to make sure that you can make an informed decision regarding whether you would like your data included in this study. We include this form after explaining the true purpose of our study and the reasons for which deception was necessary. This form is meant to give you an opportunity to withdraw your data from the study, now that you are aware of its purpose. If you wish to withdraw your data, it will be deleted. You will still be compensated for your participation.

By signing this form, you indicate that you understand that you were not informed of the true purpose of this study prior to completing your participation in the study, and that you understand the reasons regarding the necessity of the use of deception in this study.

This study has been cleared by the Carleton University Research Ethics Board - B (CUREB-B Clearance \# 106488).

Please indicate whether you do / do not continue to consent to the use of your data.

I consent to the use of my data

I do not consent to the use of my data 